INSTITUTO DE PESQUISAS ENERGÉTICAS E NUCLEARES

Autarquia associada à Universidade de São Paulo

\title{
OBTENÇÃO, USINAGEM E DESGASTE DE MATERIAIS COMPÓSITOS DE MATRIZ METÁLICA PROCESSADOS VIA METALURGIA DO PÓ.
}

EDILSON ROSA BARBOSA DE JESUS

Dissertação apresentada como parte dos requisitos para obtenção do grau de Mestre em Tecnologia Nuclear - Materiais.

Orientador:

Dr. Jesualdo Luiz Rossi

SÃO PAULO 
À memória de minha mãe

À minha esposa

Aos meus familiares

eu dedico este trabalho.

“... sem Mim nada podeis fazer"

(João 15:5) 
Agradecimentos

À Deus pela presença constante.

Ao meu orientador Dr. Jesualdo Luiz Rossi, por ter acreditado no meu trabalho e pela valiosa participação em todas as etapas do mesmo.

Ao CNPq pela concessão da bolsa de estudos.

Ao Dr. Luís Felipe C. P. de Lima, pelas orientações e apoio iniciais.

Ao Dr. Arnaldo H. P. de Andrade, pelas discussões e sugestões na elaboração dos textos.

Ao meu irmão Eng. Edson Souza de Jesus Filho pelo auxílio constante.

Aos colegas do MM e IEO que direta ou indiretamente participaram da elaboração deste trabalho.

Ao Laboratório de Ensaios da Faculdade de Engenharia Civil da Escola Politécnica da USP, nas pessoas do Sr. Reginaldo Mariano da Silva e Srta Patrícia Rodrigues de Freitas, pela utilização do equipamento de ensaio para compactação dos pós.

Ao Laboratório de Caracterização Mecânica do IPT, na pessoa do Dr. Marcelo Gonçalves pela utilização da extrusora na fabricação do material utilizado na pesquisa.

Ao Laboratório de Fenômenos de Superfície da Faculdade de Engenharia Mecânica da Escola Politécnica da USP, nas pessoas do Dr. Amilton Sinatora e MSc Engenheiro Carlos Henrique da Silva pela utilização do equipamento e auxílio na condução dos ensaios de desgaste.

Ao Laboratório de Metalografia da Faculdade de Engenharia Metalúrgica da Escola Politécnica da USP, na pessoa da Srta. Márcia Ribeiro pela utilização de equipamentos e auxílio na preparação de amostras.

A todo o pessoal da biblioteca do Ipen e à Sra Clélia Megherditchian e Srta Cláudia F. de Lima da biblioteca da Faculdade de Engenharia Metalúrgica da Escola Politécnica da USP, pela colaboração e paciência dispensadas.

À minha esposa Valéria Tomi K. de Moraes Jesus pela compreensão, apoio e incentivo constantes e fundamentais para mais esta conquista. 


\title{
OBTENÇÃO, USINAGEM E DESGASTE DE MATERIAIS COMPÓSITOS DE MATRIZ METÁLICA PROCESSADOS VIA METALURGIA DO PÓ.
}

\author{
Edilson Rosa Barbosa de Jesus
}

\begin{abstract}
RESUMO
O objetivo deste trabalho foi a obtenção de compósitos de matriz metálica (CMM) pela rota da metalurgia do pó, e a avaliação destes quanto às suas características de usinagem e desgaste. Inicialmente foram obtidos materiais compósitos de matriz de alumínio comercialmente puro, com frações volumétricas de partículas de reforço de carboneto de silício iguais a 5, 10 e $15 \%$. Foi obtida também uma quantidade de material somente com o material da matriz (sem partículas de reforço) para que se pudesse durante o trabalho, verificar por comparação a influência da adição de material de reforço na matriz. O material obtido foi caracterizado física (densidade hidrostática), mecânica (dureza, ensaios de tração) e microestruturalmente (microscopia óptica e microscopia eletrônica de varredura). Os resultados mostraram para os materiais compósitos uma distribuição homogênea das partículas de reforço e melhoria das propriedades mecânicas principalmente o limite de resistência (LR) em relação ao material sem reforço. Na etapa seguinte foram realizados ensaios para verificação do comportamento dos materiais frente à usinagem, e avaliação de desempenho de diversos materiais de ferramenta (carboneto cementado, cerâmica e diamante policristalino). Nestes ensaios foram coletados valores de força de corte a partir de porta-ferramentas instrumentados com medidores de deformação. Fenômenos tais como desgaste da ferramenta, formação ou não de aresta postiça de corte e formação de cavaco também foram observados e avaliados. Os resultados encontrados nos ensaios com ferramenta de carboneto duro sinterizado foram utilizados para a determinação dos índices de usinabilidade de cada material; estes valores foram ainda aplicados na equação de Taylor e as constantes da equação para os materiais e condições de ensaio foram também determinadas. Os resultados mostraram que a inclusão de partículas de reforço cerâmico torna extremamente difícil a usinagem desses materiais e, somente com ferramenta de diamante foi possível obter resultados satisfatórios. Na fase final foram realizados testes de desgaste de efeito comparativo para verificação da influência da adição de partículas de reforço nas características de resistência ao desgaste do material. Neste caso a adição de partículas de reforço mostrou ser eficiente na melhoria da resistência ao desgaste de todos os materiais compósitos em relação ao material sem reforço.
\end{abstract}


OBTAINMENT, MACHINING AND WEAR OF METAL MATRIX COMPOSITES

PROCESSED BY POWDER METALLURGY.

\author{
Edilson Rosa Barbosa de Jesus
}

\begin{abstract}
The aim of this investigation was the obtainment of metal matrix composites $(M M C)$ by the route of powder metallurgy, and the valuation of these materials with relation to their machining and wear characteristics. Firstly, were obtained pure comercial aluminium matrix composites materials, with 5, 10 and 15\% volumectric fraction of silicon carbide particles. Was also obtained a material without reinforcement particles in order to verify by comparison, the influence of adittion of reinforcement particles. The obtained materials were characterized physics (hidrostatic density), mechanics (hardness and tensile tests) and microstructurally (optical microscopy and scanning electron microscopy). The results showed a homogeneous distribution of reinforcement particles in the composite, and improvement in the mechanical properties, mainly tensile strength (UTS) in comparison to the unreinforced material. After, tests were made to verify the materials behavior during machining and to check the performance of several tool materials (cemented carbide, ceramics and polycrystalline diamond). In these tests, values of the cutting force were measured by instrumented tool-holders. Phenomena such as tool wear, built-up edge formation and mechanism of chip formation were also observed and evaluated. The results from the cemented carbide tool tests, were utilisated for the machinability index determination of each material. These results were applied to the Taylor equation and the equation constants for each material and test conditions were determinated. The results showed that the inclusion of silicon carbide particles made extremely difficult the machining of the composites, and only with diamond tool, satisfactory results were obtained. At last, wear tests were performed to verify the influence of the reinforcement particles in the characteristics of wear resistance of the materials. The results obtained were utilized in the wear coefficient determination for each material. The results showed an improvement in wear resistance, with the increase in volume fraction of reinforcement particles.
\end{abstract}




\section{ÍNDICE}

ASSUNTO

PÁGINA

1 - Introdução

01

2 - Fundamentos teóricos .................................................................. 03

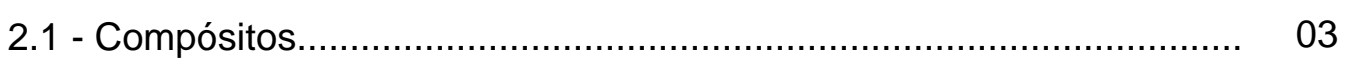

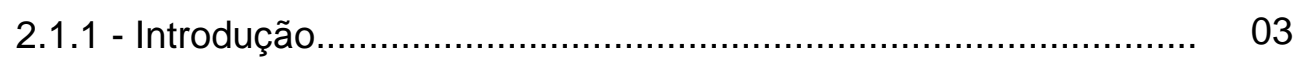

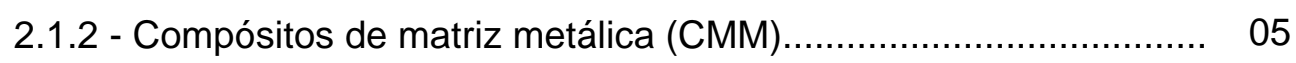

2.1.2.1 - Processos de fabricação............................................ 08

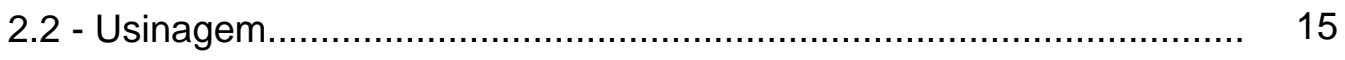

2.2.1 - Origens e conceitos.................................................... 15

2.2.2 - Desgaste da ferramenta.................................................... 16

2.2 .3 - Usinabilidade ........................................................... 17

2.3 - Tribologia......................................................................... 18

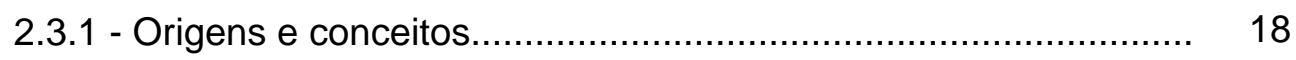

3 - Materiais e métodos..................................................................... 22

3.1 - Obtenção do material........................................................ 22

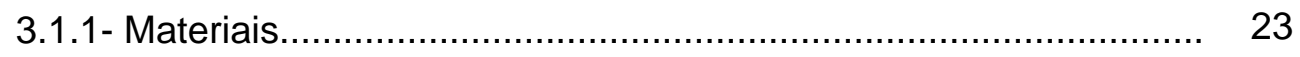

3.1 .2 - Procedimentos........................................................... 24

3.1.3 - Caracterização física, mecânica e microestrutural do material

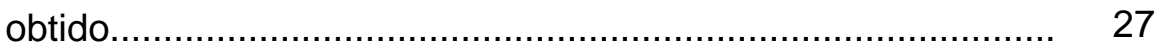

3.2 - Ensaios de usinagem e usinabilidade ....................................... 29

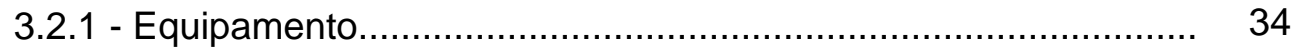

3.2.2 - Forças de corte............................................................ 35

3.2 .3 - Usinabilidade............................................................. 36

3.3 - Ensaios de desgaste ....................................................... 37 
4 - Resultados e discussão.

4.1 - Caracterização física, mecânica e microestrutural do material obtido 39

4.1 .1 - Caracterização física..................................................... 39

4.1 .2 - Caracterização mecânica................................................... 40

4.1.3 - Caracterização microestrutural........................................... 42

4.1.3.1 - Fractografia............................................................. 42

4.1.3.2 - Metalografia............................................................. 43

4.1.3.3 - Dissolução de amostras (extração do reforço).................. 45

4.2 - Ensaios de usinagem e usinabilidade........................................ 45

4.2 .1 - Desgaste da ferramenta.............................................. 45

4.2.2 - Forças de corte............................................................ 52

4.2 .3 - Aresta postiça de corte...................................................... 54

4.2.4 - Formação de cavacos....................................................... 55

4.2 .5 - Usinabilidade .......................................................... 59

4.2 .6 - Equação de Taylor...................................................... 62

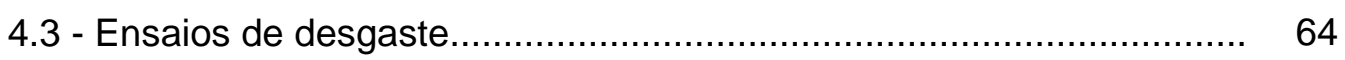

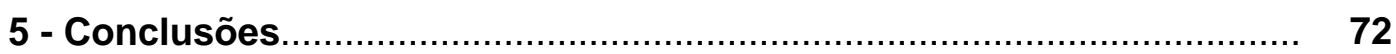

Sugestões para trabalhos futuros................................................. 74

Referências bibliográficas............................................................... 75

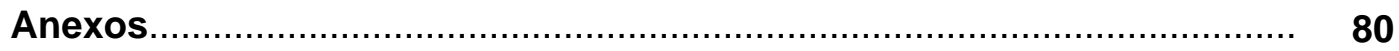




\section{1 - INTRODUÇÃO}

Os materiais compósitos de matriz metálica têm se destacado nas últimas décadas e têm atraído a atenção de pesquisadores e empresários, principalmente dos setores aeronáutico e aeroespacial e mais recentêmente do setor automobilístico. Estes materiais se caracterizam normalmente por possuírem propriedades mecânicas superiores em relação a outros materiais convencionais aliadas, em alguns casos, à redução de peso proporcionada pela utilização de ligas leves em sua composição. A tendência na busca incessante pela redução de custos e manutenção ou melhoria da segurança de máquinas e equipamentos, indica que o número de aplicações para este tipo de material pode aumentar consideravelmente provocando um aumento na demanda de produção dos mesmos.

As características de usinagem, mais especificamente a usinabilidade e também as características de desgaste de determinado material, podem ditar a viabilidade ou não da produção deste material em grande escala. A usinagem exerce forte influência nos custos finais de produção de determinada peça ou componente. O desgaste exerce sua influência na etapa após a produção quando da aplicação (utilização) destas peças e componentes, podendo representar grandes dispêndios financeiros em manutenção e controle e, também, grandes prejuízos quando não é feita manutenção ou quando ocorre falha de controle.

Estudar e avaliar os fenômenos de usinagem e desgaste de materiais compósitos de matriz metálica, significa entender melhor o comportamento destes novos materiais durante a confecção de peças e componentes e às solicitações que os mesmos estarão sujeitos durante utilização nos seus mais diversos campos de aplicação. Essa utilização implica na concepção (projeto) de variadas formas em que este material poderá se apresentar dependendo, é claro, da necessidade de aplicação de cada uma delas. 
A materialização dessas formas pode se dar das mais variadas maneiras possíveis, sendo quase que imprescindível porém, em praticamente todas elas, a necessidade de pelo menos uma operação de usinagem para complementação e garantia dos padrões de dimensionamento e acabamento superficial estabelecidos no projeto. Mesmo com métodos de manufatura que possibilitam a obtenção destas praticamente acabadas "near net shape", como por exemplo nos métodos de fabricação via metalurgia do pó, a necessidade da usinagem ainda não foi completamente eliminada.

Daí a importância de que se avalie a usinabilidade de materiais compósitos de matriz metálica e de que se compreenda melhor os mecanismos de desgaste envolvidos no processo, propondo se necessário o desenvolvimento de novos materiais de ferramenta ou processos alternativos de usinagem. Isto para que se viabilize a produção e utilização destes materiais em larga escala, pela redução dos custos nas operações de usinagem e na utilização em campo de peças e componentes. 


\section{2 - FUNDAMENTOS TEÓRICOS}

\section{1 - Compósitos}

\subsection{1 - Introdução}

Na busca constante pela melhoria do desempenho, que pode ser avaliada sob vários aspectos como redução de peso, maior resistência, maior resistência ao desgaste e melhor estabilidade térmica entre outras, os materiais normalmente usados já alcançaram o limite de suas aplicações. Neste sentido cientistas, engenheiros e pesquisadores da área de materiais estão constantemente trabalhando para melhorar o desempenho dos materiais tradicionais ou desenvolver materiais completamente novos. Materiais compósitos são um exemplo de novos materiais concebidos dentro desta filosofia.

A idéia de material compósito não é recente. Compósitos naturais como por exemplo a madeira e alguns outros compósitos sintéticos têm sido usados pelo homem a milhares de anos; porém, o desenvolvimento maior nesta área ocorreu somente nas últimas décadas. Segundo Chawla [1], pode-se considerar como origem da disciplina de materiais compósitos o início dos anos 60, sendo que grande parte das pesquisas e desenvolvimento nesta área começou em meados da mesma década.

Existe muita divergência quanto à definição de material compósito, contudo Schwartz [2] salienta que uma definição correta deve ser estabelecida em função do nível de observação. O dicionário define "compósito" como algo feito ou composto de várias partes ou elementos. Neste contexto, avaliando-se do ponto de vista atômico e molecular todo e qualquer material poderia ser classificado como um compósito, visto que é composto por vários átomos e moléculas. Para que se possa definir melhor o termo compósito dentro do campo da engenharia metalúrgica e de materiais, é necessário que se faça uma avaliação menos abrangente.

Schwartz [2], subdivide o sentido amplo fornecido pelo dicionário em três níveis de definição: 
- No nível básico ou elementar todo material composto de dois ou mais átomos diferentes pode ser considerado um compósito. Neste nível pode-se incluir as misturas, ligas, polímeros e cerâmicas. Apenas elementos puros podem ser excluídos.

- No nível microestrutural, incluem-se materiais compostos de dois ou mais cristais, estruturas moleculares ou fases diferentes. Por esta definição muitos materiais considerados monolíticos ou homogêneos podem ser classificados como materiais compósitos. Aços e ligas multifase de carbono e ferro podem ser compósitos.

- No nível macroestrutural o que se caracteriza são formas estruturais ou constituíntes grosseiros, isto é, matrizes, partículas, whiskers e fibras que podem na grande maioria das vezes ser distinguidos a olho nú.

Os materiais compósitos caracterizados pelo nível de observação macroestrutural, são os responsáveis pela recente revolução tecnológica na área de novos materiais. Somente a observação do ponto de vista macroestrutural ainda não é suficiente para que se possa definir perfeitamente estes novos materiais. Para tanto, é necessário considerar ainda segundo Schwartz [2] duas outras características muito importantes na identificação destes materiais. Primeiro, os constituintes individuais que formam um compósito são quase sempre diferentes quimicamente; segundo, eles são essencialmente insolúveis entre si. Chawla [1] coloca algumas outras características igualmente importantes, que podem ser adicionadas às de Schwartz [2]; primeiro, o material compósito é um material fabricado (isto é, compósitos que ocorrem naturalmente como a madeira são excluídos); segundo, consiste de duas fases química e/ou fisicamente distintas devidamente arranjadas ou distribuídas com uma interface de separação entre elas; e finalmente, esses materiais têm características diferenciadas das dos seus componentes isoladamente. Matthews e Rawlings [3] destacam uma outra característica que se diferencia das anteriores, e que também é bastante importante; os constituintes desses materiais têm normalmente que estar presentes em proporções razoáveis, maiores que $5 \%$. 
Feitas as devidas considerações, Schwartz [2] define material compósito como sendo um "sistema de materiais composto de uma mistura ou combinação de dois ou mais macroconstituintes que se diferem na forma e/ou composição e são essencialmente insolúveis entre si". Chawla [1], define como sendo "materiais consistindo de dois ou mais materiais física e/ou químicamente distintos arranjados ou distribuídos de maneira conveniente".

Nestes materiais, uma das fases normalmente mais dúctil se apresenta em maior proporção sendo comumente denominada "matriz". A fase ou fases complementares apresentam-se em menor proporção, na maioria dos casos é mais dura do que a matriz e é normalmente denominada "reforço". Existe uma quantidade enorme de possibilidades de características que podem ser usadas para a classificação de materiais compósitos, contudo, de modo geral eles são classificados de acordo com o tipo de reforço e orientação dos mesmos (figura 1.2).

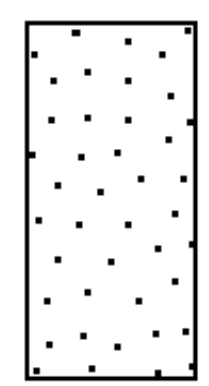

[a]

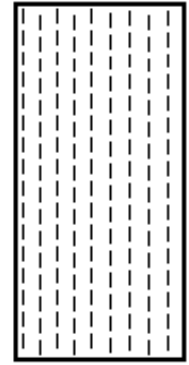

[b]

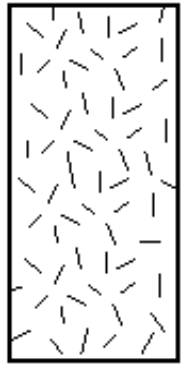

[c]

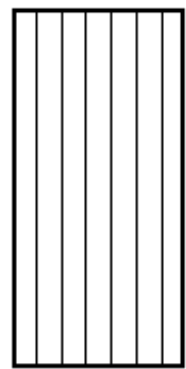

[d]

Figura 1.2 - Exemplos de materiais compósitos: (a) particulado, randômico; (b) fibras descontínuas, unidirecional; (c) fibras descontínuas, randômicas; (d) fibras contínuas, unidirecional (adaptação) [3].

\subsection{2 - Compósitos de matriz metálica (CMM)}

O início das pesquisas no campo de materiais compósitos foi marcado em particular por um grande número de estudos e aplicações em compósitos de matriz polimérica, décadas de 70 e 80 . A idéia evoluiu, e com o passar do tempo intensificouse também o número de pesquisas e aplicações em compósitos de matriz metálica e 
cerâmica, devido à possibilidade de poderem ser usados a temperaturas mais altas (figura 2.2) [4].

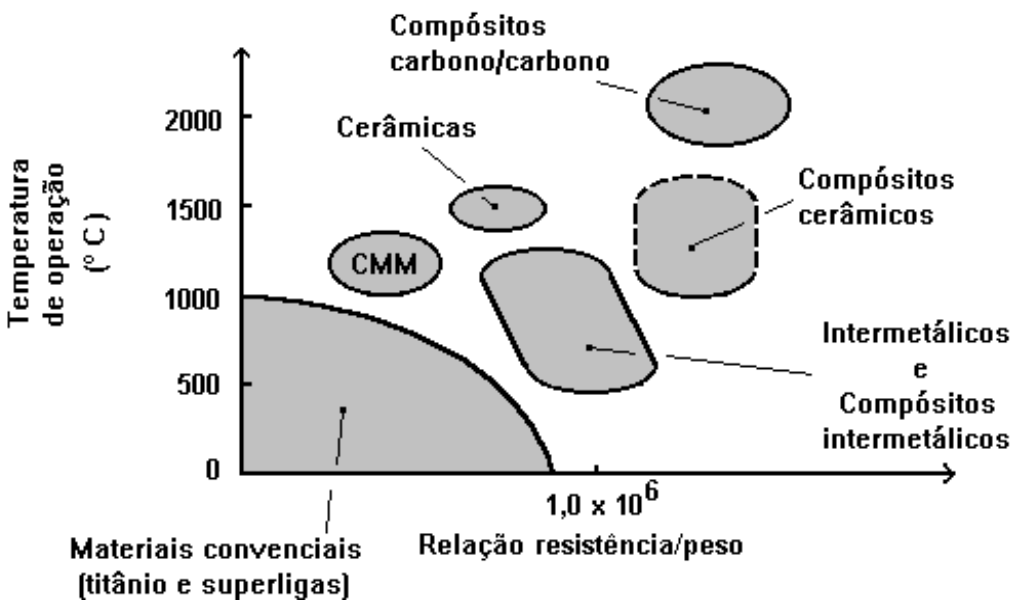

Figura 2.2 - Mapa de desempenho de vários materiais de engenharia, em termos de temperatura de operação $\left({ }^{\circ} \mathrm{C}\right)$ e relação resistência/peso (adaptação) [5].

Os materiais compósitos de matriz metálica têm muitas vantagens sobre os materiais convencionais, tais como: maiores limites de resistência mecânica e módulo de elasticidade, melhores propriedades a altas temperaturas, baixo coeficiente de expansão térmica e melhor resistência ao desgaste, entre outras (figuras 3.2 e 4.2). E graças a estas propriedades estes materiais podem ser usados em um grande número de aplicações (tabela 1.2).

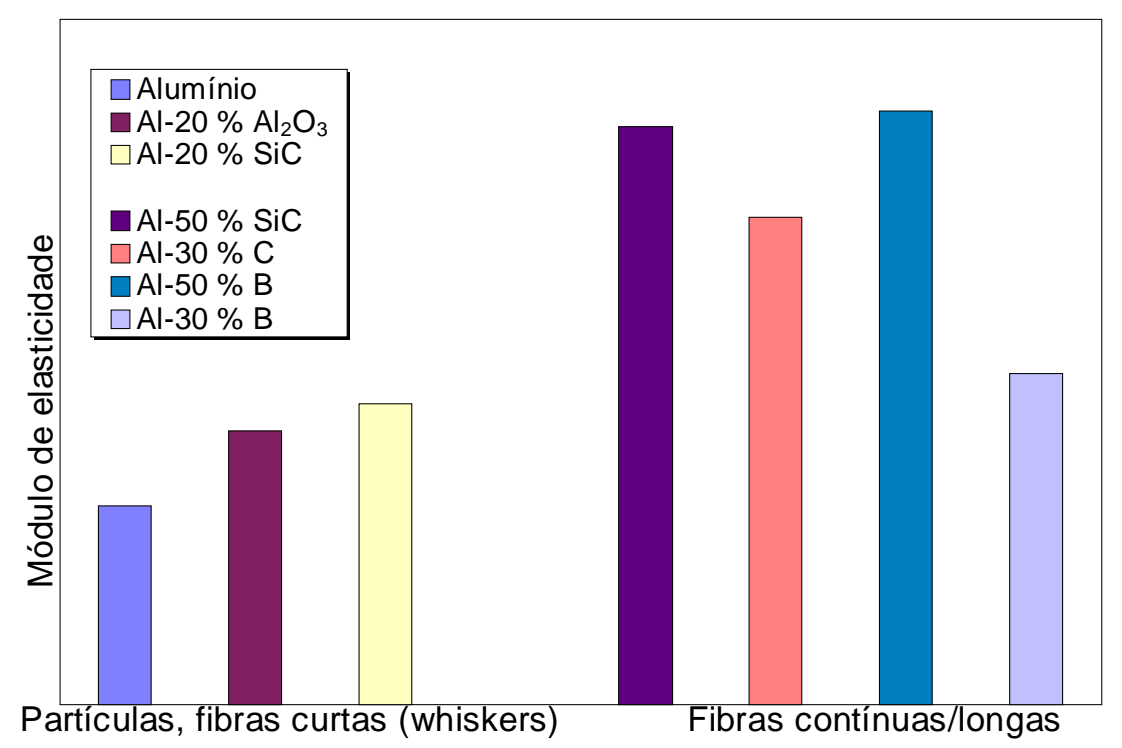

Figura 3.2 - Efeito da quantidade de reforço sobre o módulo de elasticidade do alumínio (adaptação) [3]. 


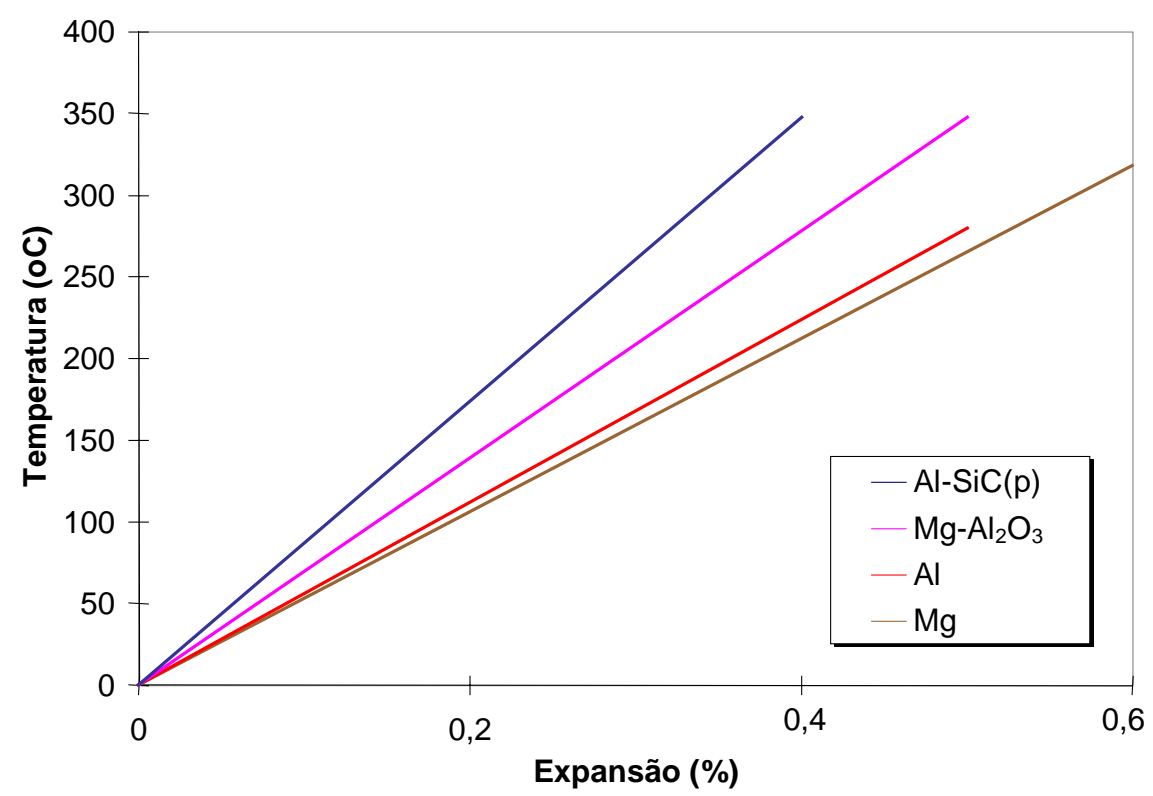

Figura 4.2 - Comparação da expansão térmica de metais em relação aos CMM (adaptação) [3].

Tabela 1.2 - Exemplos de materiais compósitos de matriz metálica (CMM) para aplicações aeroespaciais [3].

\begin{tabular}{|c|c|c|}
\hline Matriz & Reforço & Aplicação \\
\hline \multirow[t]{3}{*}{$\mathrm{Cu}$} & $\mathrm{C}$ & câmara de combustão \\
\hline & $\mathrm{SiC}$ & nariz (foguete, lançadores) \\
\hline & W & NASP $^{a}$ - Trocadores de calor \\
\hline $\mathrm{Fe}$ & W & tanques \\
\hline Ni e intermetálicos & $\begin{array}{l}\mathrm{Al}_{2} \mathrm{O}_{3} \\
W\end{array}$ & $\begin{array}{l}\text { lâminas, discos } \\
\text { lâminas, discos }\end{array}$ \\
\hline \multirow[t]{3}{*}{ Ti e intermetálicos } & $\mathrm{SiC}$ & alojamentos, tanque \\
\hline & $\mathrm{TiB}_{2}$ & lâminas, discos \\
\hline & TiC & cabos \\
\hline \multirow[t]{4}{*}{$\mathrm{Al}$} & $\mathrm{SiC}$ & $\begin{array}{l}\text { alojamentos (bombas, instrumentação), } \\
\text { conectores mecânicos, satélite, estruturas }\end{array}$ \\
\hline & $\mathrm{Al}_{2} \mathrm{O}_{3}$ & fuselagem \\
\hline & $\mathrm{C}$ & membros estruturais \\
\hline & $\mathrm{SiC}$ & anéis, lâminas \\
\hline $\mathrm{Mg}$ & $\mathrm{Al}_{2} \mathrm{O}_{3}$ & membros estruturais \\
\hline
\end{tabular}

${ }^{a}$ Hipersonic American National Aerospace Plane 
Os compósitos de matriz metálica podem ter uma variada combinação de elementos de matriz e reforço dependendo da aplicação e propriedades que se deseja obter. Entretanto, devido a principal aplicação ser estrutural buscam-se elementos mais leves e mais resistentes e utilizam-se normalmente materiais que apresentam baixas densidades (vide tabela 1.2). Nestes materiais, o reforço é normalmente um material cerâmico, embora possa ocorrer também por exemplo, a utilização de metais.

Clyne e Withers [6], subdividem os CMM de acordo com os tipos de reforço que os constituem, que podem ser contínuos (fibras longas), descontínuos (fibras curtas e "whiskers") e particulados. Acrescentam ainda que outras distinções podem ser feitas com base no diâmetro das fibras, orientação e distribuição do reforço.

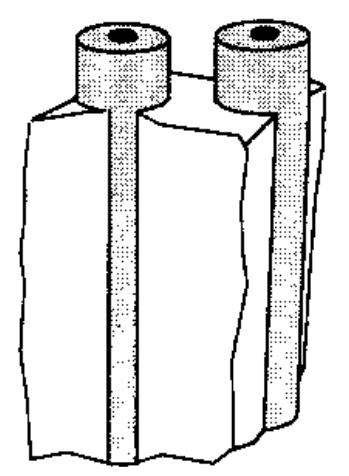

Fibras contínuas "Whiskers" / fibras curtas

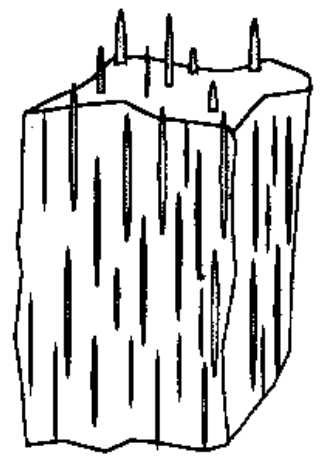

Figura 5.2 - Descrição esquemática dos três tipos de CMM, classificados de acordo com o tipo de

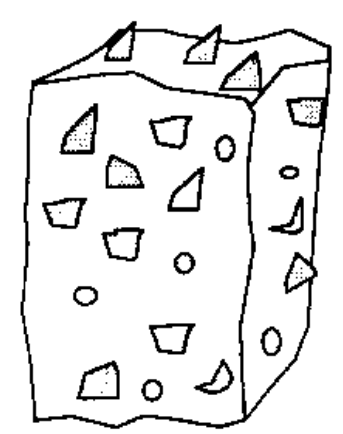

Particulados reforço [6].

\subsubsection{1 - Processos de fabricação}

Uma série de técnicas de processamento têm sido estudadas e utilizadas com o objetivo de otimizar a microestrutura e as propriedades mecânicas de compósitos de matriz metálica; entretanto, existe uma certa divergência quanto à classificação destes processos. Matthews e Rawlings [3], classificam os processos de fabricação de CMM dentro de quatro grupos básicos: a) estado sólido, b) estado líquido, c) deposição e d) in situ. Cada um destes métodos se diferencia dos demais, basicamente pela forma em que a matriz se encontra no momento em que é colocada em contato com o reforço, e também pela rota seguida até a consolidação efetiva entre as partes. 
Segundo Srivatsan, Ibrahim, Mohamed e Lavernia [7], os métodos de processamento utilizados na fabricação de compósitos de matriz metálica, mais especificamente aqueles com reforço particulado, podem ser agrupados de acordo com a temperatura em que o material da matriz se encontra durante o processo. Consequentemente podem ser divididos em três categorias: (1) processos de fase sólida; (2) processos de fase líquida; (3) processos de duas fases (sólido/líquido).

No processo de fase líquida, o material de reforço é incorporado dentro da matriz fundida usando-se várias técnicas as quais normalmente envolvem mistura e eventual fundição da mistura resultante em forma de componentes ou tarugos para posterior retrabalho. No processo de fase sólida, os materiais da matriz e do reforço são adicionados na forma de pós envolvendo uma série de estágios antes da efetiva consolidação do material. Processos de duas fases envolvem a mistura de material de reforço e matriz onde o material da matriz encontra-se em fases líquida e sólida.

Ambrozio Filho, Rossi, Gonçalves, Goldenstein, Souza e Yoshimura [8], adotam uma classificação mais abrangente e dividem os processos de fabricação de CMM em duas categorias básicas: processos com fase líquida e processos em estado sólido.

Dentro da classificação proposta por Ambrozio Filho et alli [8], alguns processos podem ser exemplificados. São eles: a) via metal líquido ("compocasting", co-deposição por "spray" e infiltração entre outros) e b) via metalurgia do pó. Clyne e Withers [6], nomeiam todos os processos citados anteriormente, como processos primários de fabricação. Alguns desses processos, exigem uma fase complementar que envolve normalmente transformação termomecânica como extrusão, laminação ou forjamento. A estes processos, eles dão o nome de processos secundários.

\section{a) Fabricação via metal líquido}

Na fabricação via metal líquido, a produtividade é maior. Não há necessidade da utilização de prensas ou matrizes metálicas (exceto se for utilizado o processo "squeeze- 
casting" como será visto mais adiante), possibilitando menores custos de produção e maior produtividade se comparada com a metalurgia do pó . Existe entretanto, dificuldade em se conseguir distribuição homogênea do reforço na matriz, bem como a introdução do reforço na forma de pó no banho metálico. Uma solução seria a refusão/solidificação de lingotes do compósito, de maneira muito bem controlada para evitar segregação e porosidades, mas isto encarece o processo e em muitos casos causa reações interfaciais indesejáveis [4].

Existe ainda a limitação quanto a quantidade de reforço que pode ser introduzido na matriz, com $20 \%$ em média de partículas em um banho, a viscosidade do mesmo aumenta de tal forma, que inviabiliza a produção via metal líquido (fundição) ou mesmo a homogeneização e vazamento do banho [4].

Um outro problema na produção via metal líquido, é a falta de molhabilidade do reforço e as reações adversas que podem ocorrer entre a matriz e o reforço devido as altas temperaturas envolvidas. Várias abordagens têm sido propostas para minimizar estes efeitos, dentre as quais a mais viável têm sido o pré-recobrimento do reforço com material apropriado para proteger contra algumas reações e aumentar a molhabilidade do mesmo [3].

\section{a.1) - "Compocasting" ("rheocasting")}

No processo "compocasting", basicamente o reforço é misturado à matriz fundida e em sequida a mistura é moldada de maneira convencional. Naturalmente, uma mistura uniforme é dificil de ser alcançada, levando-se em consideração as diferenças de densidade entre a matriz e o reforço. No "rheocasting" (figura 6.2), a mistura é melhorada graças a um resfriamento controlado da mesma, o que a coloca numa condição mais viscosa e facilita a homogeneização. 


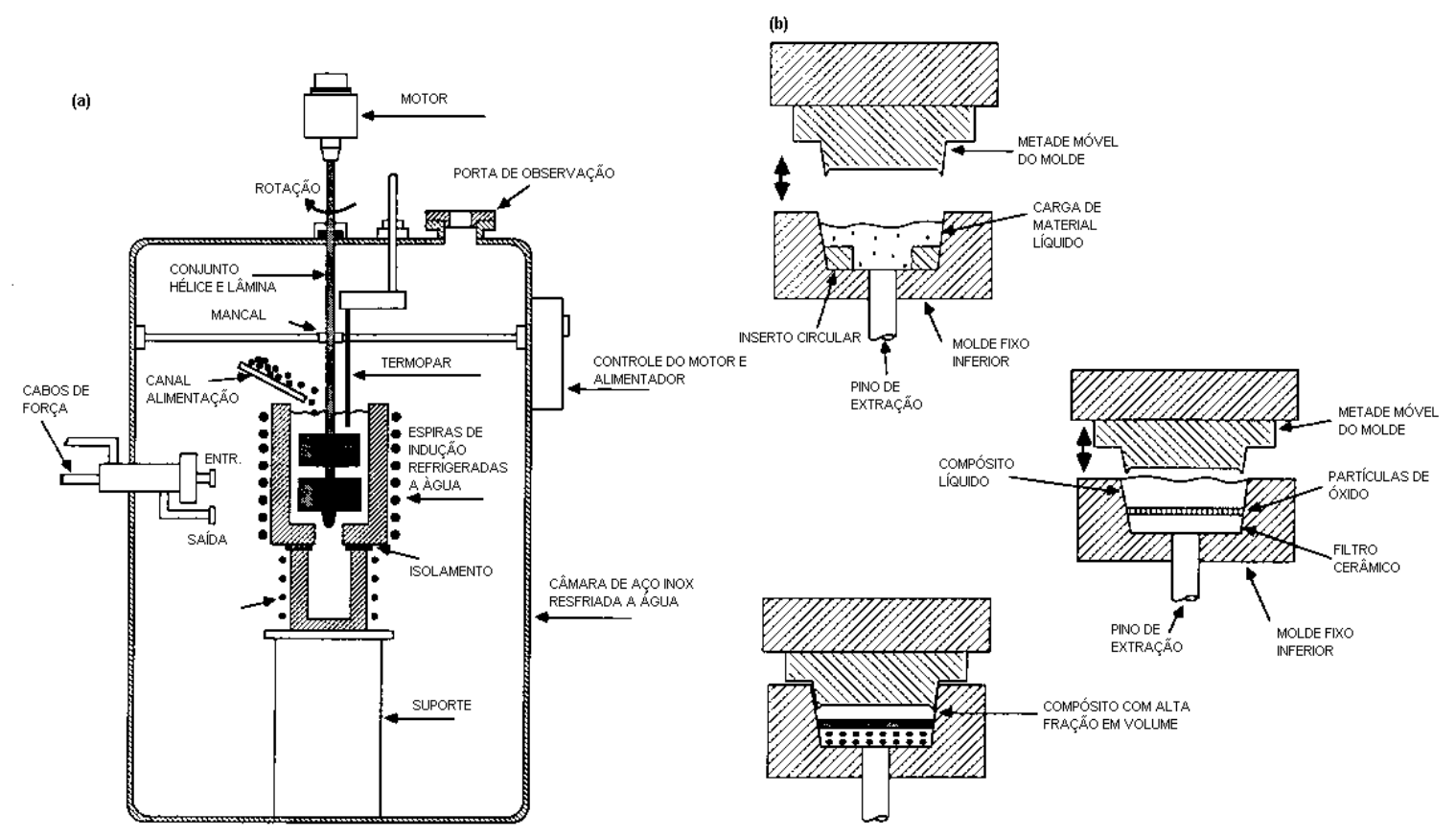

Figura 6.2 - "Rheocasting": (a) mistura das fibras ou partículas com o metal, seguido por (b) fundição em molde [5]

\section{a.2) Infiltração}

Em contraste com o caso de mistura de fases como no "compocasting", muitos processos via líquida envolvem a utilização de pré-formados de reforço, onde a matriz líquida precisa infiltrar. Uma infiltração mais eficiente pode ser conseguida pela aplicação de uma pressão maior que a atmosférica. Esta pressão é normalmente obtida mecanicamente por gás, mas outros métodos têm sido estudados incluindo indução eletromagnética [3]. Os processos de infiltração são aplicados a CMM reforçados por fibras e consistem em se obter um fluxo de metal líquido através de interstícios de um pré-formado que é um emaranhado de fibras curtas ou partículas. Após a infiltração obtem-se como produto final uma peça ou uma barra solidificada onde o metal líquido preencheu todas as cavidades possíveis desse pré-formado. Esses pré-formados podem ser obtidos nas mais variadas frações volumétricas sendo que, quanto maior a fração volumétrica desejada de reforço, menor o tamanho das cavidades e maior a dificuldade de infiltração. 


\section{a.2.1) Fundição sob pressão ("squeeze-casting")}

A fundição sob pressão é caracterizada pela aplicação mecânica da pressão e é adequada para a produção de pequenos componentes. Basicamente, um pré-formado de reforço é introduzido dentro de uma cavidade, onde uma quantidade precisa de metal fundido é adicionada e em seguida pressionada sobre o pré-formado para que o metal se infiltre. As vantagens desse processo são: altas taxas de produção, baixos custos se grandes quantidades são produzidas, alta qualidade da microestrutura nas regiões não reforçadas e altas taxas de solidificação resultando em baixas degradações das fibras. Algumas desvantagens são: os altos custos de ferramentais; dificuldade na fabricação de protótipos e dificuldade no controle de parâmetros importantes como temperatura do préformado.

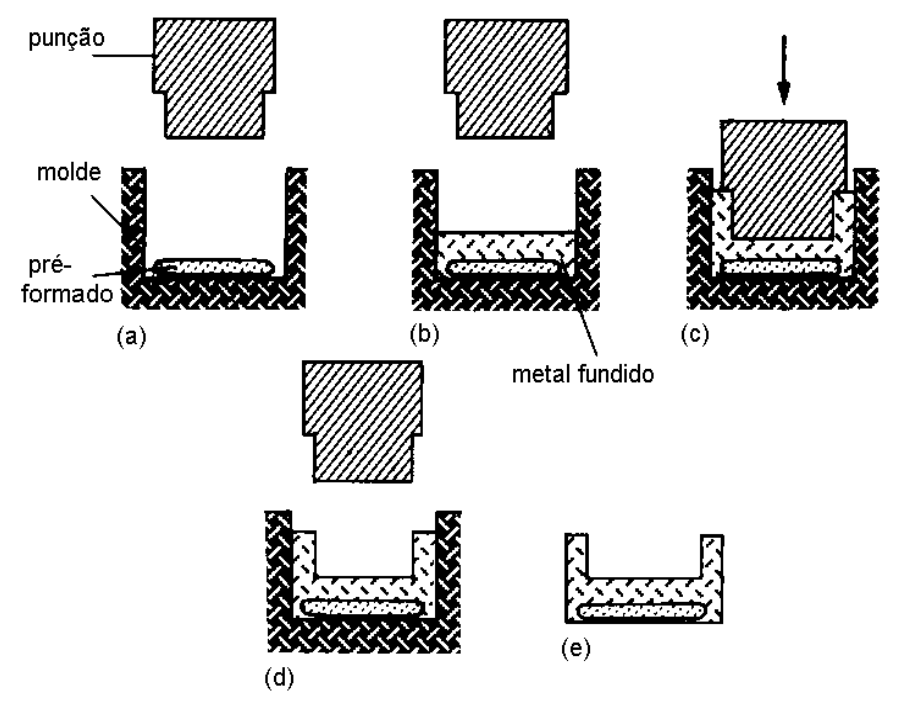

Figura 7.2 - Fundição sob pressão: (a) inserção do pré-formado dentro da cavidade do molde; (b) adição de uma quantidade precisa de metal; (c) fechamento do molde e aplicação de pressão; (d) abertura do molde; (e) componente pronto [3].

\section{a.2.2) Infiltração sob pressão}

Neste processo, o pré-formado é colocado dentro de um molde que por sua vez se encontra dentro de uma câmara. O metal que se encontra dentro de um recipiente também no interior da câmara é liquefeito pela ação de resistências elétricas que envolvem o recipiente. A alta pressão é conseguida fazendo-se inicialmente vácuo nesta 
câmara para que o metal seja levado a se infiltrar no pré-formado. Posteriormente a câmara é pressurizada e o banho metálico é forçado ainda mais a se infiltrar no préformado (figura 8.2).

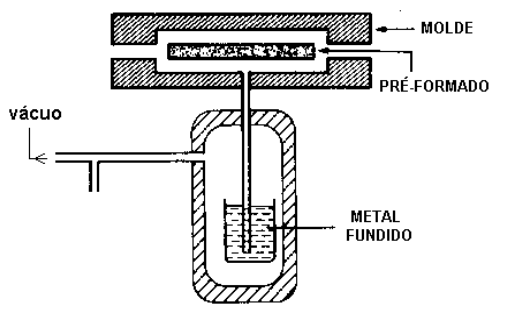

(a)

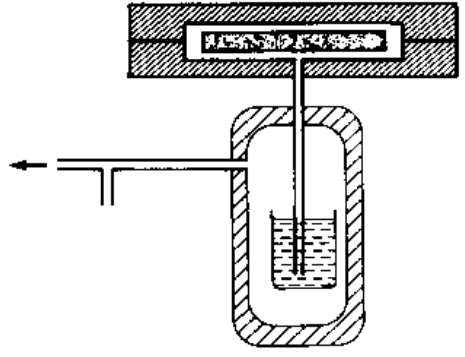

(b)

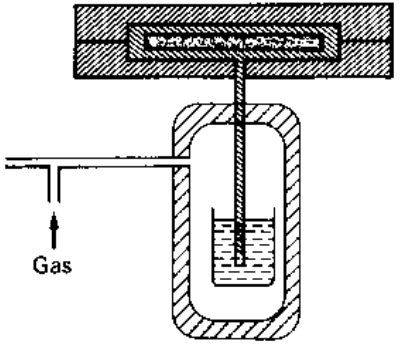

(c)

Figura 8.2 - Infiltração da liga fundida sob pressão de gás: (a) inserção do pré-formado e fechamento do molde, (b) aplicação de vácuo, (c) aplicação de pressão de gás, mantida durante a solidificação [3].

\section{a.2.3) Infiltração por vácuo}

Este processo é muito parecido com o processo anterior com a diferença de que a infiltração é feita apenas com a presença de vácuo. É geralmente usado quando se têm fibras grossas $(140 \mu \mathrm{m})$ e espaço necessário entre elas para que se crie uma diferença de pressão suficiente, (no mínimo $1 \mathrm{~atm}$ ) para que o metal penetre entre as mesmas. Devido às baixas pressões aplicadas, podem ocorrer regiões não infiltradas do préformado, mesmo em materiais com boas propriedades de molhabilidade (fig. 9.2).

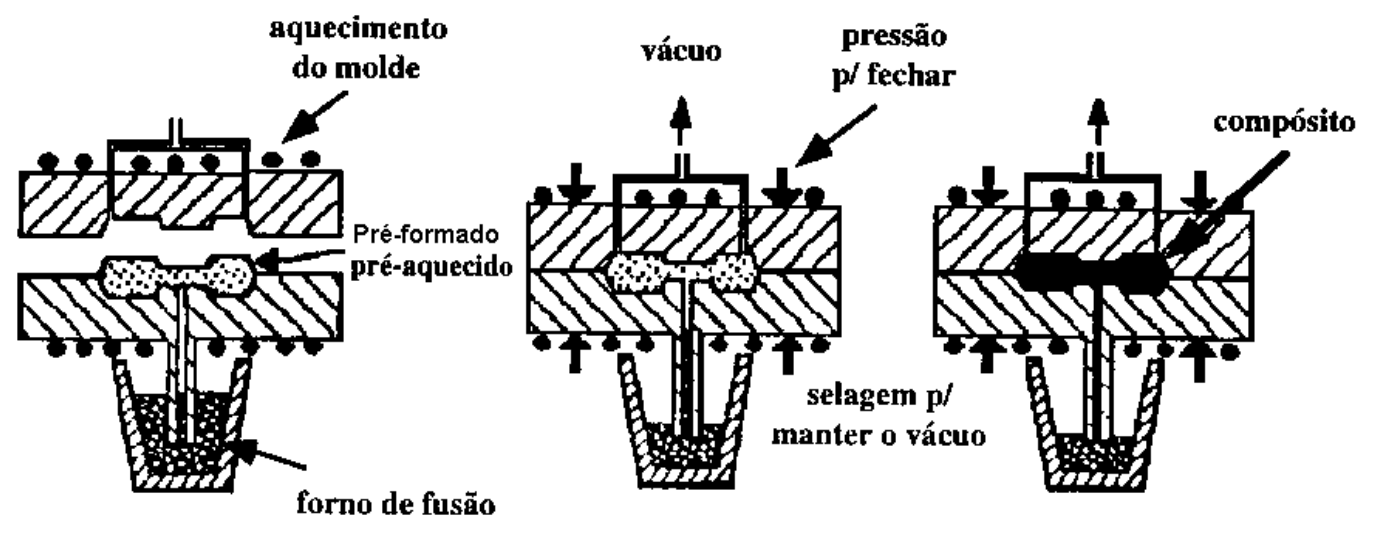

Figura 9.2 - Desenho esquemático do processo de infiltração por baixas pressões [4]. 


\section{a.2.4) Co-deposição por "spray"}

Neste processo, a matriz fundida é pulverizada juntamente com o reforço sobre um substrato de maneira semelhante àquela que ocorre nos processos de atomização; com a diferença de se adicionar as partículas de reforço na saída do material que está sofrendo o processo de atomização. Pode ser aplicado para grandes produções, $(0,2$ a 6 kg/s) [4]. O metal atomizado permite uma rápida solidificação levando à obtenção de uma matriz com microestrutura fina e reduzindo a possibilidade de reação química extensiva da matriz com o reforço [8] (figura 10.2).

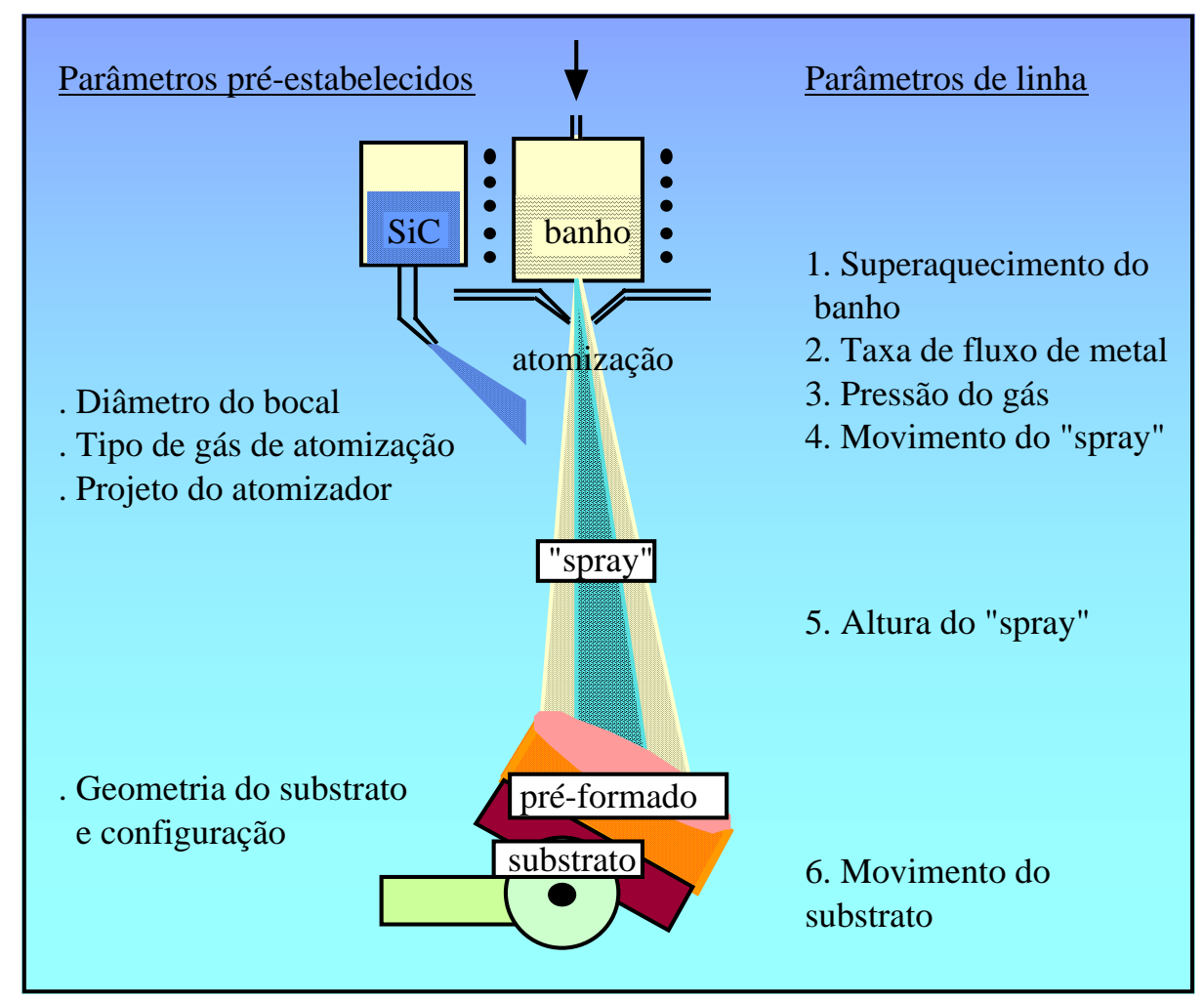

Figura 10.2 - Desenho esquemático do processo "Osprey" para fabricação de materiais compósitos por co-deposição de material de matriz e reforço.

b) Fabricação via metalurgia do pó

O processo via metalurgia do pó se enquadra na categoria de processos de fase sólida. Este processo envolve a mistura de pós do material da matriz e do material de 
reforço através de uma sequência de etapas que levam à efetiva consolidação do material, podendo incluir basicamente as seguintes etapas:

(a) peneiramento do material da matriz; (b) mistura do material da matriz com o material de reforço; (c) compactação da mistura; (d) desgaseificação; (e) consolidação por extrusão, forjamento, laminação ou outro método qualquer de trabalho à quente.

Srivatsan et al. [7], salientam que a tecnologia de produção via metalurgia do pó têm sido desenvolvida com sucesso por vários fabricantes comerciais. Os resultados revelam ainda que o processamento via metalurgia do pó, possibilita a obtenção de materiais com níveis de resistência mecânica superiores, se comparados a materiais equivalentes obtidos por processamento via metal líquido. Uma abordagem mais detalhada deste processo será feita no capítulo 3, já que este foi o processo utilizado na obtenção dos materiais utilizados na pesquisa.

\section{2 - Usinagem}

\subsection{1 - Origens e conceitos}

Existem basicamente três processos pelos quais se obtêm peças e produtos prontos para a utilização. O primeiro se caracteriza pela deposição de material e junção de partes como por exemplo no caso da solda e metalização; o segundo é o processo por deformação ou conformação que produz peças e componentes com as propriedades mecânicas necessárias por deformação plástica, onde o material é movido e o seu volume conservado; o terceiro processo é exatamente o processo de usinagem que produz peças pela remoção de material em partes ou em toda a extensão da peça por meio da utilização de ferramentas de corte. Um outro processo têm se destacado nos últimos anos revolucionando o campo de fabricação de peças e componentes principalmente de pequeno e médio porte, é o processo por metalurgia do pó, que permite em alguns casos a confecção de peças tão precisas quanto aquelas obtidas pelos processos mais delicados de usinagem. 
Dificilmente ocorre a presença isolada de um ou outro destes processos na fabricação de peças ou componentes, sendo que, normalmente o processo de usinagem atua como processo complementar com relação aos demais processos.

Há muito tempo o homem se esforça para concretizar formas que visualiza em sua mente. Sempre insatisfeito com os resultados obtidos na concretização de suas obras, têm buscado constantemente meios que possam facilitar e auxiliá-lo na busca da perfeição rumo a excelência. Percebeu então, que a forma tinha enorme influência em sua existência e que tinha poder para transformá-la, podendo não só torna-la bela, mas também adequada à conquista dos seus objetivos. Este é o conceito global de usinagem "alcançar a perfeição da matéria, não apenas enquanto a torna bela, mas também enquanto a torna útil e com razão suficiente de existência" [9].

Tecnicamente, usinagem é a operação executada por uma máquina operatriz que removendo matéria prima e produzindo cavacos por meio de ferramentas de corte, confere a forma, dimensão e acabamento planejados a uma peça.

Existe uma extensa variedade de processos de usinagem de que se pode fazer uso, dependendo é claro da geometria da peça a usinar, da geometria final que se deseja obter e do grau de acabamento e tolerâncias especificadas no projeto. Ferraresi [10] em seu livro "Fundamentos da usinagem dos metais", cita 23 processos e 32 subprocessos dos quais pode-se exemplificar três processos considerados processos universais de usinagem: torneamento, fresamento e furação. Cada um destes processos ou subprocessos se caracteriza pela utilização de equipamentos diferenciados e de ferramentas também diferenciadas, que irão auxiliar na efetiva consolidação do processo. Então, pode-se ter equipamentos como tornos, fresadoras, furadeiras, retificadoras, etc, utilizando ferramentas como fresas, brocas, rebolos e outras.

\subsection{2 - Desgaste da ferramenta}

No processo de corte dos metais por métodos convencionais, um fator indesejável e que exerce forte influência nos custos finais de produção de determinada peça ou 
componente, é o desgaste da ferramenta de usinagem. De modo geral, o processo de desgaste na ferramenta de usinagem obedece os príncípios teóricos estabelecidos pela "tribologia" (ciência que estuda os fenômenos e mecanismos envolvidos no processo de desgaste) vide ítem 2.3.

Mais especificamente para as ferramentas de usinagem de ponta única, existe uma classificação que denomina os efeitos do desgaste de acordo com o tipo (local e forma visual em que se apresentam). São eles: a) desgaste de flanco, b) desgaste de cratera, c) desgaste de sulco, d) deformação plástica, e) lascamento, f) desgaste em forma de pente, g) falha catastrófica.

Dentre estes os mais importantes são o de flanco e o de cratera, pois além de serem os de maior ocorrência, são inevitáveis e os maiores responsáveis pelo fim da vida da ferramenta em condições normais de trabalho.

\subsection{3 - Usinabilidade}

A chave para a produção industrial econômica com qualidade assegurada é a escolha e a configuração correta do processo produtivo. Quando este processo é o de usinagem a grande preocupação dos fabricantes de materiais, bem como dos fabricantes de peças e componentes que irão utilizar estes materiais e também dos fabricantes de ferramentas, é com a usinabilidade dos mesmos, ou seja, a facilidade ou não com que podem ser usinados.

Usinabilidade pode ser definida como sendo uma grandeza tecnológica que expressa por meio de um valor numérico comparativo (índice ou porcentagem) um conjunto de propriedades de usinagem de um metal, em relação a outro tomado como padrão [10]. Propriedades de usinagem de um metal, são aquelas que expressam o seu efeito sobre grandezas mensuráveis inerentes ao processo de usinagem dos metais tais como vida da ferramenta, força de usinagem, acabamento superficial da peça, temperatura de corte, etc. 
A usinabilidade têm grande influência na produtividade e nos custos finais de fabricação do produto de uma empresa. Se o índice de usinabilidade é muito baixo, por exemplo, leva à necessidade da utilização de velocidades de corte menores para que não ocorra um desgaste acentuado e prematuro da ferramenta; isto implica em maior tempo de produção e consequentemente maior custo. Uma opção seria a utilização de uma ferramenta mais resistente ao desgaste com aumento simultâneo da velocidade de corte. Esta alternativa diminuiria o tempo de produção mas aumentaria o custo com ferramental já que ferramentas mais resistentes normalmente custam mais caro. Restaria saber qual alternativa seria a mais vantajosa e ainda assim o acréscimo no custo final da produção seria evidente. É sabido, que o ideal é que se trabalhe com altas velocidades de corte e que para isso, não seja necessária a utilização de ferramentas especiais e mais caras; somente um material com alto índice de usinabilidade pode oferecer estas condições e é neste sentido que fabricantes de materiais, cientistas e pesquisadores da área de materiais têm se empenhado.

\section{3 - Tribologia}

\subsection{1 - Origens e conceitos}

O movimento de uma superfície sólida sobre outra, é de fundamental importância para o funcionamento de muitos tipos de mecanismos naturais e artificiais. A tribologia, engloba o estudo do atrito, desgaste e lubrificação e é definida como a ciência e tecnologia da interação entre superfícies em movimento relativo e as respectivas práticas que envolvem o processo [11]. Huchings [12] define tribologia como sendo a ciência e tecnologia da interação de superfícies em movimento relativo. Jost [13] define como sendo a ciência e tecnologia da interação de superfícies em movimento relativo, e das práticas e assuntos relacionados. A palavra tribologia é derivada da palavra grega "tribos" que significa atrito e foi implantada basicamente a partir de 1966. 
A falha de um componente ou estrutura segundo Gahr [11], pode ocorrer por meio de 4 mecanismos básicos, ou em alguns casos pela interação de dois ou mais desses mecanismos em conjunto sendo que os demais têm efeito secundário. São eles:

- deformação plástica;

- formação e propagação de trincas;

- corrosão;

- desgaste.

Cada um destes mecanismos têm característica própria e, compreende ramos de estudos e pesquisas diferenciados dentro do campo das diversas áreas da engenharia. $\mathrm{O}$ desgaste é um mecanismo que danifica a superfície de componentes. A vibração, o aquecimento, as mudanças geométricas e sobras de desgaste podem ser causados pela presença de atrito e desgaste. Estes podem resultar em perda futura da função do componente e pode ou não levar a uma falha catastrófica.

O desgaste e atrito são fenômenos antigos para a raça humana. Em épocas remotas, o fogo era obtido pelo atrito madeira contra madeira, ou pela colisão entre pedras muito duras. Muito mais tarde no período da renascença ocorreram importantes contribuições para o melhor entendimento dos fenômenos do atrito e desgaste. Conceitos como coeficiente de atrito foram implantados e a influência benéfica da utilização de lubrificantes na redução dos efeitos do atrito e desgaste também foi comprovada.

A importância econômica da tribologia e a grande necessidade por uma pesquisa sistemática e melhoria da transferência de conhecimentos teóricos nesta área, têm sido bem reconhecida durante as últimas quatro décadas. Muitos estudos têm sido conduzidos em diferentes países industrializados no sentido de avaliar o impacto econômico provocado pelos fenômenos de desgaste e atrito. De acordo com alguns desses estudos perdas econômicas chegam a atingir cerca de $4,5 \%$ do produto interno bruto de alguns países [11]. Daí a necessidade de que estudos e pesquisas sejam 
intensificadas nesta área para que se entenda melhor estes fenômenos e para que se elimine, minimize ou se tenha controle sobre as suas causas e efeitos.

Existe uma variada gama de aplicações onde pode ser verificada a ocorrência de desgaste: equipamentos de movimentação, bombas, moinhos, anéis de pistão, engrenagens, discos de freio, etc. Em todos os casos uma ampla variedade de condições causam desgaste. A solução de determinado problema de desgaste depende da identificação exata da natureza do problema. Sistemas de análise podem ser usados para identificação dos parâmetros de sistemas tribológicos (tribotecnologia ou tribossistemas). Dependendo dos parâmetros de um tribossistema, diferentes tipos de desgaste podem ocorrer. Mecanismos de desgaste descrevem a interação energética e material entre os elementos de um tribossistema. O tipo de movimento relativo entre os corpos em contato pode também ser usado para classificação dos diferentes processos de desgaste. Embora a norma DIN 50320 [14] não considere o processo tribológico que ocorre nos processos de fabricação, como desgaste em relação à peça trabalhada, Bayer [15] sugere que usinagem e polimento são formas de desgaste e que existe o lado positivo do desgaste e dos fenômenos de desgaste.

Um termo que geralmente acompanha o desgaste é o atrito. Bayer [15] define atrito como "uma força que se opõe ao movimento relativo entre duas superficies". Ela age em direção paralela às superfícies de contato e em sentido oposto ao do movimento. Geralmente a magnitude do efeito do atrito é descrita em termos de um coeficiente dito coeficiente de atrito $(\mu)$ que é a relação entre a força de atrito $\mathrm{F}$ e a força normal $\mathrm{N}$, responsável por manter unidas as superfícies em contato.

$$
\mu=\mathbf{F} / \mathbf{N} \quad \text { (equação 1.2) }
$$

Pode-se ainda considerar variações no conceito de coeficiente de atrito, na medida em que existe uma diferença entre o valor da força de atrito no início do movimento, e o seu valor quando o movimento é mantido em velocidade constante. 
Assim, tem-se no primeiro caso o chamado coeficiente de atrito estático $\left(\mu_{\mathrm{s}}\right)$ e no segundo caso o coeficiente de atrito dinâmico $\left(\mu_{k}\right)$.

Bayer [15] classifica desgaste basicamente em três caminhos: o primeiro leva em conta a aparência da marca do desgaste; o segundo relaciona o mecanismo físico que remove o material ou causa a falha e o terceiro as condições que envolvem a situação do desgaste. Assim tem-se a seguinte configuração:

- Corroído ("Pitted")

- Lascado ("Spalled")

- Riscado ("Scratched")

- Polido ("Polished")

APARÊNCIA

- Rachado ("Crazed")

- Fadigado ("Fretted")

- Escavado ("Gouged")

- Brunido ("Scuffed")

MECANISMO FÍSICO $\quad$ - Adesão

- Delaminação / fadiga de superfície [11]

- Oxidativa / reações triboquímicas [11]

$\begin{array}{cl} & \text { - Desgaste lubrificado } \\ \text { CONDIÇÕES QUE } & \text { - Desgaste não lubrificado } \\ \text { ENVOLVEM A } & \text { - Desgaste por escorregamento metal/metal } \\ \text { SITUAÇÃO DO DESGASTE } & \text { - Desgaste por rolamento } \\ & \text { - Desgaste por deslizamento de alto esforço } \\ & \text { - Desgaste metálico a alta temperatura }\end{array}$

O desgaste é avaliado por meio de testes tribológicos, através dos quais obtém-se resultados que permitem estabelecer relações comparativas entre os materiais. Gahr [11], cita em seu livro diversas normas relacionadas ao assunto dentre elas a DIN 50321 [16], que estabelece meios para a determinação da quantidade de desgaste baseados nos resultados encontrados em testes tribológicos. 


\section{3 - MATERIAIS E MÉTODOS}

\section{1 - Obtenção do material}

A obtenção do material objeto desta pesquisa foi feita pela rota da metalurgia do pó. Vale salientar que todos os parâmetros utilizados na obtenção foram retirados das dissertações de mestrado de Aroldo José Mourisco [4] e Humberto N. Yoshimura [17].

No presente trabalho foram avaliados materiais compósitos com matriz de alumínio reforçados com partículas de carboneto de silício (SiC), em três diferentes quantidades (frações volumétricas) de reforço. Foi produzida também, pela mesma rota e nas mesmas condições uma quantidade de material somente com o componente da matriz (sem partículas de reforço) objetivando comparar e verificar a influência da adição das partículas de reforço na matriz. Para que este último (material sem reforço) seja diferenciado em relação aos demais, o mesmo será ao longo do presente trabalho denominado "Al/SiC 0 \%" ou simplesmente "material sem reforço" (vide tabela 1.3).

Tabela 1.3 - Relação de materiais produzidos para a pesquisa

\begin{tabular}{|c|c|c|c|}
\hline Item & Material & $\begin{array}{l}\text { Fração volumétrica de reforço presente } \\
\text { na matriz (expressa em \%) }\end{array}$ & $\begin{array}{l}\text { Denominação ao longo do } \\
\text { presente trabalho }\end{array}$ \\
\hline 1 & $\mathrm{Al} / \mathrm{SiC}$ & 5 & $\mathrm{Al} / \mathrm{SiC} 5 \%$ \\
\hline 2 & $\mathrm{Al} / \mathrm{SiC}$ & 10 & $\mathrm{Al} / \mathrm{SiC} 10 \%$ \\
\hline 3 & $\mathrm{Al} / \mathrm{SiC}$ & 15 & $\mathrm{Al} / \mathrm{SiC} 15 \%$ \\
\hline 4 & $\mathrm{Al}$ & 0 & $\mathrm{Al} / \mathrm{SiC} 0 \%$ \\
\hline
\end{tabular}

Partindo de um compactado de 127 mm de diâmetro externo e aproximadamente $150 \mathrm{~mm}$ de comprimento (dimensões da caneca), a idéia inicial era utilizar uma relação de redução na extrusão de 45:1 obtendo-se ao final da operação barras de aproximadamente 6 metros de comprimento e diâmetro de $19 \mathrm{~mm}$. Como o escopo do trabalho é voltado para o estudo da usinagem e usinabilidade do material produzido, optou-se então por uma relação menor que possibilitasse o aumento do diâmetro usinável. Esta embora ainda não fosse a melhor condição foi a melhor solução 
encontrada. Assim a relação de redução passou a ser de $16: 1$ obtendo-se ao final da operação barras com diâmetro de 31,75 mm e comprimento em torno de 2,5 metros.

\subsection{1 - Materiais}

Na produção do material para a pesquisa foram utilizados pós comerciais de alumínio puro (AA1100) produzido pela ALCOA (MG), e de carboneto de silício (SiC) produzido pela EMAS/CARBORUNDUM (SP). O pó de alumínio foi produzido por atomização a ar e manipulado sob atmosfera de gás inerte com tamanho mediano de partículas igual a $22 \mu \mathrm{m}$. O pó de carboneto de silício utilizado como reforço é do tipo preto, denominado industrialmente como grão 800 e tem tamanho mediano de partículas igual a $6 \mu \mathrm{m}$. As composições químicas do pó de alumínio e SiC utilizados encontram-se na tabela 2.3.

Tabela 2.3 - Composição química (nominal) em peso dos pós utilizados.

\begin{tabular}{|c|c|c|}
\hline Material & Elemento & $(\%)$ em peso \\
\hline & $\mathrm{Al}$ & $99,7-99,83$ \\
\hline Pó de Alumínio & $\mathrm{Si}$ & $0,037-0,120$ \\
\hline & $\mathrm{Fe}$ & $0,089-0,180$ \\
\hline & Outros * $^{*}$ & $0,001-0,069$ \\
\hline * Entende-se como outros a soma das impurezas excetuando-se o Fe e o Si. \\
\hline & $\mathrm{SiC}$ & 98,87 \\
\hline & $\mathrm{Si}+\mathrm{SiO}_{2}$ & 0,6 \\
\hline & $\mathrm{Fe}$ & 0,18 \\
\hline Pó de SiC & $\mathrm{Al}$ & 0,15 \\
\hline & $\mathrm{Cu}$ & 0,20 \\
\hline
\end{tabular}

Embora não conste da tabela anterior deve-se considerar a presença de uma pequena parcela de alumina $\left(\mathrm{Al}_{2} \mathrm{O}_{3}\right)$, resultante da camada óxida que se forma em torno da partícula de alumínio. Vale salientar que, o processo de extrusão utilizado na obtenção dos materiais do presente trabalho, como será visto mais adiante (ítem 3.1.2), quebra essa camada óxida que reveste as partículas de alumínio; entretanto ela se mantém presente no material acabado 


\subsection{2 - Procedimentos}

O primeiro passo para a produção do material, foi um levantamento inicial das necessidades para a execução de todas as etapas do processo. Nesta etapa foi verificada a necessidade de construção de um dispositivo de contenção e compactação dos pós dentro das canecas, foi elaborado um projeto e o dispositivo foi confeccionado (vide figura 2.3).

Foram também confeccionadas canecas para a acomodação dos pós no processo de produção, estas foram retiradas de uma barra tubular de liga de alumínio extrudado com comprimentos de 150 mm e diâmetros externo e interno de 127 mm e 114 $\mathrm{mm}$ respectivamente. A utilização de canecas de alumínio serve no caso da produção de compósitos via metalurgia do pó, não só para conter a mistura mas também para evitar o contato direto do material compósito com a matriz da extrusora o que poderia danificá-la, visto que a fase de reforço nestes materiais é normalmente um material cerâmico, portanto, de dureza muito mais elevada. As dimensões das canecas estão associadas aos limites dimensionais do vão da mesa do equipamento utilizado na etapa de extrusão.

Em seguida foi feita a pesagem dos pós de alumínio e carboneto de silício em quantidades suficientes para preencher um volume de 1,4 litros do total da caneca, considerando-se densidade de compactação 80 \% e observando-se a manutenção da relação de porcentagem em volume de reforço em cada material. Assim foram os seguintes os valores utilizados (tabela 3.3):

Tabela 3.3 - Quantidade em peso de alumínio e SiC utilizados em cada caneca.

\begin{tabular}{|c|c|c|}
\hline Material & Massa alumínio $(\mathrm{kg})$ & Massa SiC $(\mathrm{kg})$ \\
\hline Al/SiC 5 \% & 2,87 & 0,18 \\
\hline Al/SiC 10 \% & 2,72 & 0,36 \\
\hline Al/SiC 15 \% & 2,57 & 0,54 \\
\hline Al/SiC 0 \% & 3,026 & -- \\
\hline
\end{tabular}


Após a etapa de pesagem teve início a produção propriamente dita do material para a pesquisa. Esta foi feita pela rota da metalurgia do pó, obedecendo as seguintes etapas conforme indicadas no fluxograma (figura 1.3) e melhor detalhadas em seguida:
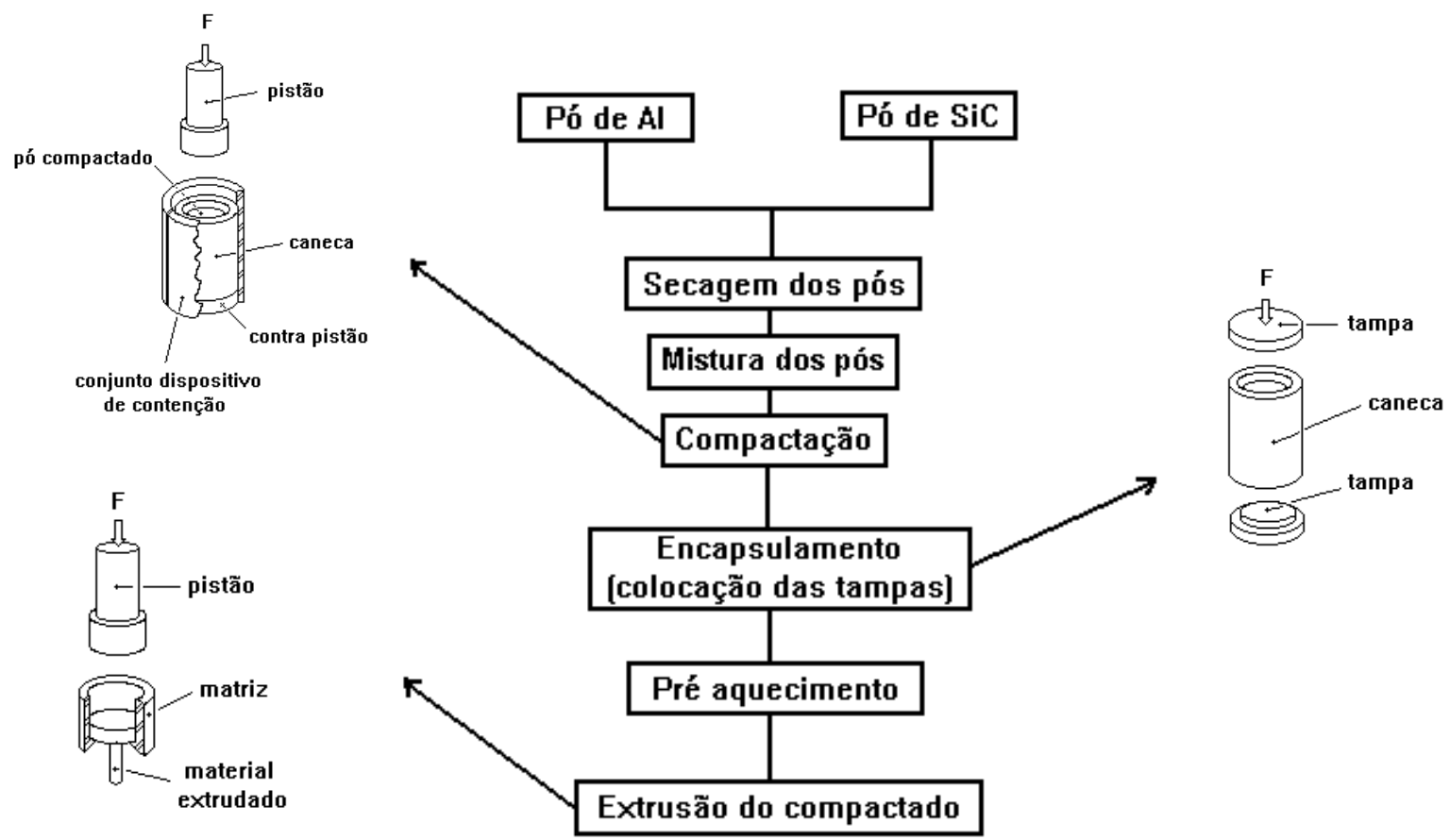

Figura 1.3 - Fluxograma da sequência de produção do material compósito Al/SiC utilizado na pesquisa.

- Secagem dos pós:

Os pós de alumínio e SiC foram colocados em estufa por um período de 4 horas à temperatura de $100{ }^{\circ} \mathrm{C}$. Este procedimento permitiu a retirada de umidade dos pós evitando aglomeração dos mesmos quando da mistura.

- Mistura dos pós:

Nesta etapa os pós já secos foram misturados em um misturador tipo "V" por 4 horas à 40 rotações por minuto.

- Compactação dos pós:

A compactação dos pós foi feita em um equipamento de ensaio mecânico. A carga aplicada em cada caneca para a obtenção de uma densidade inicial de $80 \%$ foi de 100 toneladas (o que equivale pelo valor do diâmetro externo da caneca a uma pressão 
de $7,9 \mathrm{~kg} / \mathrm{mm}^{2}$ ). Nesta etapa foi utilizado o dispositivo citado no item 3.1 .2 (figura 2.3).
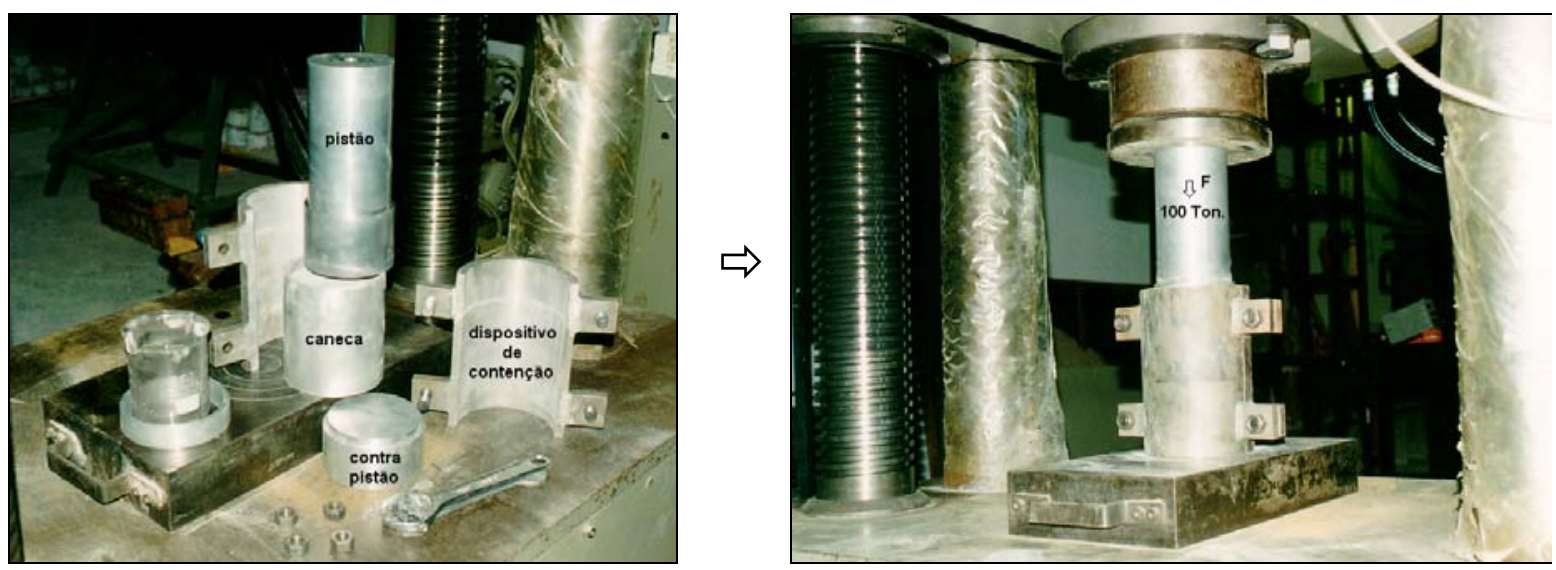

Figura 2.3 - Detalhe da etapa de compactação dos pós

- Encapsulamento do compactado (fechamento das canecas):

Uma vez compactadas as canecas foram fechadas, ou seja, em suas extremidades foram colocadas tampas de alumínio as quais foram torneadas de acordo com as dimensões de cada caneca e depois foram encaixadas com carga de aproximadamente 1,5 toneladas em uma prensa hidráulica manual.

- Pré-aquecimento das canecas:

A operação de extrusão requer um pré-aquecimento das canecas para que possíveis gases oriundos da etapa de mistura de pós sejam eliminados através de orifícios existentes nas tampas, e também para que o material tenha maior escoabilidade no momento da aplicação de pressão. Entretanto, a finalidade principal é a de facilitar a consolidação do material por caldeamento. Esta operação foi feita em forno comum deixando-se as canecas por um período de aproximadamente quatro horas a $450{ }^{\circ} \mathrm{C}$ (temperatura em que as mesmas são introduzidas na extrusora).

\section{- Extrusão das canecas:}

A extrusão foi feita em uma extrusora vertical de 1500 toneladas, com a matriz de extrusão a uma temperatura de $220{ }^{\circ} \mathrm{C}$. A velocidade de extrusão foi acima de 50 $\mathrm{mm} / \mathrm{seg}$ e a força máxima chegou a 450 toneladas momento em que o material começou 
a escoar pela matriz de extrusão. Para facilitar o escoamento do material pela matriz de extrusão foi utilizada graxa Molikote como lubrificante (figura 3.3).
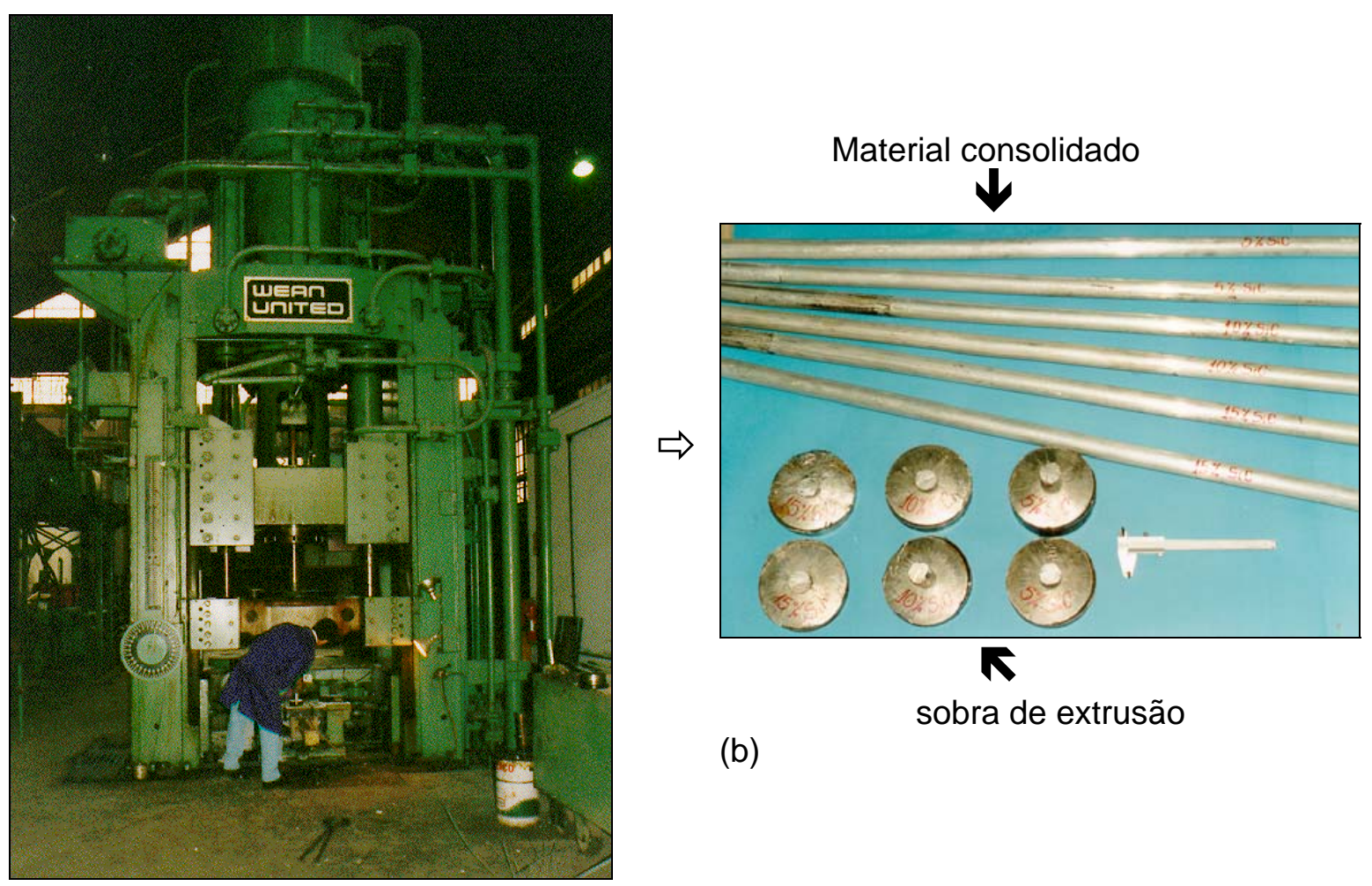

$\boldsymbol{\kappa}$

(b)

sobra de extrusão

a)

Figura 3.3 - Detalhe da extrusora vertical de 1500 toneladas utilizada para extrusão das canecas (a) e do material consolidado (b).

3.1.3 - Caracterização física, mecânica e microestrutural do material obtido.

Como característica física, foi avaliada a densidade hidrostática do material produzido. Para isto foi preparada (torneada) uma amostra de cada material com diâmetro de $26 \mathrm{~mm}$ por $8 \mathrm{~mm}$ de altura, em seguida estas amostras foram submetidas a ensaio para a determinação da densidade hidrostática.

A caracterização das propriedades mecânicas foi feita por intermédio de ensaios de dureza e tração uniaxial; para os ensaios de dureza usou-se as mesmas amostras utilizadas anteriormente (densidade hidrostática), procedeu-se um ligeiro polimento em uma de suas faces e efetuou-se o ensaio de dureza Brinell. A carga aplicada foi de 62,5 $\mathrm{kg}$ e o diâmetro do penetrador esférico utilizado foi de $2,5 \mathrm{~mm}$. As calotas esféricas impressas resultantes foram posteriormente mensuradas em projetor óptico e os valores 
encontrados foram aplicados na equação para a determinação da dureza Brinell. Para a determinação da resistência mecânica, foram preparados doze corpos de prova conforme DIN 50125 [18] vide figura 4.3, sendo três de cada material. Estes foram então submetidos a ensaio de tração.

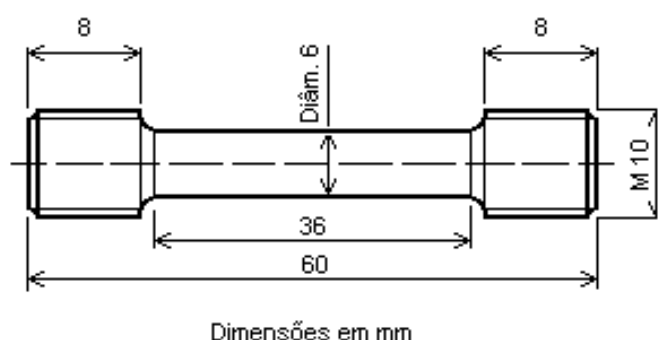

Fig. 4.3 - Detalhe dimensional do corpo de prova utilizado nos ensaios de tração.

Para a caracterização microestrutural, foram preparadas para análise em microscópio óptico duas amostras de cada material sendo uma no sentido transversal e uma no sentido longitudinal à direção de extrusão. Somente as amostras do sentido longitudinal foram embutidas em baquelite. Em seguida todas elas foram submetidas a polimento que obedeceu à seguinte ordem seqüencial:

- Lixas $\Rightarrow$ grana $280 \rightarrow 320 \rightarrow 400 \rightarrow 600$

- Panos $\Rightarrow$ pasta de diamante $6 \mu \mathrm{m} \rightarrow 3 \mu \mathrm{m} \Rightarrow$ sílica coloidal $0,25 \mu \mathrm{m}$

No polimento com pasta de diamante foi utilizado como lubrificante uma solução de álcool e glicerina na proporção de 2/1.

As amostras devidamente polidas foram então observadas em microscópio óptico. Como resultado da impregnação de partículas de SiC no material da matriz dos compósitos, oriundas das lixas utilizadas na etapa de lixamento; foi verificado que as imagens obtidas a partir das observações em microscópio se apresentaram confusas e, levantaram dúvidas quanto à proporção real de partículas de reforço presentes em cada material. A impressão é de que havia uma proporção muito maior do que a que realmente deveria haver, a preocupação também era de que a distribuição dessas partículas não estivesse muito homogênea. 
Optou-se então pela utilização do processo de extração química do reforço para que fosse verificada com exatidão a quantidade de material de reforço presente em cada um. O ensaio consiste basicamente em dissolver em ácido uma amostra de material de massa conhecida, e em seguida efetuar a filtragem da solução final. O material que fica retido no filtro é subtraído da massa inicial da amostra e sua porcentagem real em volume pode então ser determinada.

Foram preparadas amostras dos materiais (uma amostra de cada), estas sofreram uma pré-dissolução para eliminação de impurezas superficiais, em seguida foram secas e pesadas. As amostras foram então dissolvidas uma a uma em solução de ácido clorídrico (35\% vol.) em água destilada. Depois toda a solução passou por um processo de filtragem em micro filtro de PTFE (teflon) com diâmetro de poro de 0,2 $\mu \mathrm{m}$. Os filtros com os resíduos remanescentes foram colocados em dessecador durante 24 horas para a eliminação de umidade. Após a secagem os filtros foram pesados e os valores foram determinados.

\section{2 - Ensaios de usinagem e usinabilidade}

Estes ensaios foram realizados com o objetivo de avaliar o comportamento dos materiais a usinagem e o desempenho de diversos materiais de ferramenta. Fenômenos tais como desgaste da ferramenta, formação ou não de aresta postiça e formação do cavaco também foram observados e avaliados.

Um aspecto em particular que mereceu especial atenção, foi o estabelecimento do índice de usinabilidade para cada material avaliado. Como não foram encontradas referências a respeito de trabalhos que tenham feito uma avaliação deste aspecto em materiais deste tipo, esta pode ser efetivamente uma contribuição original do presente trabalho. 
Para estes ensaios foram preparados um total de quatorze corpos de prova com diâmetro de $31,75 \mathrm{~mm}$ e comprimento de $160 \mathrm{~mm}$, sendo conforme a tabela $4.3 \mathrm{a}$ distribuição para cada tipo de estudo:

Tabela 4.3 - Distribuição dos corpos de prova de acordo com a natureza do estudo.

\begin{tabular}{|c|c|c|c|}
\hline Natureza do estudo & $\begin{array}{l}\text { Material da } \\
\text { ferramenta }\end{array}$ & Material & $\begin{array}{l}\text { Quantidade de } \\
\text { corpos de prova }\end{array}$ \\
\hline $\begin{array}{l}\text { Usinagem, usinabilidade e } \\
\text { comportamento do material da } \\
\text { ferramenta }\end{array}$ & $\begin{array}{l}\text { Carboneto duro } \\
\text { sinterizado } \\
\text { (CERMET) }\end{array}$ & $\begin{array}{l}\text { Al/SiC } 5 \% \\
\mathrm{Al} / \mathrm{SiC} 10 \% \\
\mathrm{Al} / \mathrm{SiC} 15 \% \\
\mathrm{Al} / \mathrm{SiC} 0 \%\end{array}$ & $\begin{array}{l}2 \\
2 \\
2 \\
2\end{array}$ \\
\hline $\begin{array}{l}\text { Usinagem e comportamento } \\
\text { do material da ferramenta }\end{array}$ & Cerâmica & $\begin{array}{l}\text { Al/SiC } 5 \% \\
\text { Al/SiC } 10 \% \\
\text { Al/SiC } 15 \%\end{array}$ & $\begin{array}{l}1 \\
1 \\
1\end{array}$ \\
\hline $\begin{array}{l}\text { Usinagem e comportamento } \\
\text { do material da ferramenta }\end{array}$ & Diamante & $\begin{array}{l}\text { Al/SiC } 5 \% \\
\text { Al/SiC } 10 \% \\
\text { Al/SiC } 15 \%\end{array}$ & $\begin{array}{l}1 \\
1 \\
1\end{array}$ \\
\hline
\end{tabular}

Como o equipamento utilizado nos ensaios foi um torno a comando numérico conforme será visto no ítem 3.2.1, foram desenvolvidas rotinas (programas) na linguagem do comando do equipamento, para que os ensaios fossem realizados. Foram desenvolvidos dois programas: um para a utilização com ferramenta de carboneto duro sinterizado e outro para utilização com ferramentas de cerâmica e diamante.

O programa para utilização com ferramenta de carboneto duro sinterizado (anexo 1), compreende a aplicação de um total de quatro velocidades de corte diferentes para cada dois corpos de prova ensaiados e, considera inicialmente um bloco de desbaste. Nesta etapa o diâmetro inicial dos corpos de prova é usinado até o diâmetro de $27 \mathrm{~mm}$ para retirada da camada de alumínio resultante das canecas utilizadas para compactação e encapsulamento da mistura de pós. A partir daí o programa considera as usinagens e paradas para medição de desgaste a intervalos regulares garantindo a constância de comprimento de cavaco e volume de material removido, e também a mudança no valor da velocidade de corte a cada seis passes efetuados.

O programa para utilização com ferramentas de cerâmica e diamante (anexo 2), é praticamente o mesmo utilizado com ferramenta de carboneto duro sinterizado. A 
diferença é que neste caso são aplicadas apenas duas velocidades de corte diferentes para cada corpo de prova ensaiado. O ciclo de desbaste foi mantido para que também nesses corpos de prova a camada de alumínio resultante das canecas utilizadas no encapsulamento dos pós fosse retirada.

Foram utilizados (conforme mostrado na tabela 4.3), três tipos diferentes de material de ferramenta. Um destes materiais é composto por partículas de TiC, ligadas por uma fase metálica de níquel, e é comumente denominada CERMET. CERMET segundo Black, Chiles, Lissaman e Martin [19], é o nome coletivo para carbonetos duros sinterizados onde as partículas duras são baseadas em outros elementos que não o carboneto de tungstênio (WC). Quando a ferramenta é baseada em (WC) dá-se o nome de metal duro.

Carboneto duro sinterizado é um material de ferramenta obtido a partir de partículas duras de carboneto cimentadas por um elemento aglutinante. Neste contexto CERMET e metal duro podem ser considerados ferramentas de carboneto duro sinterizado.

Ao longo deste trabalho será adotada a classificação geral proposta por Black et alli e para simplificar mais ainda, a ferramenta de carboneto duro sinterizado (CERMET), será simplesmente denominada "ferramenta de carboneto".

Particularidades, especificações e características físicas das ferramentas (pastilhas e suportes) utilizadas nos experimentos seguem as indicações das tabelas 5.3 e 6.3 .

Tabela 5.3 - Particularidades básicas das ferramentas utilizadas nos experimentos

\begin{tabular}{|c|c|}
\hline Ferramenta & \multicolumn{1}{|c|}{ Particularidades básicas } \\
\hline Ferramenta de carboneto & $\begin{array}{c}\text { Carboneto duro sinterizado (CERMET): partículas } \\
\text { cerâmicas (TiC) + material metálico (Ni) como ligante. }\end{array}$ \\
\hline Cerâmica & $\begin{array}{c}\text { Cerâmica mista à base de alumina com adição de } \\
\text { carboneto de titânio. }\end{array}$ \\
\hline \multirow{2}{*}{ Diamante } & $\begin{array}{l}\text { Artificial policristalino (PCD): partículas de diamante } \\
\text { sinterizadas à alta pressão e alta temperatura com } \\
\text { pequena quantidade de cobalto como metal ligante. }\end{array}$ \\
\hline
\end{tabular}


Tabela 6.3 - Especificações e características físicas das ferramentas utilizadas.

\begin{tabular}{|c|c|c|c|c|c|}
\hline \multirow[t]{2}{*}{$\begin{array}{c}\text { Suporte } \\
\text { (Ref. ISO) }\end{array}$} & \multicolumn{2}{|c|}{ Pastilha } & \multicolumn{3}{|c|}{$\begin{array}{l}\text { Características de conjunto } \\
\text { (suporte + pastilha) (fig. 5.3) }\end{array}$} \\
\hline & $\begin{array}{c}\text { Geometria } \\
\text { Ref. ISO } \\
\left({ }^{*} \text { Ref. fabricante }\right)\end{array}$ & $\begin{array}{c}\text { Classe } \\
\text { Ref. ISO } \\
\text { (* Ref. fabricante) }\end{array}$ & $\begin{array}{l}\text { Ângulo } \\
\text { saída } \\
\text { (W) }\end{array}$ & $\begin{array}{c}\text { Ângulo de } \\
\text { incidência } \\
\text { ou folga } \\
(\mathrm{K})\end{array}$ & $\begin{array}{l}\text { Ângulo de } \\
\text { posição } \\
(X)\end{array}$ \\
\hline STGCR 1616 H11 & $\begin{array}{c}\text { Carboneto } \\
\text { TCMT } 110204-\left(\mathrm{UF}^{\star}\right)\end{array}$ & $\begin{array}{c}\text { K05 } \\
{ }^{*} \text { CT515 }\end{array}$ & $0^{\circ}$ & $11^{\circ}$ & $90^{\circ}$ \\
\hline CTGPR 2525 M11 & $\begin{array}{c}\text { Cerâmica } \\
\text { TPGN110304(T01020*) }\end{array}$ & ${ }^{*} \mathrm{CC} 650$ & $0^{\circ}$ & $11^{\circ}$ & $90^{\circ}$ \\
\hline STGCR $1616 \mathrm{H} 11$ & $\begin{array}{c}\text { Diamante } \\
\text { TCMW 16T304(F*) }\end{array}$ & ${ }^{*} \mathrm{CD} 10$ & $0^{\circ}$ & $11^{\circ}$ & $90^{\circ}$ \\
\hline
\end{tabular}

* Ref. Sandvik

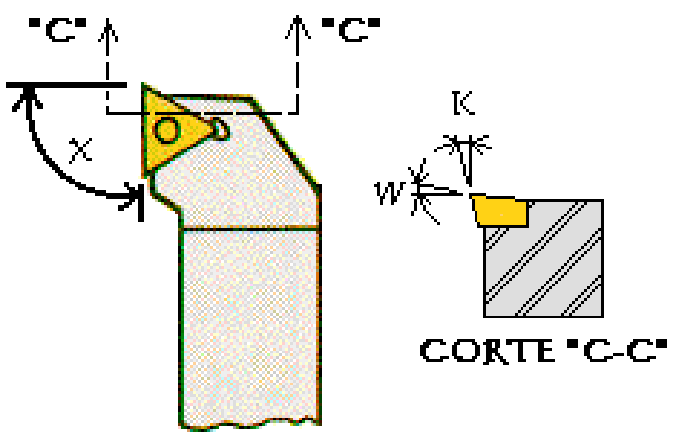

Figura 5.3 - Principais ângulos das ferramentas utilizadas.

Quanto ao ângulo de posição $(\chi)$ utilizado no presente trabalho (tabela 6.3), é necessário que se faça algumas considerações. Na indústria e mesmo em pesquisa, é recomendável sempre que possível que se utilize um ângulo de posição menor que $90^{\circ}$; na prática um valor bastante usado, sendo inclusive adotado pela ISO 3685 é de $75^{\circ}$. Esta condição favorece o processo de usinagem na medida em que equilibra as forças radiais e axiais resultantes do processo de usinagem, minimizando os seus efeitos sobre a ferramenta de corte. A utilização de um ângulo de posição de $90^{\circ}$ no torneamento se faz necessária em casos de faceamento, usinagens com terminações a $90^{\circ}$ ou então na usinagem de eixos esbeltos (pequena relação diâmetro/comprimento) o que foi o caso dos corpos de prova utilizados no presente trabalho. A utilização de um ângulo de posição de $90^{\circ}$ em eixos esbeltos, praticamente anula a resultante radial das forças de 
corte que poderia resultar em flexão do corpo de prova ou trepidação excessiva durante o processo de usinagem.

Os ensaios consistiram basicamente na usinagem dos corpos de prova a profundidade de corte $\mathbf{p}$ e avanço $\mathbf{f}$ constantes iguais a 0,875 $\mathrm{mm}$ e $0,1 \mathrm{~mm} / \mathrm{rot}$ respectivamente, para um raio de ponta $\mathbf{r}$ também de mesmo valor para todas as ferramentas igual a 0,4 mm de acordo com indicações da norma ISO 3685 [20]. As condições de profundidade de corte e avanço constantes, faz com que em cada passe não só o comprimento de cavaco seja constante, mas também o volume de material removido (vide figura 6.3).

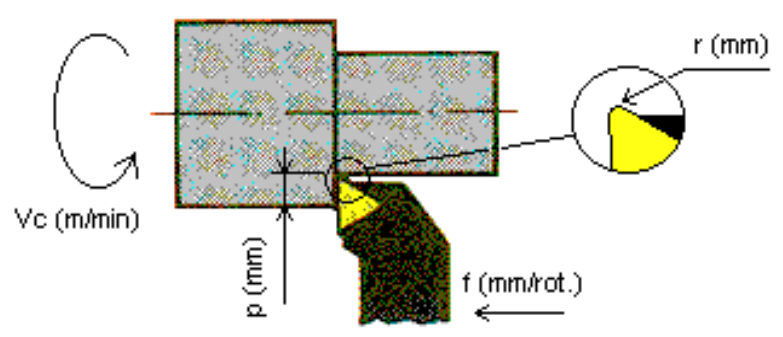

Figura 6.3 - Representação esquemática ilustrativa dos parâmetros de usinagem utilizados nos experimentos.

A velocidade de corte foi o parâmetro variável tendo sido aplicadas, conforme mencionado anteriormente, um total de quatro velocidades $(273,229,185$ e $141 \mathrm{~m} / \mathrm{min}$ ) na usinagem com ferramenta de carboneto; e apenas duas (273 e $229 \mathrm{~m} / \mathrm{min}$ ) com ferramentas de cerâmica e diamante. Para cada velocidade de corte, a ferramenta de corte percorreu um total de 393,96 metros (comprimento de cavaco), com paradas para avaliação da evolução do desgaste da ferramenta a cada 65,66 metros, perfazendo-se um total de 6 paradas para cada velocidade de corte utilizada.

A cada parada a pastilha era retirada do suporte e levada até o microscópio óptico para medição e registro da evolução do desgaste de flanco (VB) vide figura 6.4 pag. 46. Em seguida a pastilha era fotografada em um microscópio estereoscópico e então recolocada no suporte para continuidade do ensaio. Com a mudança no valor de 
velocidade de corte, a aresta de corte danificada da pastilha era substituída por uma nova aresta, iniciando-se então um novo ciclo de medições.

Foram coletados valores de força, e foram observados fenômenos tais como formação ou não de aresta postiça de corte e também formação do cavaco. Foi utilizado em todos os ensaios, o fluido refrigerante ref.: Monol 9420 - IORGA na concentração de 5 \% em solução aquosa com vazão sobre a região de corte em torno de 2000 l/h.

\subsection{1- Equipamento de usinagem}

O equipamento utilizado foi um torno a comando numérico computadorizado (CNC), vide figura 7.3. A escolha desse tipo de equipamento está associada a algumas características superiores em relação a um equipamento convencional dentre elas principalmente os seguintes ítens:

- Alto valor de rotação no eixo árvore podendo atingir 4000 rpm o que possibilita também acesso a altos valores de velocidade de corte.

- Variação infinita (dentro de dois valores limites) do valor de velocidade de corte possibilitada pela presença de um variador de frequência no sistema de transmissão do equipamento.

- Mínima folga e boa rigidez característicos de equipamento novo recentemente adquirido, o que possibilitou a utilização de ferramentas de diamante e cerâmica sem comprometimento de desempenho das mesmas.

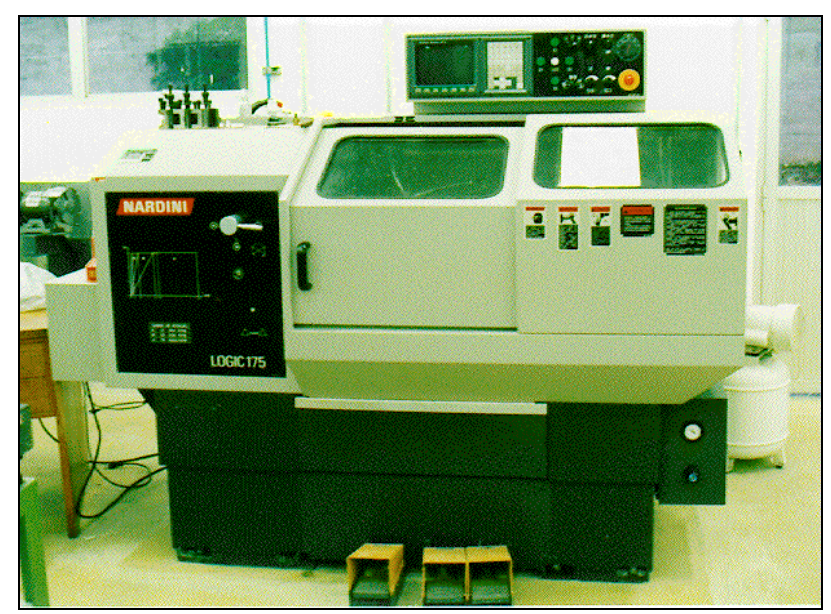

Figura 7.3 - Detalhe do equipamento utilizado nos experimentos. 


\subsection{2 - Forças de corte}

Para que se pudesse medir as forças atuantes no momento da usinagem em cada um dos materiais, foi feita uma montagem a base de medidores de deformação ("strain gauges"). Por limitação do equipamento que possui apenas um canal de leitura, optou-se por instrumentar as ferramentas de modo que fosse feita a leitura da força principal de corte $(\mathrm{Fc})$, ou seja aquela tangencial ao movimento circular da peça, e por conseguinte a que normalmente tem maior intensidade (vide figura 8.3).
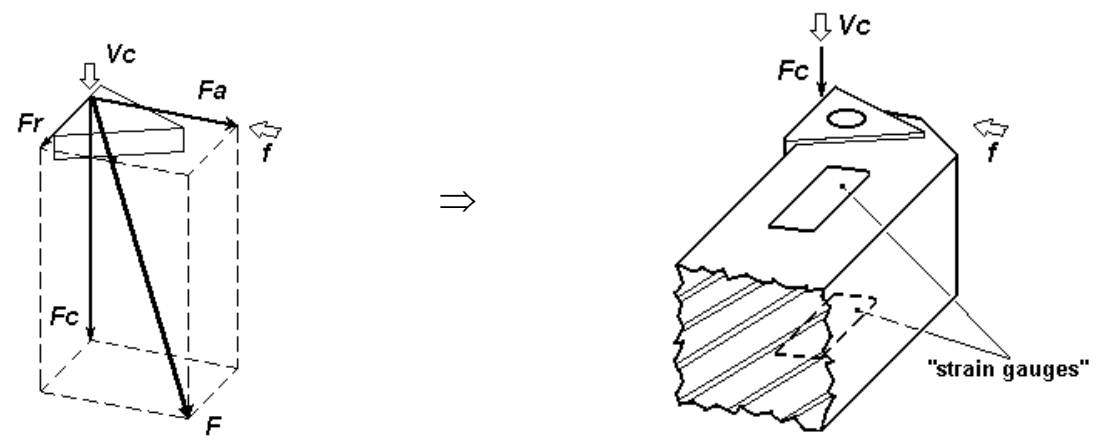

Figura 8.3 - Esquema ilustrativo mostrando a direção da força de corte medida (Fc).

Com as ferramentas devidamente instrumentadas foi feita uma calibração estática das mesmas com a utilização de massas conhecidas. As curvas de calibração foram construídas e demonstraram ter comportamento linear (vide figura 9.3). Nas equações das retas foram aplicados os resultados obtidos nos experimentos transformando-os em unidade de força.

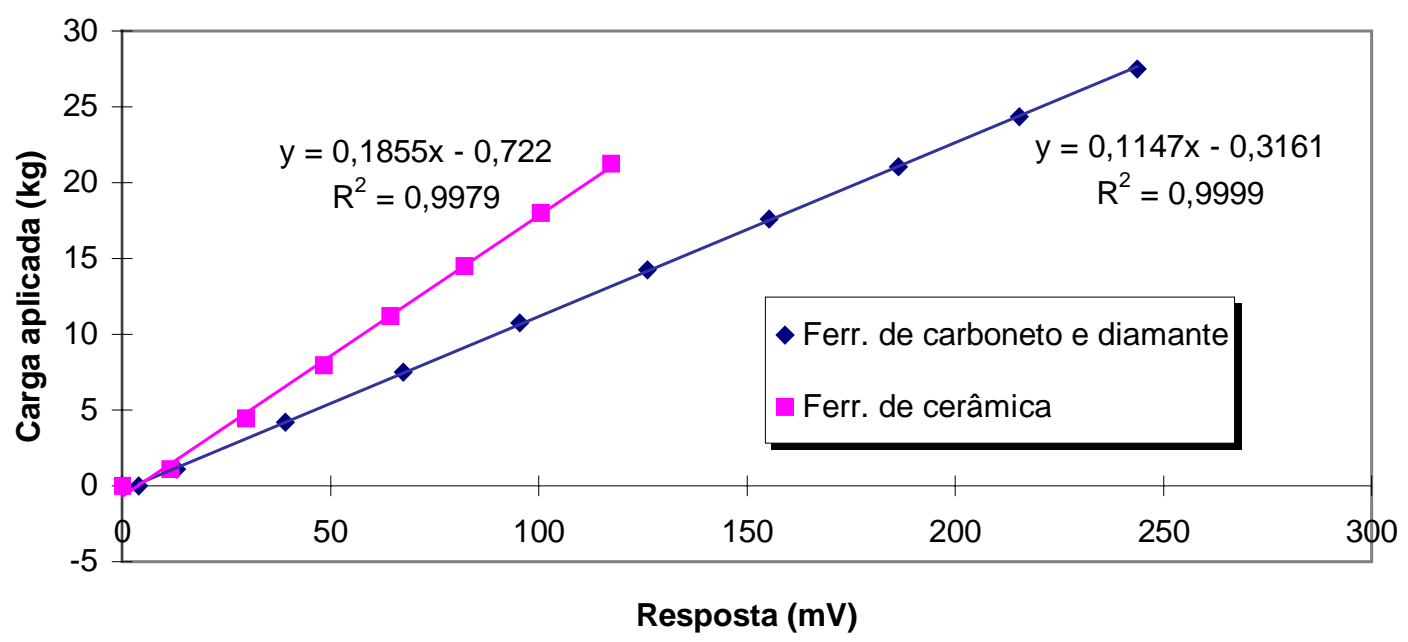

Figura 9.3 - Curvas de calibração das ferramentas utilizadas nos experimentos, variação da carga aplicada versus resposta em ( $\mathrm{mV}$ ). 
As micro deformações acusadas pelos "strain gauges", foram convertidas em milivolts por uma ponte de Wheatstone. Por um multímetro acoplado ao sistema os valores foram enviados a um microcomputador por intermédio da interface de comunicação RS 232, onde os mesmos foram armazenados por um software de registro de dados para que fossem trabalhados posteriormente (vide figura 10.3).

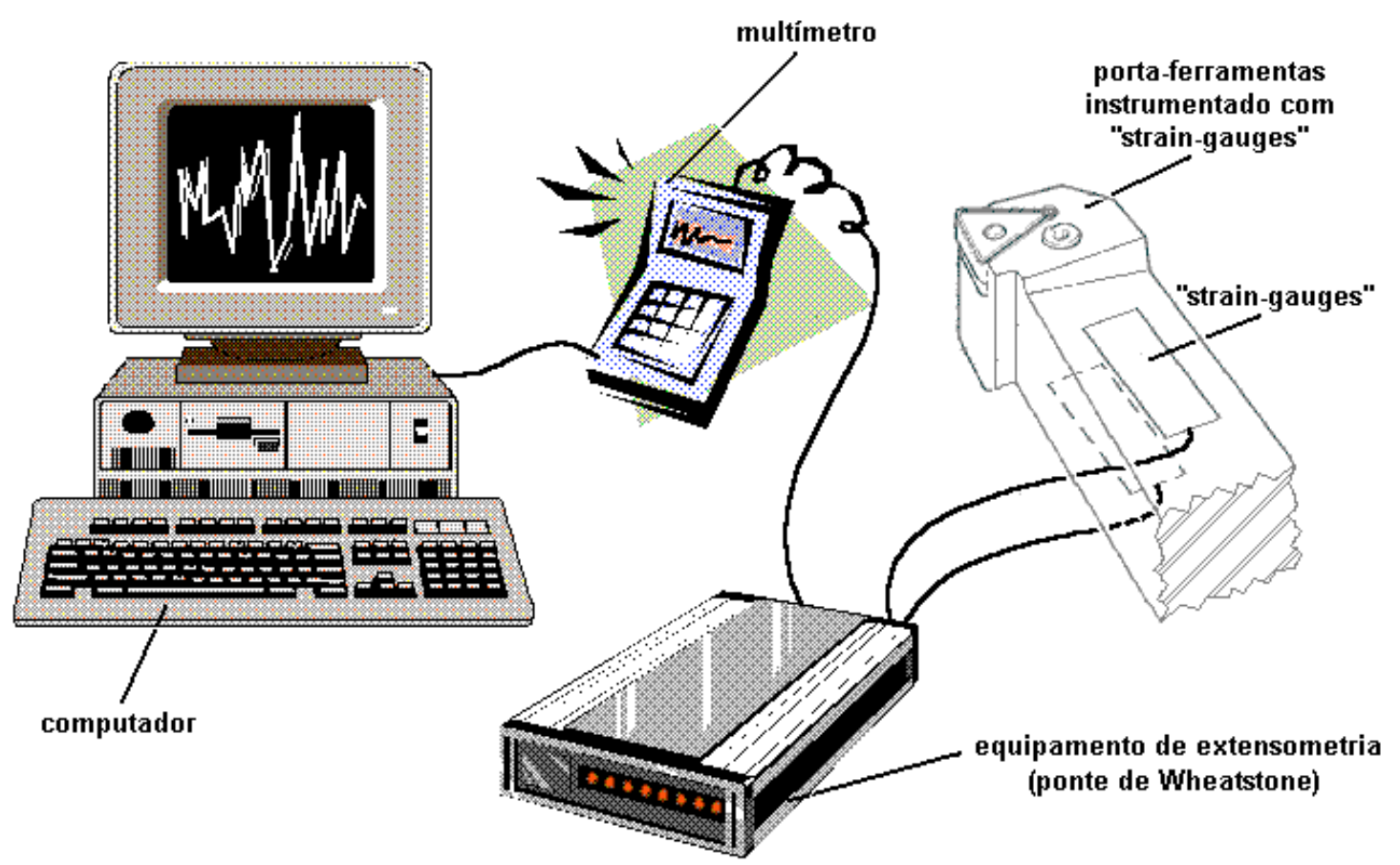

Figura 10.3 - Representação esquemática do equipamento utilizado para medição de forças.

\subsection{3 - Usinabilidade}

Para determinação do índice de usinabilidade de cada material, foram utilizados os resultados obtidos nos testes com ferramenta de carboneto. Foi aplicado o método do comprimento usinado citado por Ferraresi [10]. Este é um método de ensaio de curta duração que não requer grandes quantidades de material, tão pouco longos períodos de ensaio. A escolha deste método esteve relacionada principalmente à limitação na quantidade de material disponível.

Métodos de ensaio dessa natureza (curta duração) normalmente não apresentam boa correspondência com os equivalentes de longa duração. Entretanto, Ferraresi [10] faz algumas considerações quanto aos ensaios de curta duração, referindo-se a um 
trabalho onde é feita uma comparação estatística de vários ensaios de curta duração baseados no desgaste da ferramenta, com o correspondente ensaio de longa duração. Os resultados mostram que dentre todos os métodos analisados apenas dois apresentaram boa correlação com o correspondente de longa duração, dentre eles o método do comprimento usinado. O Metals Handbook [21], sugere um procedimento para determinação da usinabilidade que na realidade está intimamente relacionado e é bastante similar ao método do comprimento usinado a diferença é que ao invés de fazer uma relação do desgaste pelo comprimento usinado, faz uma relação do desgaste pelo tempo, o que faz segundo Ferraresi com que o erro nos resultados no caso do método do comprimento usinado seja minimizado já que o comprimento é de vários metros. Os valores encontrados nos experimentos foram ainda aplicados na equação de Taylor (equação 1.4 - pag. 62), e as constantes da equação para os materiais e condições de ensaio foram determinadas.

\section{3 - Ensaios de desgaste}

Foram feitos basicamente ensaios de desgaste por deslizamento do tipo pino sobre disco sem lubrificação. Para estes ensaios que visam estabelecer uma relação comparativa entre os materiais estudados, foram preparados oito corpos de prova (vide figura 11.3), sendo dois de cada material.

Como contracorpo foram utilizados discos de aço SAE 1045 com espessura de 5 mm e diâmetro de 63,5 mm, tratados térmicamente e retificados, atingindo dureza em torno de $48 \mathrm{HRC}$ e acabamento superficial de 0,14 Ra.

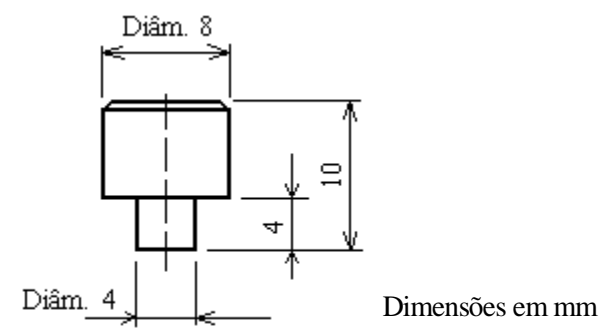

Figura 11.3 - Detalhe dimensional do pino utilizado nos ensaios de desgaste. 
O equipamento utilizado foi um tribômetro do tipo pino contra disco (figura 12.3). Procedimentos de ensaio e nomenclaturas utilizadas foram baseados nas normas ASTM G99 [22] e G118 [23]. Cada pino foi previamente pesado, em seguida foi ensaiado por um período de quatro horas e meia com paradas regulares (a cada 45 minutos) para determinação da perda de massa. Os valores totais de perda de massa encontrados, foram aplicados na equação para a determinação do coeficiente de desgaste (equação 2.4 - pag. 65). Também foi analisado em microscópio eletrônico de varredura o aspecto das regiões desgastadas. A perda de massa do contra corpo não foi considerada nos ensaios e os parâmetros de ensaio utilizados foram os seguintes:

- Velocidade (relativa do pino sobre o disco): 0,75 m/s

- Raio: $26 \mathrm{~mm}$

- Carga: $5 \mathrm{~N}$

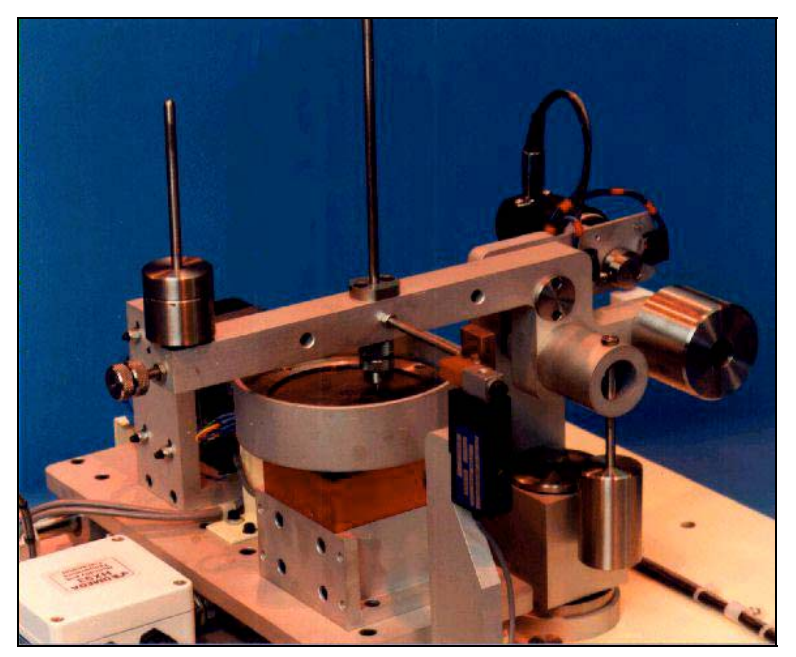

Figura 12.3 - Equipamento utilizado nos ensaios de desgaste. 


\section{4 - RESULTADOS E DISCUSSÃO}

Neste capítulo serão mostrados e discutidos os resultados obtidos na caracterização dos materiais, testes de usinagem e usinabilidade e testes de desgaste, procurando sempre que possível estabelecer uma relação com o material sem reforço na verificação da influência da adição de partículas de reforço nas propriedades e características de usinagem e desgaste dos compósitos Al/SiC.

\section{1 - Caracterização física, mecânica e microestrutural do material obtido}

A tabela 1.4 fornece uma visão geral dos resultados de densidade, dureza e resistência mecânica encontrados durante a caracterização física e mecânica dos materiais obtidos. Estes resultados serão melhor evidenciados e discutidos nos itens subsequentes.

Tabela 1.4 - Aspecto geral das características físicas e mecânicas dos materiais produzidos.

\begin{tabular}{|c|c|c|c|c|c|c|c|}
\hline Material & $\begin{array}{c}\text { Densidade } \\
\text { teórica } \\
\left(\mathrm{g} / \mathrm{cm}^{3}\right)\end{array}$ & $\begin{array}{c}\text { Densidade } \\
\text { hidrostática } \\
\left(\mathrm{g} / \mathrm{cm}^{3}\right)\end{array}$ & $\begin{array}{c}\text { Valores de } \\
\text { dureza } \\
(\mathrm{HB})\end{array}$ & $\begin{array}{c}\text { Limite de } \\
\text { escoamento } \\
\mathrm{LE}_{0,2}(\mathrm{MPa})\end{array}$ & $\begin{array}{c}\text { Limite de } \\
\text { resistência } \\
\text { LR (MPa) }\end{array}$ & $\begin{array}{c}\text { Alongamento } \\
\text { e (\%) }\end{array}$ & $\begin{array}{c}\text { Redução em } \\
\text { área } \\
\text { RA (\%) }\end{array}$ \\
\hline Al/SiC 0 \% & 2,702 & $2,687 \pm 0,003$ & $32 \pm 1$ & $88 \pm 1$ & $120 \pm 1$ & $32 \pm 2$ & $64 \pm 4$ \\
\hline Al/SiC 5\% & 2,7277 & $2,713 \pm 0,002$ & $39 \pm 1$ & $84 \pm 3$ & $128 \pm 2$ & $26 \pm 2$ & $47 \pm 5$ \\
\hline Al/SiC 10\% & 2,7535 & $2,718 \pm 0,001$ & $44 \pm 1$ & $93 \pm 4$ & $135 \pm 2$ & $22 \pm 3$ & $32 \pm 5$ \\
\hline Al/SiC 15\% & 2,7793 & $2,729 \pm 0,001$ & $49 \pm 1$ & $94 \pm 3$ & $138 \pm 4$ & $15 \pm 2$ & $20 \pm 3$ \\
\hline
\end{tabular}

\subsection{1- Caracterização física}

- Densidade hidrostática

Pelo gráfico (figura 1.4), é possível notar a diferença entre os valores de densidade hidrostática encontrados e os respectivos valores de densidade teórica. Os valores inferiores de densidade hidrostática em relação à teórica, indicam a presença de vazios em todos os materiais produzidos. Ainda com relação aos materiais contendo partículas de reforço, a diferença tende a aumentar à medida em que também aumenta a fração volumétrica, indicando também que nesses materiais a formação de vazios é 
preferencial, nas regiões de aglomeração de partículas de reforço e também nas regiões interfaciais.

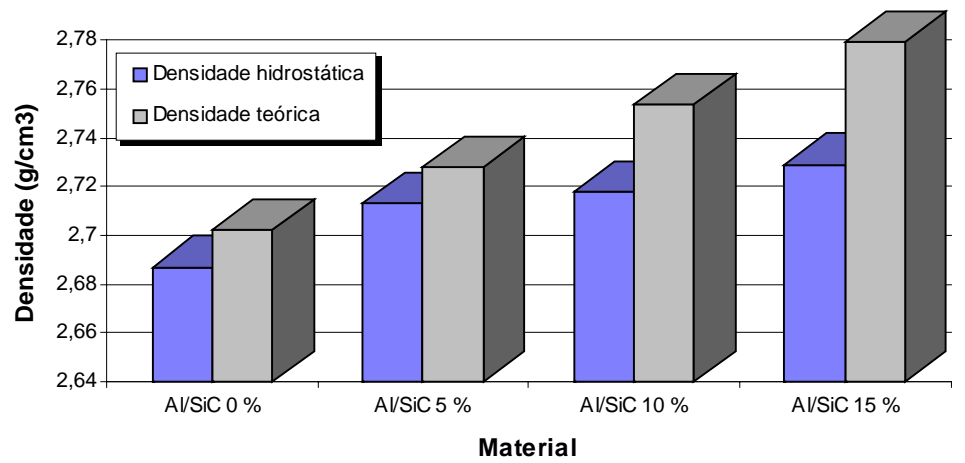

Figura 1.4 - Valores de densidade hidrostática e teórica para os materiais compósitos com diferentes frações volumétricas de SiC.

Mourisco [4] e Yoshimura [17], encontraram resultados similares em seus trabalhos. Yoshimura, sugere que existe uma fração volumétrica máxima a partir da qual deve ocorrer uma acentuada diminuição da densidade desses compósitos devido à formação de aglomerados; para uma diferença maior entre tamanho de partícula de reforço e da matriz menor é esta fração crítica. Neste caso a relação entre os tamanhos de partículas é igual à 0,27. Al-Rubaie, Goldenstein e Mello [24], apontam como primeira característica importante no processamento via metalurgia do pó, a RTP (relação tamanho da partícula do pó de alumínio/tamanho de partícula de pó de SiC). Salientam que quanto maior a relação maior a aglomeração de partículas de SiC e consequente heterogeneidade da microestrutura; e que a aglomeração de SiC é dependente também da sua fração volumétrica, ou seja, aumenta com o aumento da quantidade de material de reforço.

\subsection{2 - Caracterização mecânica}

\section{- Dureza}

Pela figura 2.4, é possível verificar o aumento do valor de dureza à medida em que a fração volumétrica de reforço é aumentada. Esse comportamento é esperado, já que neste caso as partículas de reforço (material cerâmico) isoladamente têm dureza 
muito mais elevada que o material da matriz. Ainda, pela linha de tendência (linha vermelha) é possível notar que o acréscimo nos valores de dureza tende a uma queda na taxa de aumento à medida em que a quantidade de reforço aumenta.

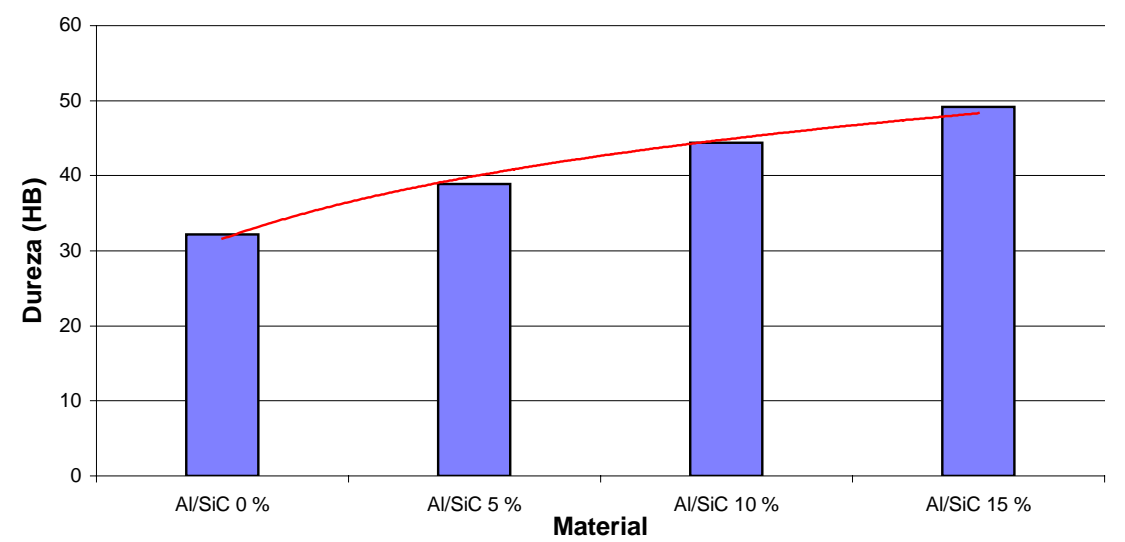

Figura 2.4 - Valores de dureza Brinell dos materiais compósitos com diferentes frações volumétricas de SiC.

\section{- Resistência mecânica}

Pelo gráfico (figura 3.4), é possível verificar que o limite de resistência aumenta à medida em que aumenta também a quantidade de SiC, entretanto, pela linha de tendência (linha verde) a taxa de crescimento vai gradativamente diminuindo. Esta tendência indica que a adição de partículas de reforço deixa de ser interessante a partir de certo ponto, se o objetivo principal for a melhoria do limite de resistência mecânica do material. O aumento no valor de resistência com o aumento da quantidade de reforço, pode ser explicado pelo aumento no número de barreiras para movimentação de discordâncias.

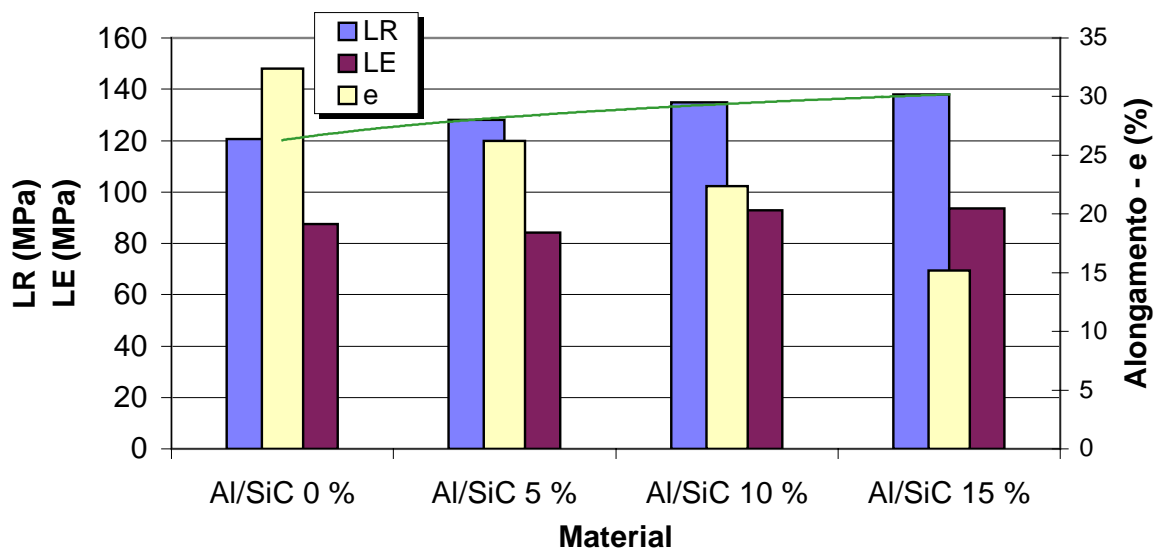

Figura 3.4 - Valores obtidos nos ensaios de tração para o material sem reforço e compósitos com diferentes frações volumétricas de SiC. 
Quanto ao limite de escoamento é verificada uma certa instabilidade nos valores obtidos (vide figura 3.4).

De qualquer forma, não é possível fazer qualquer tipo de correlação entre os materiais, já que dentre todos os parâmetros, o limite de escoamento é aquele que está mais associado ao grau de encruamento imposto durante o processo de produção dos mesmos. Seria necessária uma homogeneização entre os materiais, através de um controle rígido de alguns parâmetros durante o processo de produção, dentre eles principalmente a temperatura. Então, uma tentativa de associação teria maior confiabilidade.

\subsection{3 - Caracterização microestrutural}

\subsubsection{1- Fractografia}

As regiões fraturadas nos ensaios de tração foram observadas e avaliadas em microscópio eletrônico de varredura. Pelas imagens é possível verificar que em relação ao material sem reforço que apresentou fratura dúctil (figura 4.4 (d)), predomina nos materiais com $5 \%, 10 \%$ e $15 \%$ de reforço, fratura com características de maior fragilidade (figuras $4.4(\mathrm{a}-\mathrm{c})$ ).

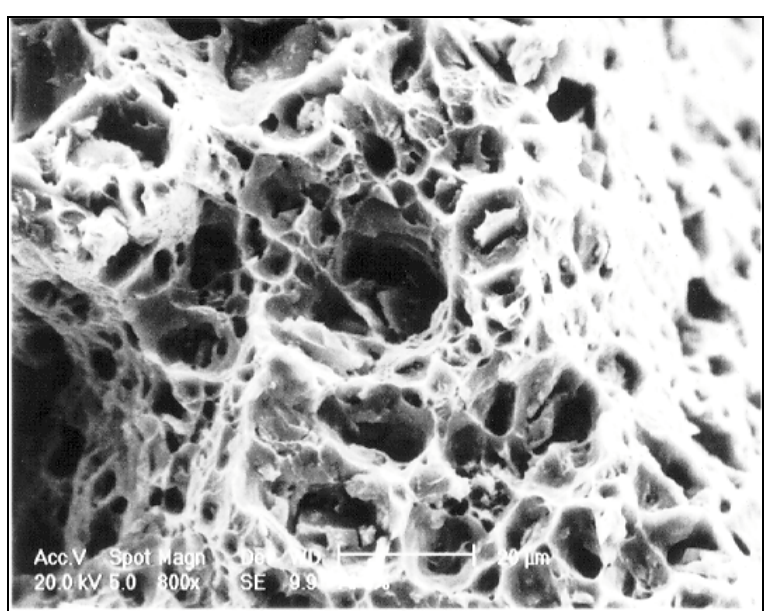

(a)

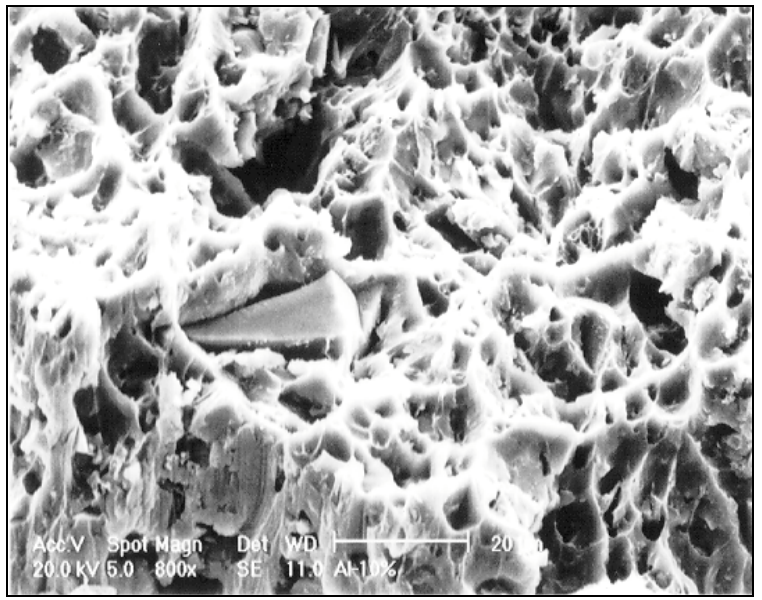

(b) 


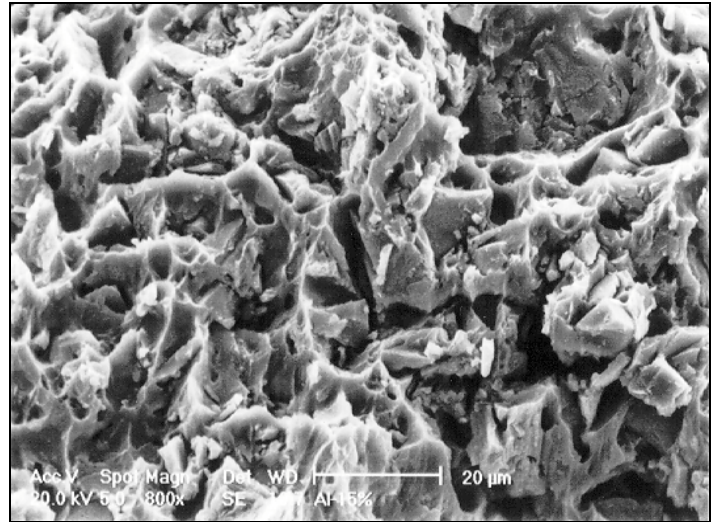

(c)

Figura 4.4 -Micrografia eletrônica de varredura mostrando o aspecto das regiões fraturadas nos ensaios de tração para o material sem reforço e para o material compósito com diferentes frações volumétricas de SiC. (a) Al/SiC $5 \%$, (b) Al/SiC $10 \%$, (c) Al/SiC 15\%, (d) Al/SiC $0 \%$.

\subsubsection{2 - Metalografia}

Pelas figuras 5.4 (c-h) é possível verificar para os materiais com $5 \%, 10 \%$ e 15 \% de reforço, a existência de aglomerados de material de reforço no material da matriz. É fácil imaginar o porque dessa tendência, já que existe uma diferença significativa entre os tamanhos das partículas de pó de alumínio e SiC utilizados na produção do material. As partículas de SiC têm em média tamanho 4 vezes menor e, por isso tendem a se concentrar nos interstícios do pó de alumínio. Mais uma vez é verificada a influência da relação entre tamanho de partículas na formação de aglomerados, neste caso conforme foi visto anteriormente (item 4.1.1) essa relação é igual a 0,27. O ideal é que este valor esteja muito próximo de 1.

Ainda, para os materiais compósitos não é tão evidente pelas figuras a diferença entre eles na quantidade de material de reforço presente no material da matriz, também a quantidade de reforço em cada material aparenta ser maior do que a que realmente deveria haver. A explicação para estas observações pode estar associada a impregnação de partículas de SiC no material da matriz dos compósitos, oriundas das lixas utilizadas na etapa de lixamento das amostras destes materiais (conforme visto no ítem 3.1.3 - pg. 27). Este impasse culminou com a dissolução química de amostras dos compósitos, objetivando a extração do reforço para a determinação da quantidade real de partículas de reforço presente em cada um. 
Para o material sem reforço (figuras $5.4(a-b)$ ), o que se verifica é a presença de vazios e inclusões homogeneamente distribuídos, proveniente provavelmente da etapa de mistura durante o processamento do material.

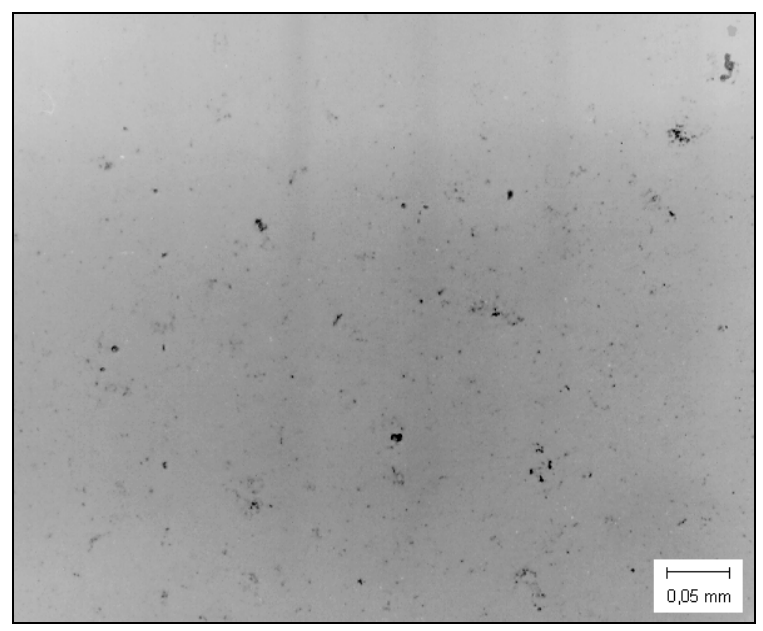

(a)

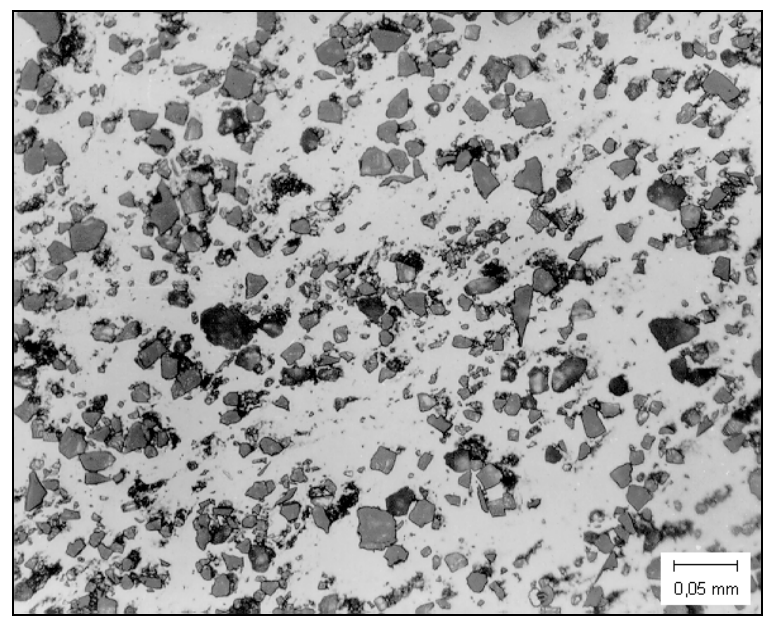

(c)

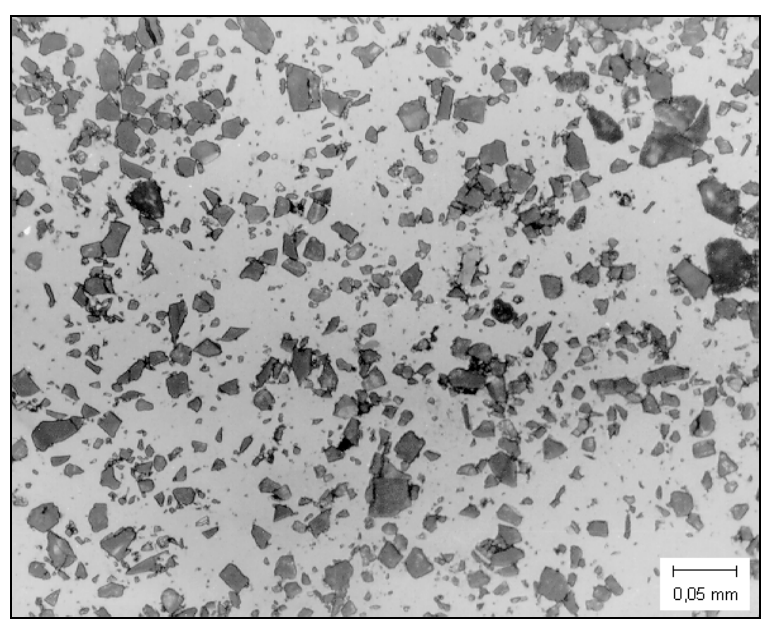

(e)

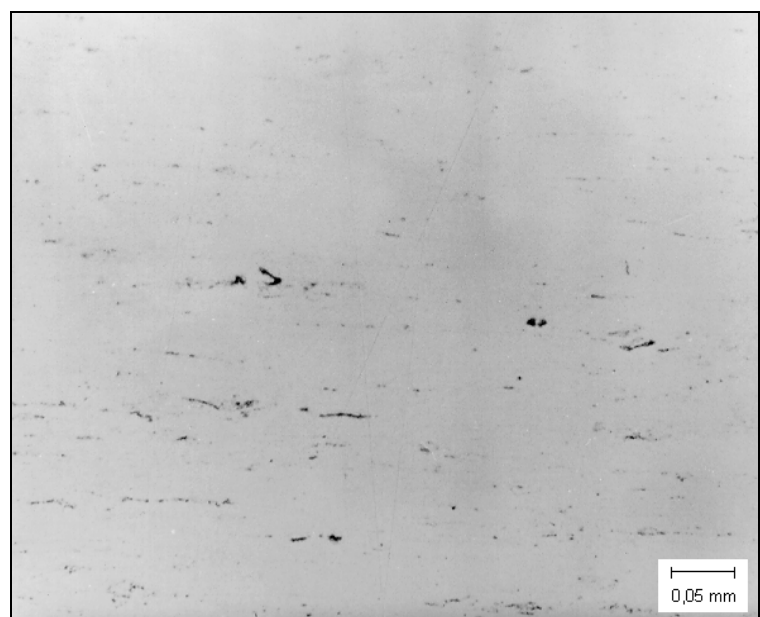

(b)

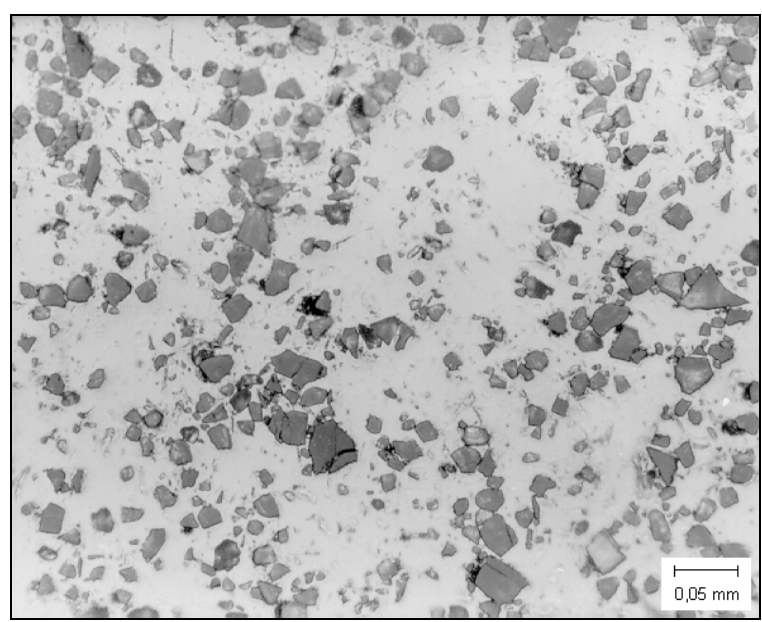

(d)

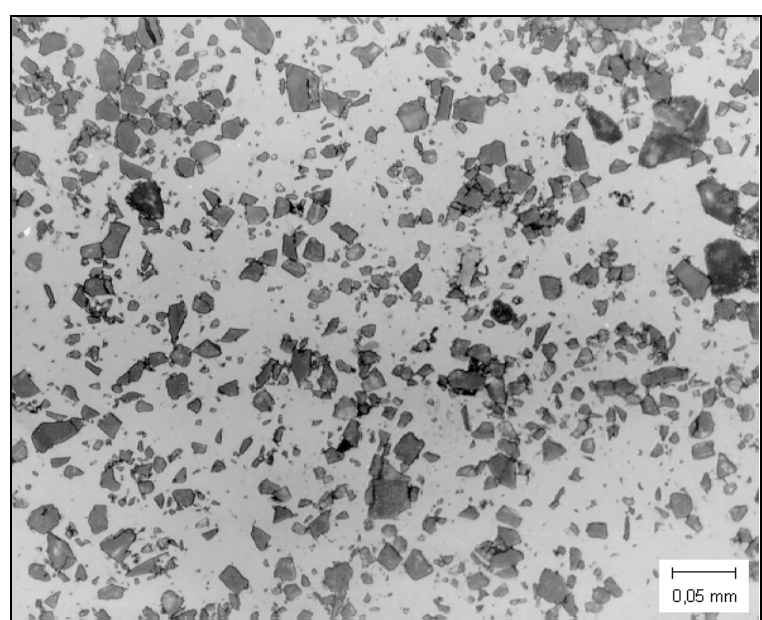

(f) 


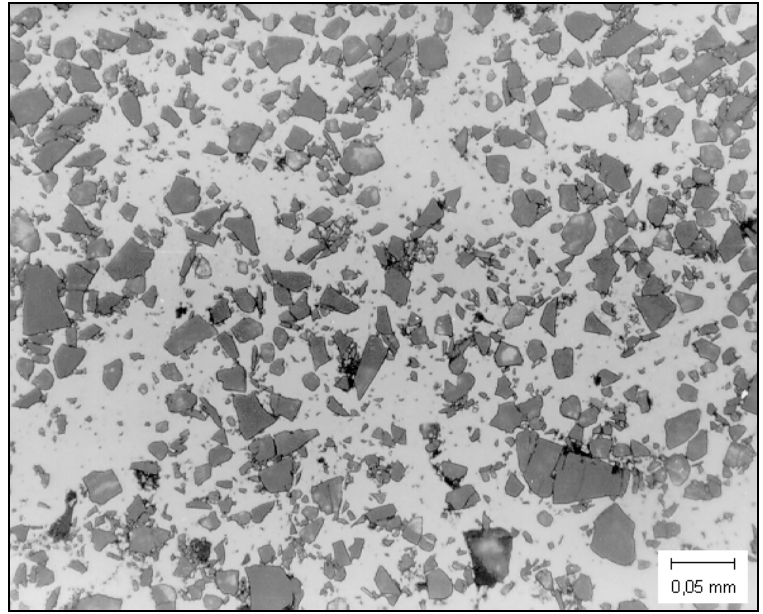

(g)

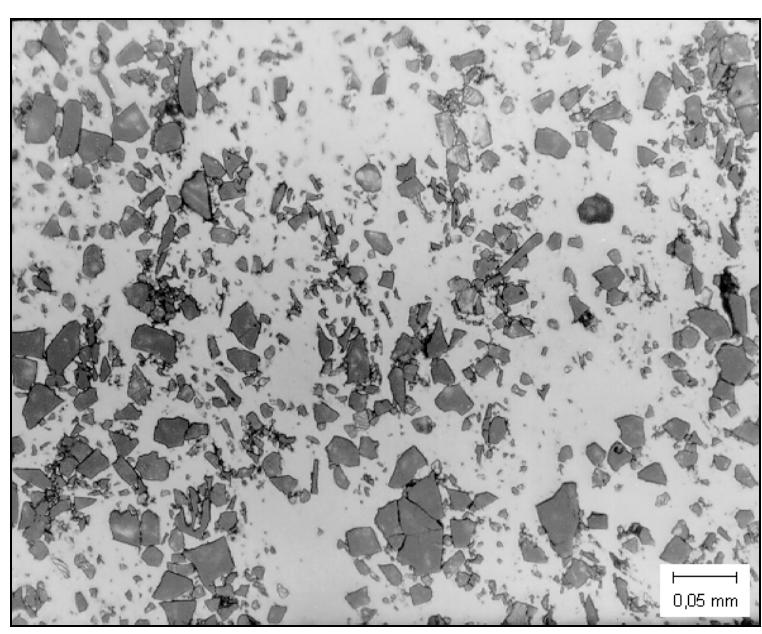

(h)

Figura 5.4 - Micrografias ópticas mostrando o aspecto microestrutural do material sem reforço e do material com diferentes frações volumétricas de SiC (sem ataque). (a) Al/SiC $0 \%$ - secção transversal; (b) Al/SiC 0 \% - secção longitudinal; (c) Al/SiC 5 \% - secção transversal; (d) Al/SiC 5 $\%$ - secção longitudinal; (e) Al/SiC $10 \%$ - secção transversal; (f) Al/SiC $10 \%$ - secção longitudinal; (g) Al/SiC 15 \% - secção transversal; (h) Al/SiC 15 \% - secção longitudinal.

\subsubsection{3 - Extração de reforço.}

Os valores encontrados com a dissolução de amostras, mostraram que os materiais obtidos estavam com as quantidades corretas de reforço. Embora o processo de dissolução tenha sido feito em apenas uma amostra de cada material, os valores encontrados sugerem que a distribuição do reforço é homogênea; já que as amostras foram retiradas em regiões aleatórias da barra em cada um dos materiais (tabela. 2.4).

Tabela 2.4 - Valores de fração em volume encontrados em cada material após a dissolução de amostras.

\begin{tabular}{|l|c|}
\cline { 2 - 2 } \multicolumn{1}{c|}{} & $\begin{array}{c}\text { \% em volume de SiC encontrado no material } \\
\text { após procedimento de extração }\end{array}$ \\
\hline Al/SiC 5\% $\%$ & $5,05 \%$ \\
\hline Al/SiC 10\% & $9,91 \%$ \\
\hline Al/SiC 15\% & $14,77 \%$ \\
\hline
\end{tabular}

4.2 - Ensaios de usinagem e usinabilidade

\subsection{1 - Desgaste da ferramenta}

Os aspectos aqui avaliados, levam em conta a análise da extensão do desgaste bem como os mecanismos e os tipos de desgaste que puderam ser detectados nos experimentos. 
Para que se possa identificar melhor os locais de desgaste, bem como visualizar a extensão do desgaste gerado em cada um dos materiais de ferramenta utilizados nos experimentos, segue um esquema indicativo dos locais de desgaste (figura 6.4) e também ilustrações das condições de cada material de ferramenta antes de serem utilizadas (figuras $7.4(a-f)$ ).
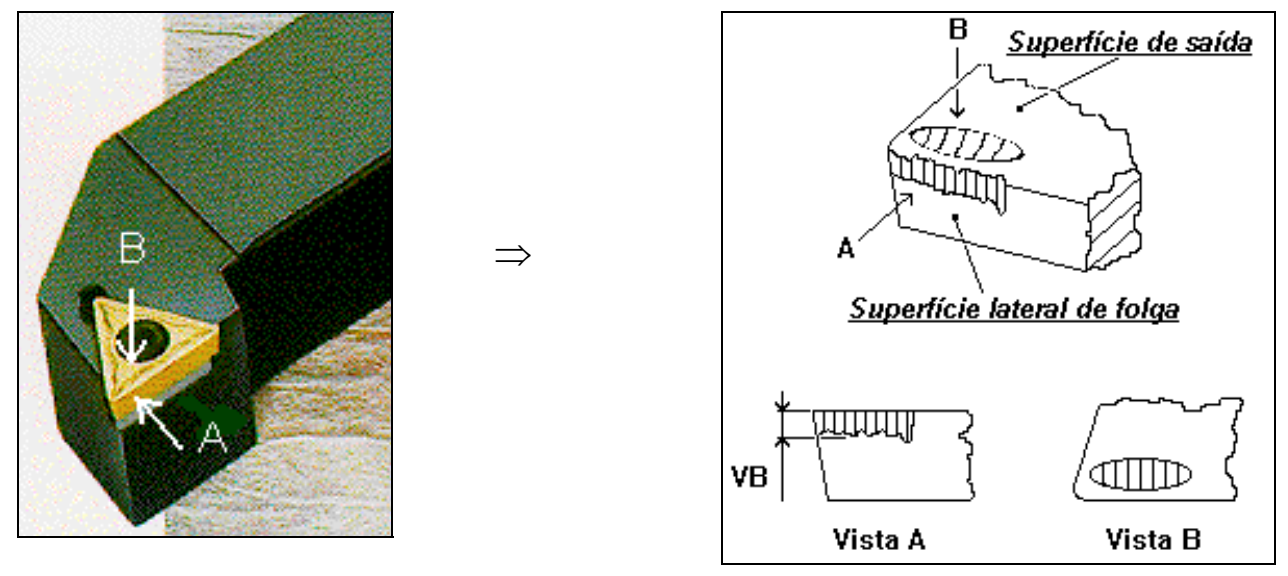

Fig. 6.4 - Esquema indicativo dos locais de desgaste

A - Desgaste de flanco (superfície lateral de folga)

$B$ - Desgaste de cratera (superfície de saída)
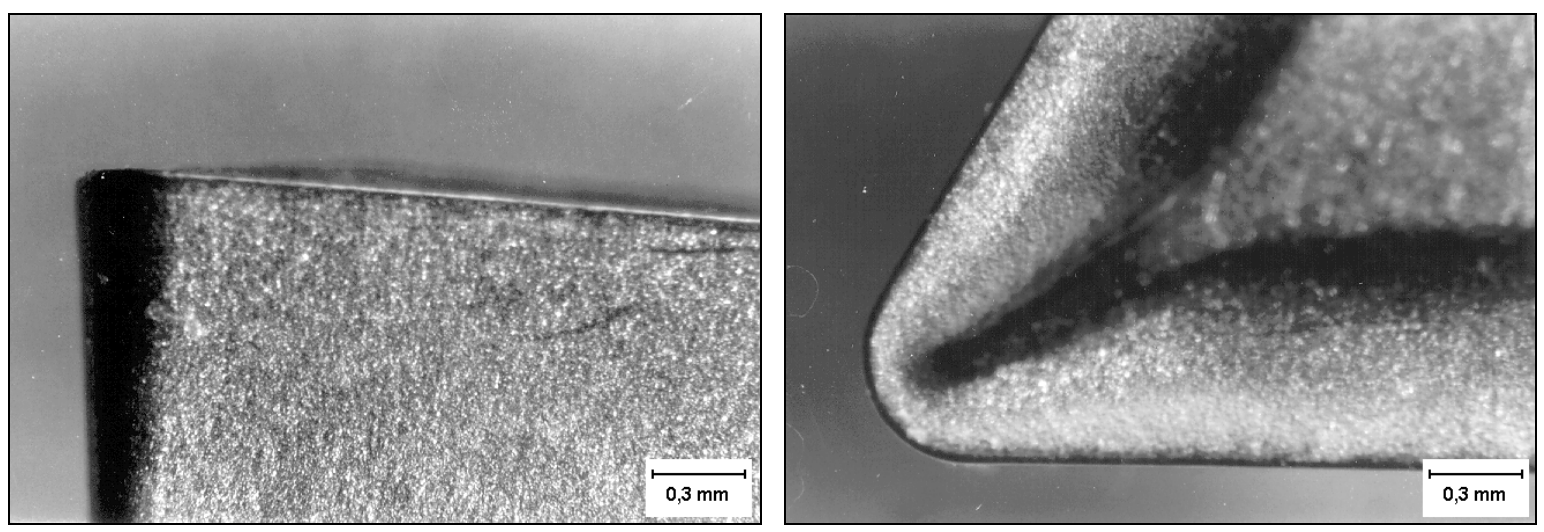

(a)

(b)
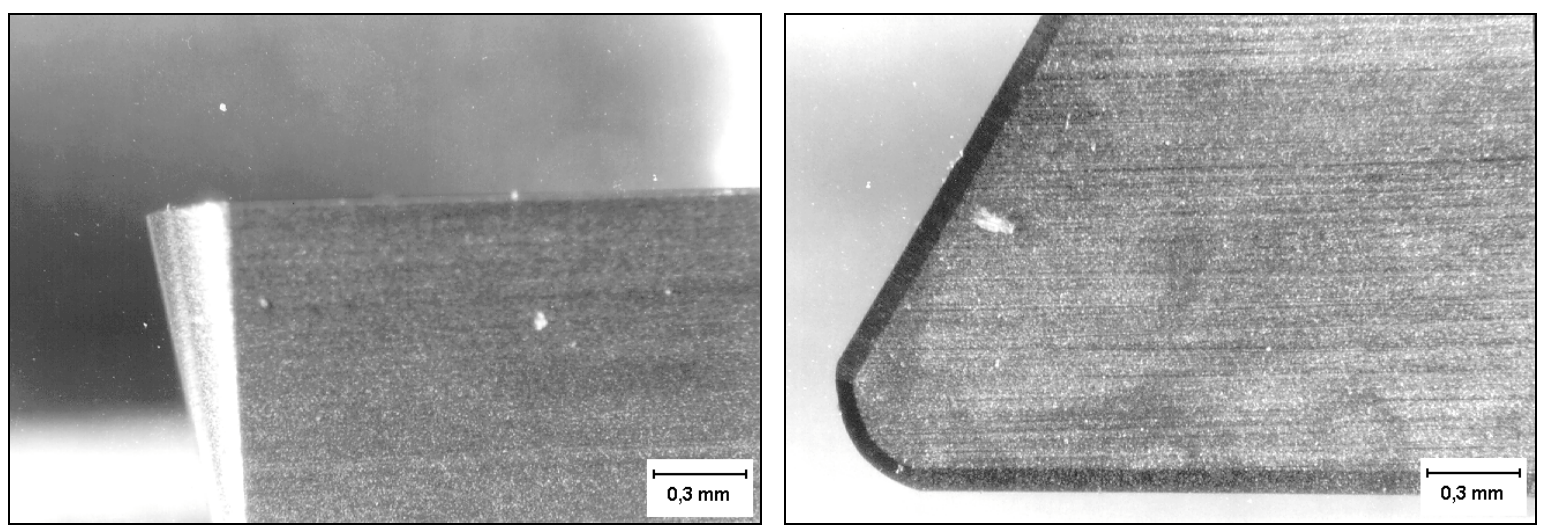

(c)

(d) 


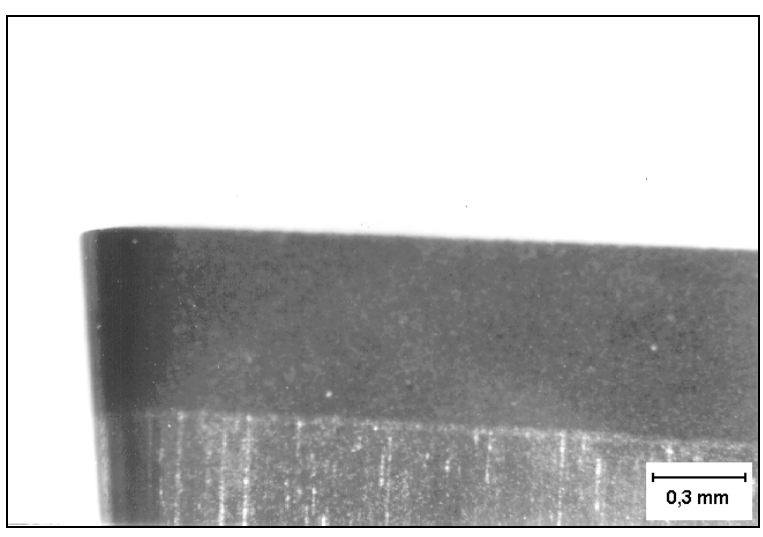

(e)

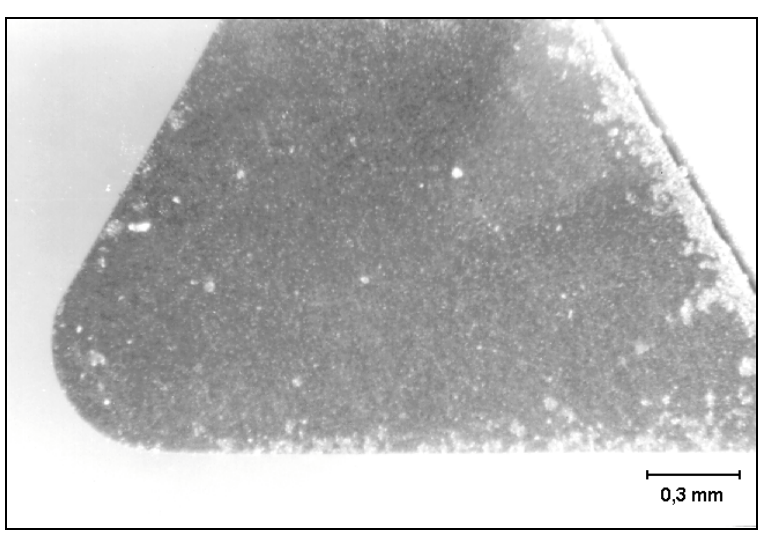

(f)

Figura 7.4 - Macrografias ópticas (microscópio estéreo) mostrando o aspecto das ferramentas de usinagem antes de serem utilizadas (novas). (a) ferramenta de carboneto (superfície lateral de folga); (b) ferramenta de carboneto (superfície de saída); (c) ferramenta de cerâmica (superfície lateral de folga); (d) ferramenta de cerâmica (superfície de saída); (e) ferramenta de diamante (superfície lateral de folga); (f) ferramenta de diamante (superfície de saída).

Pela análise da evolução do desgaste em cada um dos materiais de ferramenta utilizadas nos experimentos, foi possível notar que a ferramenta de carboneto foi a mais agredida em termos de desgaste, seguida pela ferramenta de cerâmica e por fim a de diamante cujos valores de desgaste encontrados durante os experimentos, podem ser considerados desprezíveis .

A figura 8.4 representa de modo geral, o comportamento ao desgaste de cada material de ferramenta, em todos os materiais usinados e para todas as velocidades de corte utilizadas durante os experimentos. Sempre com a ferramenta de carboneto sendo a mais agredida, seguida pela de cerâmica e por último a de diamante

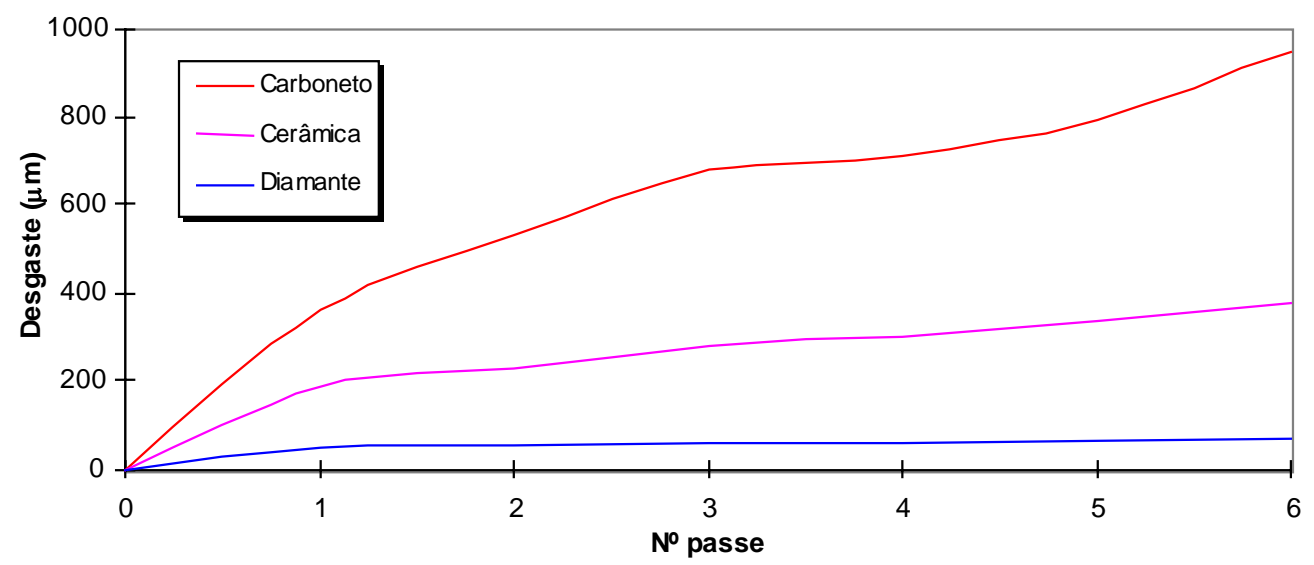

Figura 8.4 - Gráfico da evolução do desgaste de flanco (VB) para cada material de ferramenta (material usinado: Al/SiC $5 \%$ - Vc $273 \mathrm{~m} / \mathrm{min}$ ). 
Embora o desgaste da ferramenta ocorra mais rapidamente na usinagem de compósitos reforçados com partículas de SiC, é possível verificar que as curvas de desgaste (figura 8.4) têm um comportamento similar às curvas originadas com a usinagem de materiais convencionais. No ínicio ocorre um desgaste mais acentuado seguido por uma certa estabilidade, e por último novamente um acréscimo acentuado levando ao fim de vida da ferramenta.

O desempenho superior apresentado pela ferramenta de diamante em todos os materiais usinados e para todas as velocidades de corte utilizadas, demonstra que este é o único material de ferramenta capaz de suportar, a contento, a ação abrasiva provocada pelas partículas de reforço durante a usinagem. Em alguns casos (Al/SiC $15 \%$ ), chegou a ter rendimento 22 vezes superior se comparado à ferramenta de carboneto, ou seja, uma extensão total de desgaste de flanco 22 vezes menor. Vários pesquisadores [25-30], chegaram a conclusões semelhantes quando da usinagem de diversos tipos de compósitos de matriz metálica, e, são unânimes em apontar o diamante como o material mais indicado para a usinagem de materiais deste tipo.

O mecanismo de desgaste predominante na ferramenta de carboneto, na verdade é uma associação de dois fenômenos: abrasão provocada pela presença de partículas de carboneto de silício extremamente duras e abrasivas no material da peça, e adesão oriunda da formação de aresta postiça de corte durante os ensaios. Bergman e Jacobson [31], na usinagem de CMM também verificaram uma forte adesão entre o material da peça e a superfície de saída da ferramenta de carboneto, culminando com o arrancamento de partículas (grãos) dessa região da ferramenta.

Os tipos de desgaste ocorridos foram basicamente de flanco (medido), e de cratera (observado) (Figuras 9.4 (a-c)). É importante verificar que na usinagem do material sem reforço (Al/SiC $0 \%$ ) com ferramenta de carboneto, o desgaste gerado na ferramenta é imperceptível, realçando o efeito da adição de partículas de reforço nas características de usinagem desses materiais (figuras 10.4 (a-c)). 


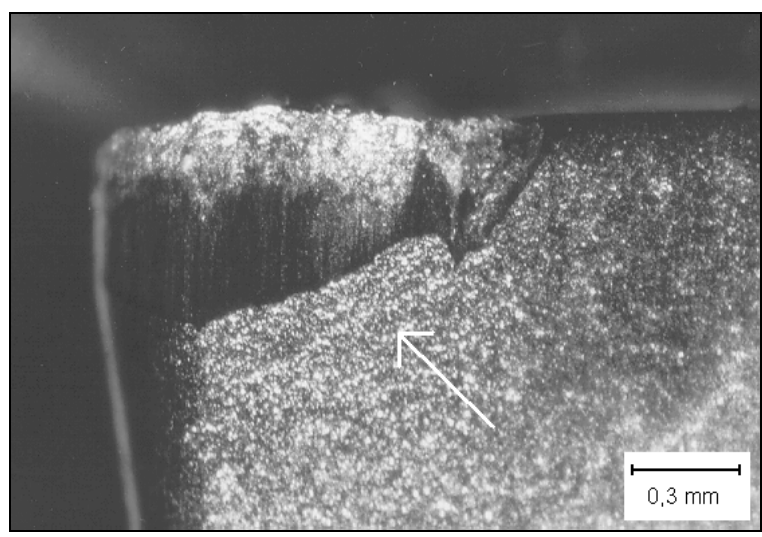

(a)

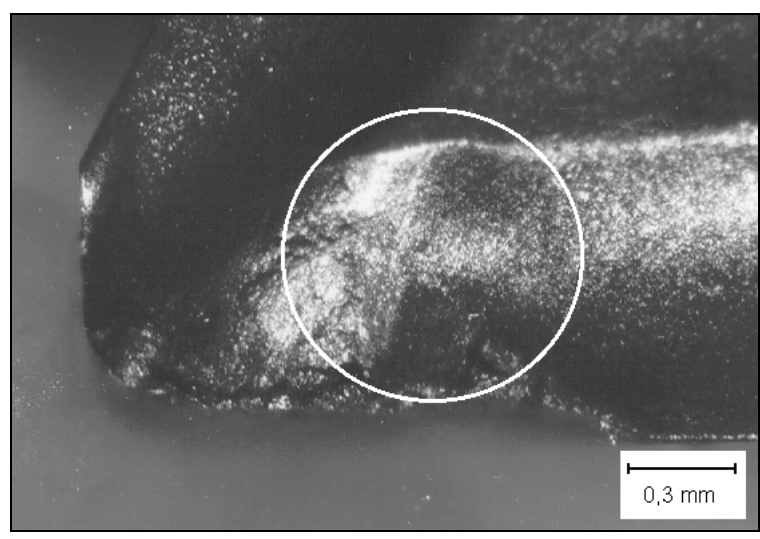

(b)

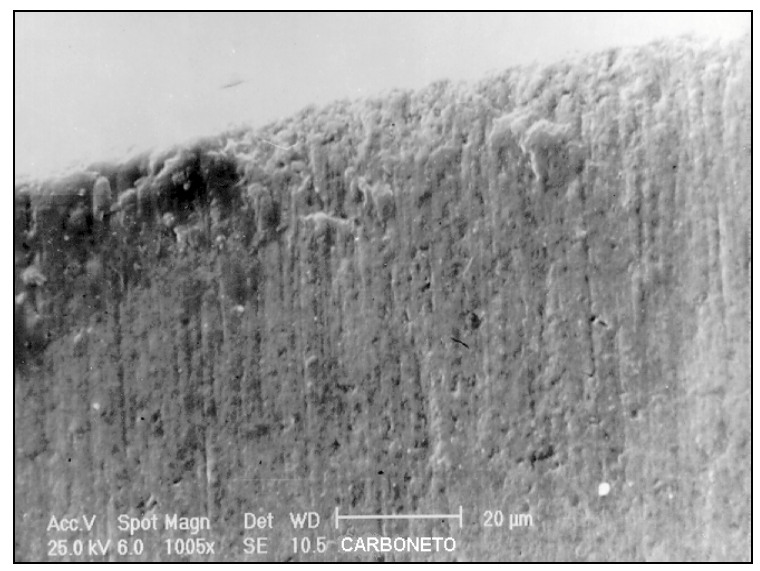

(c)

Figura 9.4 - Macrografias ópticas e micrografia eletrônica de varredura da região sujeita ao desgaste na ferramenta de carboneto. Material usinado Al/SiC $10 \%$ - Vc $273 \mathrm{~m} / \mathrm{min}$. (a) desgaste de flanco (A); (b) desgaste de cratera (B); (c) Ampliação em MEV da região desgastada (figura 9.4 (a)), (superfície lateral de folga).

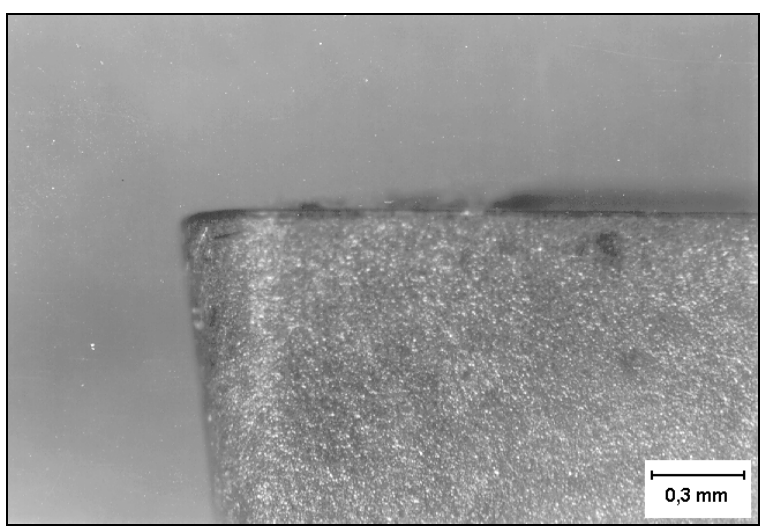

(a)

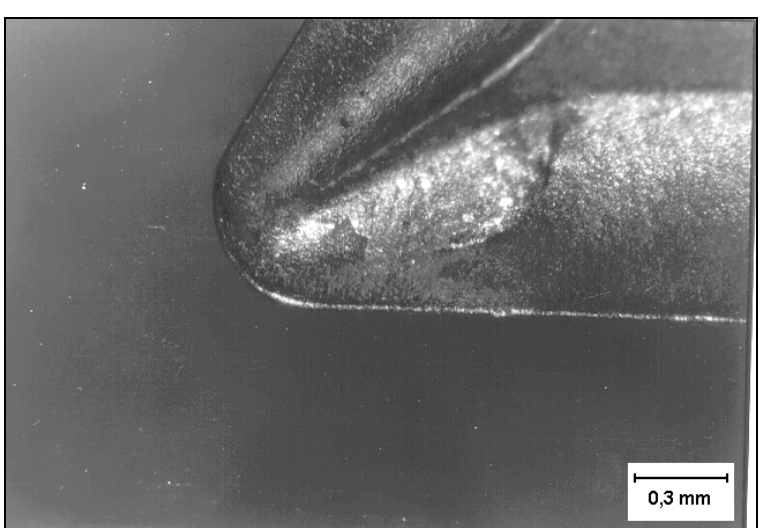

(b) 


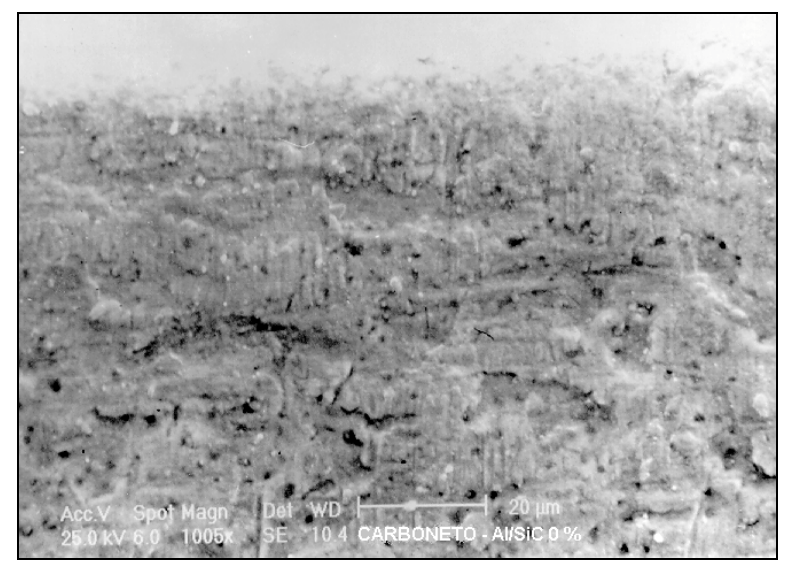

(c)

Figura 10.4 - Macrografias ópticas e micrografia eletrônica de varredura da região sujeita ao desgaste na ferramenta de carboneto. Material usinado Al/SiC $0 \%-V c 273 \mathrm{~m} / \mathrm{min}$. (a) desgaste de flanco (A); (b) superfície de saída (B); (c) Ampliação em MEV da região desgastada (figura 10.4 (a)), (superfície lateral de folga).

Nas ferramentas de cerâmica e diamante o mecanismo de desgaste predominante foi mesmo o de abrasão, já que nestes casos não foi verificada a formação de aresta postiça de corte. Coelho [32], verificou na usinagem de compósitos Al/SiC, que o desgaste gerado nas ferramentas utilizadas durante os ensaios foi típico de abrasão, e acrescenta que na usinagem de compósitos de matriz metálica (CMM) o principal mecanismo de desgaste é o de abrasão. Os tipos de desgaste verificados foram de flanco e de cratera para a ferramenta de cerâmica, e apenas de flanco para a ferramenta de diamante (figuras11.4 (a-c); 12.4 (a-c)).

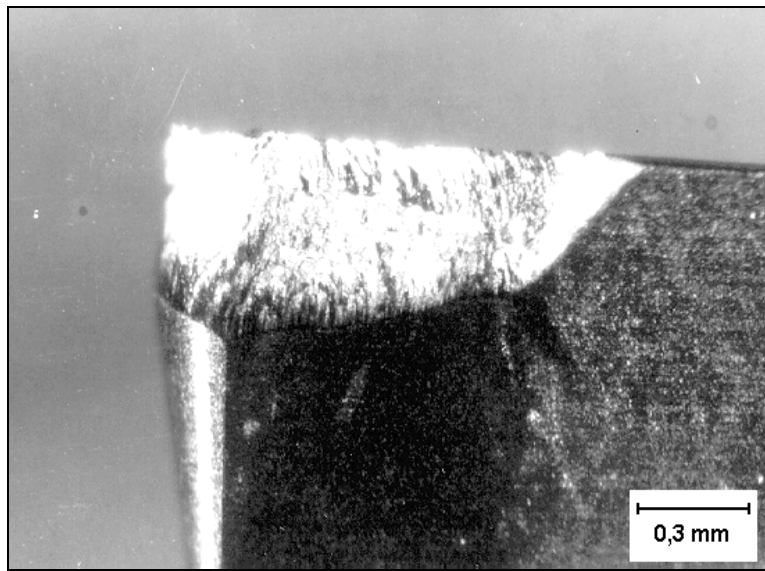

(a)

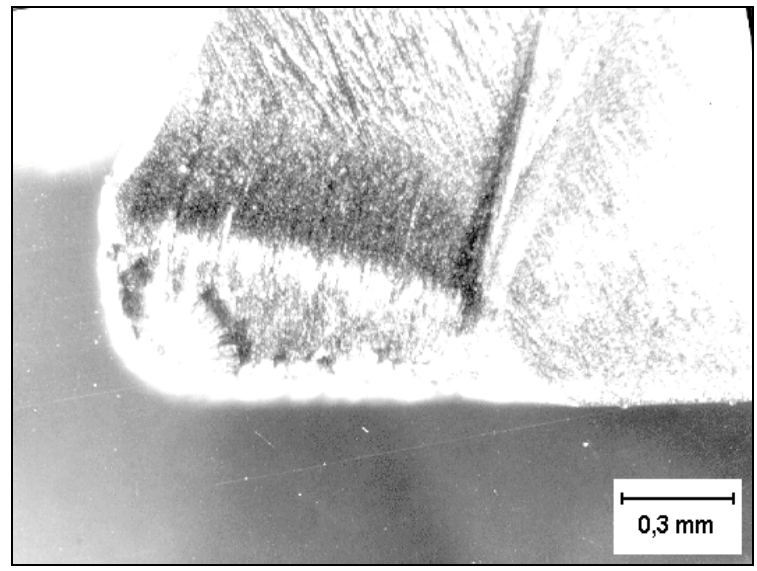

(b) 


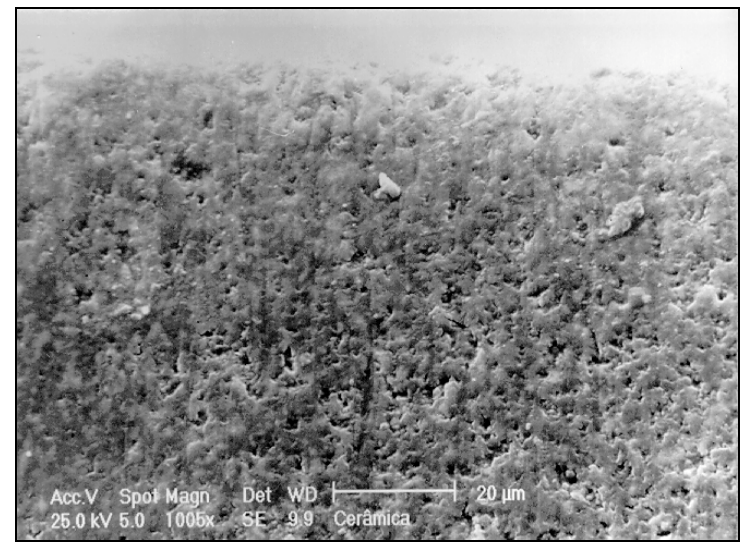

(c)

Figura 11.4 - Macrografias ópticas e micrografia eletrônica de varredura da região sujeita ao desgaste na ferramenta de cerâmica. Material usinado Al/SiC $10 \%-V c 273 \mathrm{~m} / \mathrm{min}$. (a) desgaste de flanco (A); (b) desgaste de cratera (B); (c) Ampliação em MEV da região desgastada (figura 11.4 (a)), (superfície lateral de folga).

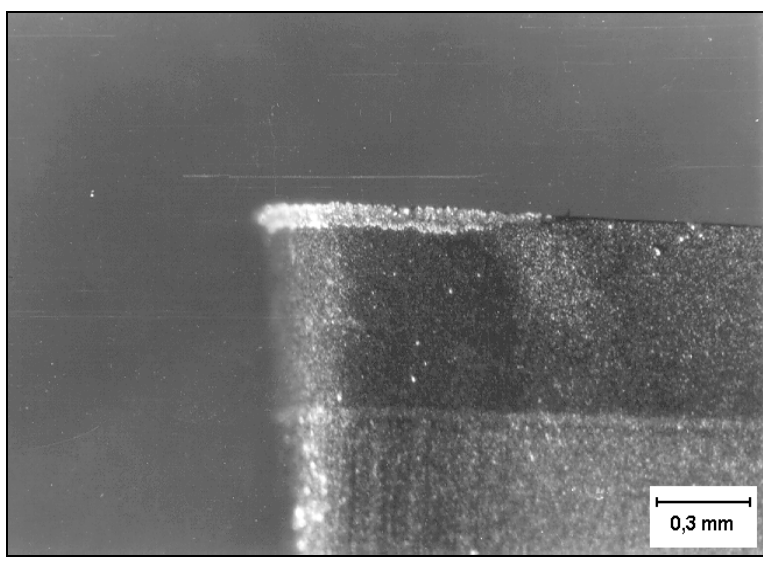

(a)

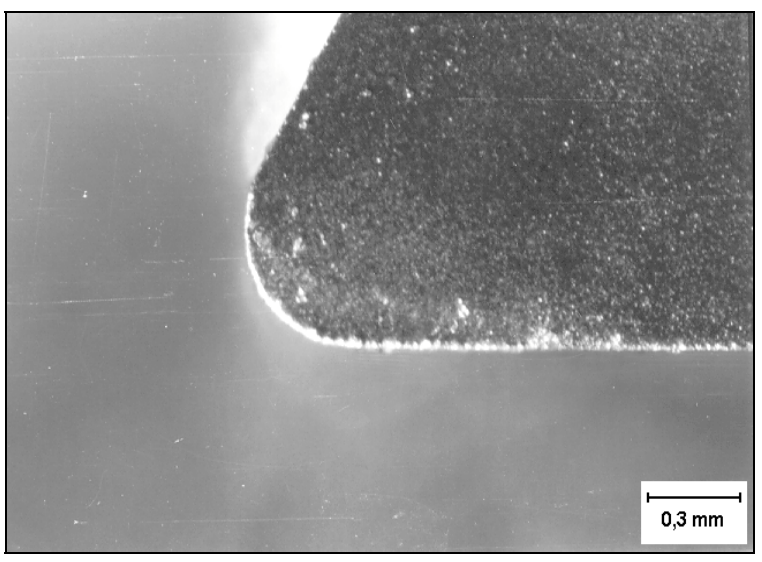

(b)

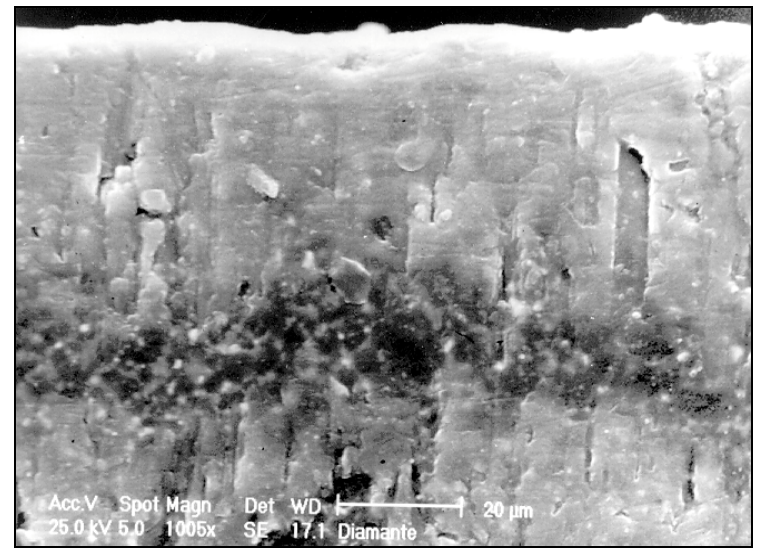

(c)

Figura 12.4 - Macrografias ópticas e micrografia eletrônica de varredura da região sujeita ao desgaste na ferramenta de diamante. Material usinado Al/SiC $10 \%-V c 273 \mathrm{~m} / \mathrm{min}$. (a) desgaste de flanco (A); (b) superfície de saída (B); (c) Ampliação em MEV da região desgastada (figura 12.4 (a)), (superfície lateral de folga). 
Embora não tenha sido feita uma avaliação quantitativa com relação ao acabamento imposto pela ferramenta na superfície do corpo de prova em cada caso, qualitativamente algumas observações podem ser consideradas. Para um mesmo material de ferramenta, o aspecto visual do acabamento superficial do corpo de prova piorou com o aumento da quantidade de material de reforço. Ainda, com a mudança no material de ferramenta o acabamento superficial do corpo de prova melhorou obedecendo à seguinte ordem com relação ao material de ferramenta utilizado: carboneto, cerâmica e diamante policristalino.

As superfícies finais dos corpos de prova obtidos a partir dos materiais compósitos com $5 \%, 10 \%$ e $15 \%$ de SiC, foram muito mais limpas e lisas na usinagem com ferramenta de diamante se comparadas àquelas obtidas na usinagem com ferramentas de carboneto e cerâmica. Esse comportamento sugere que o acabamento superficial tem forte relação com a resistência ao desgaste do material da ferramenta.

\subsection{2 - Forças de corte}

As forças de corte resultantes do processo de usinagem, podem fornecer informações bastante úteis quanto às características de usinagem do material e sua relação com as características mecânicas do mesmo.

Pelos resultados encontrados nos experimentos, é possível verificar que a força de corte aumenta para todos os materiais de ferramenta à medida em que a quantidade de reforço presente na matriz também aumenta (figura 13.4). Esse comportamento mostra que para estes materiais, tal qual ocorre com materiais convencionais, existe também uma certa relação (embora não direta) das forças resultantes do corte com certas características mecânicas desses materiais (figura. 14.4). 


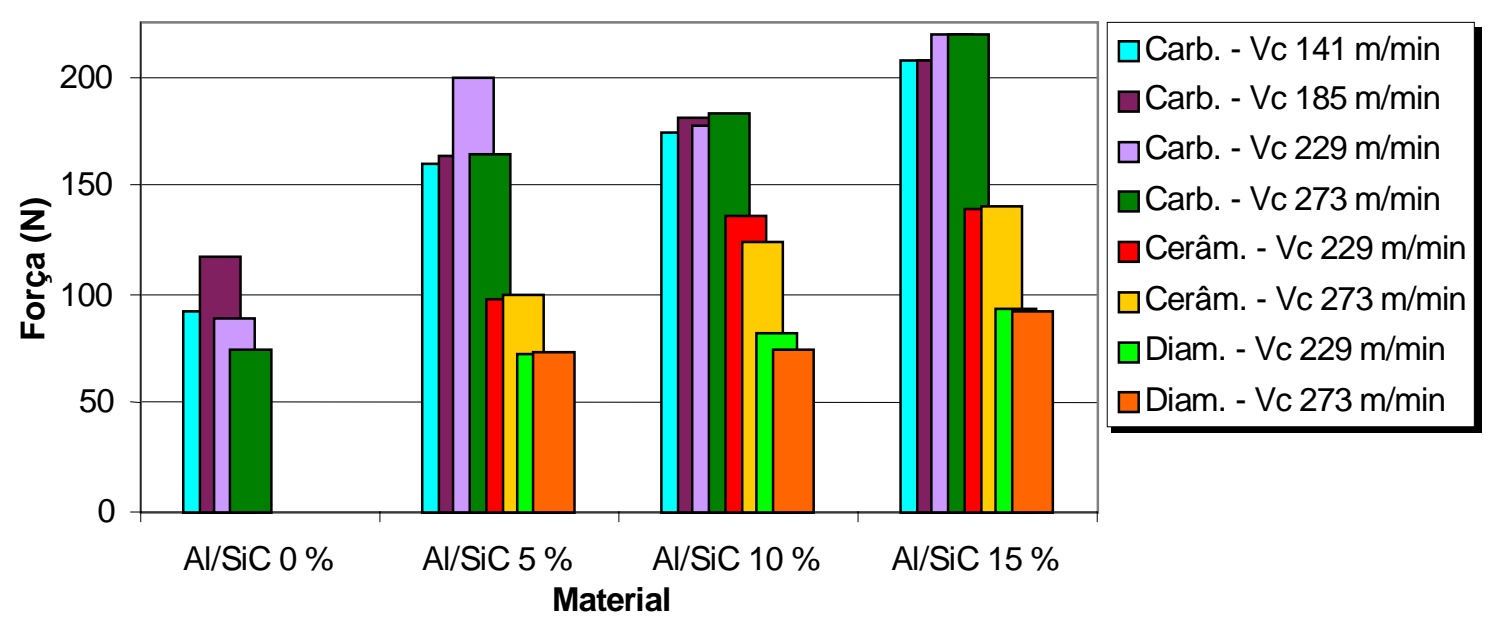

Figura 13.4- Evolução das forças de corte durante usinagem com diversos materiais de ferramenta para o material sem reforço e para os materiais compósitos com diferentes frações volumétricas de SiC.

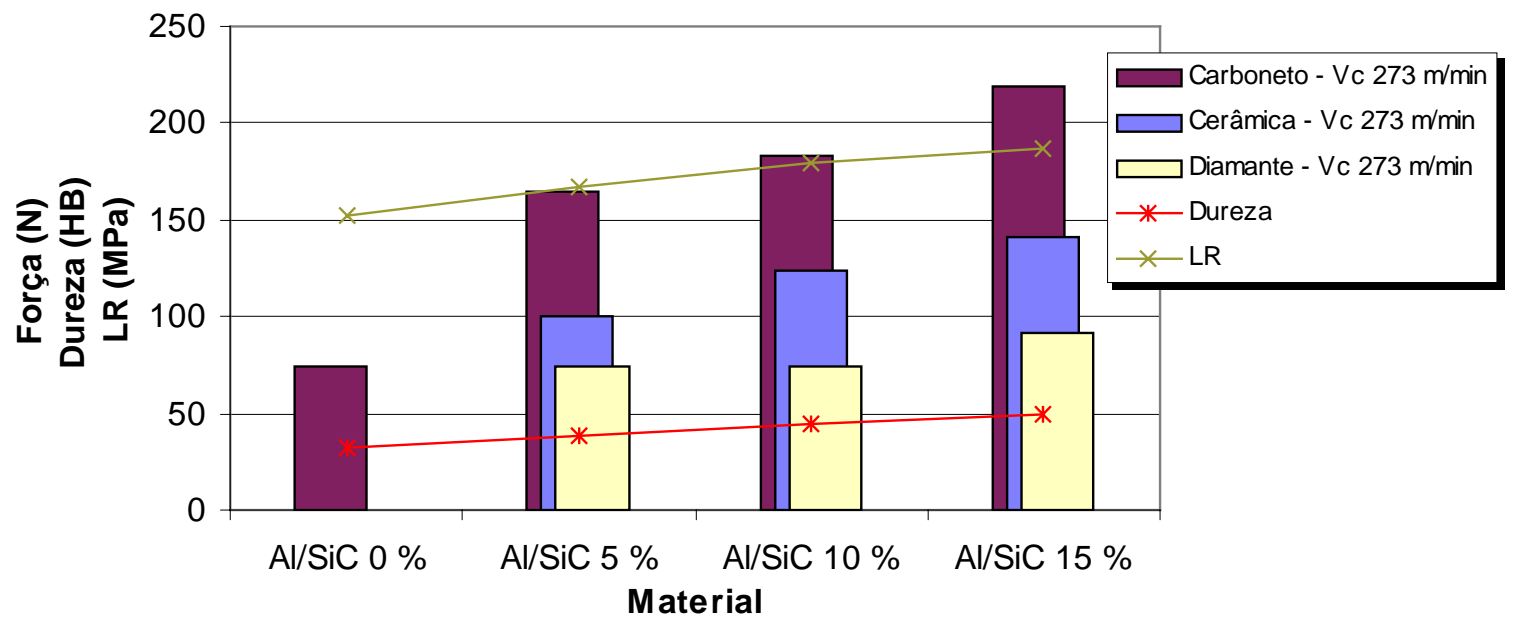

Figura 14.4 - Relação das forças de corte versus características mecânicas para o material sem reforço e para os materiais compósitos com diferentes frações volumétricas de SiC.

As forças de corte são maiores com ferramenta de carboneto, um pouco menores com ferramenta de cerâmica e menores ainda com ferramenta de diamante. Essa tendência na variação do valor das forças de corte entre os materiais de ferramenta pode estar relacionada à diferença no valor de condutividade térmica entre eles. Ferramenta de carboneto tem o valor muito próximo ao da cerâmica, que por sua vez tem o valor bem abaixo do diamante (carboneto $\cong 30 \mathrm{~W} / \mathrm{m} . \mathrm{K}$ - temp. ambiente; cerâmica $20-35 \mathrm{~W} / \mathrm{m} . \mathrm{K}$ temp. ambiente; diamante $\cong 120 \mathrm{~W} / \mathrm{m} . \mathrm{K}$ - temp. ambiente.) [33]; isto implica em temperaturas menores na região de corte, exigindo maior esforço para que a região 
recalcada do material sobre a superfície de saída da ferramenta inicie o processo de deformação plástica, que irá culminar no cisalhamento e conseqüente formação do cavaco. Entretanto, outros fatores também podem colaborar para que exista esta diferença entre os valores de força. A superfície de saída extremamente polida da ferramenta de diamante, sua enorme capacidade de resistência ao desgaste, somados ao maior valor de condutividade térmica entre os materiais de ferramenta e também o baixo valor de coeficiente de atrito (equivalente ao do teflon), podem explicar os menores valores de força encontrados durante os ensaios com este material.

\subsection{3 - Aresta postiça de corte}

Durante os ensaios verificou-se para todos os materiais ensaiados com ferramenta de carboneto, a formação de aresta postiça de corte (vide figura 15.4); tendendo esta a aumentar à medida em que a velocidade de corte diminuía. Este fenômeno do ponto de vista físico pode estar associado, no caso da ferramenta de carboneto, primeiro a um acabamento mais grosseiro da superfície de saída de cavaco da ferramenta, depois a um desgaste acentuado da mesma já no início do corte, o que provoca uma superfície ainda mais irregular portanto muito mais propícia para que ocorra soldagem de material levando à formação de aresta postiça.

Neste caso, o menor valor de condutividade térmica da ferramenta de carboneto também contribui para a ocorrência do fenômeno, já que faz com que a temperatura na região de corte seja menor, e, de acordo com a literatura $[9,10,19]$, a baixas temperaturas a possibilidade de que ocorra a formação de aresta postiça aumenta.

Um indicativo da presença de aresta postiça de corte é o aspecto da superfície do cavaco em contato com a superfície de saída da ferramenta. Nos cavacos obtidos com ferramenta de carboneto, observou-se uma tendência por uma superfície opaca sem brilho ou então alternância entre superfícies opaca e brilhante; sendo que, superfície opaca evidência a presença do fenômeno. Já nos cavacos obtidos com ferramenta de diamante e cerâmica, a tendência foi por superfícies brilhantes. 
A tendência no aumento da aresta postiça com a diminuição da velocidade de corte, pode ser explicada pela queda de temperatura na região de corte, que faz com que ocorra endurecimento do material que escoa por sobre a superfície de saída da ferramenta. Este endurecimento impede a ação das forças de corte, e também dos cavacos em escoamento constante por sobre a superfície de saída, no sentido de arrastar e retirar o material que tende a se depositar aumentando a formação da aresta postiça.

Com ferramenta de diamante o fenômeno não foi observado em nenhuma das duas velocidades de corte utilizadas. Essa tendência, reforça a hipótese de que o acabamento da superfície de saída da ferramenta, bem como o desgaste gerado durante o ensaio, e também a diferença no valor de condutividade térmica entre os materiais de ferramenta exercem grande influência sobre a formação da aresta postiça de corte, já que a superfície de saída na ferramenta de diamante é perfeitamente polida, e o desgaste gerado pode ser considerado desprezível se comparado com aqueles observados com ferramenta de carboneto . Com ferramenta de cerâmica também não foi observada a formação de aresta postiça de corte.

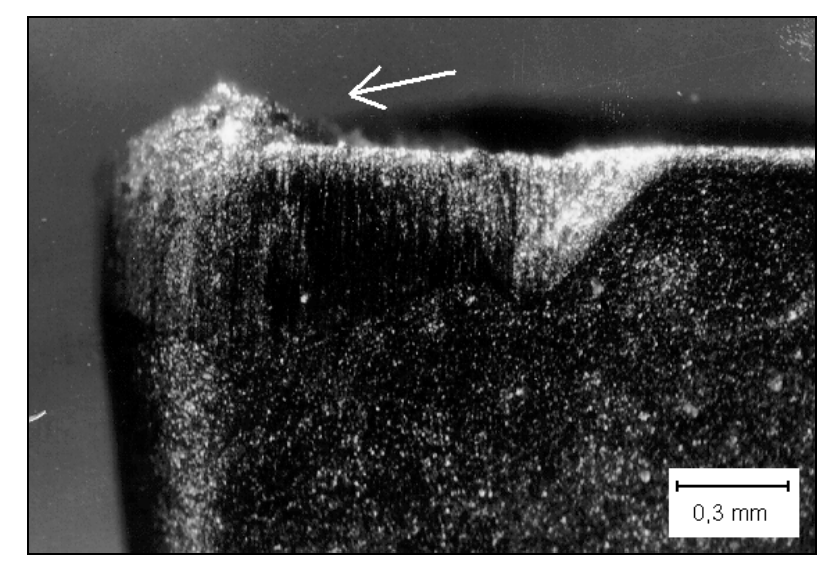

Figura 15.4 - Macrografia óptica mostrando o aspecto de formação de aresta postiça na usinagem com ferramenta de carboneto.

\subsection{4 - Formação de cavacos}

$\mathrm{Na}$ usinagem com ferramenta de carboneto, para os materiais com $5 \%, 10 \%$ e $15 \%$ de reforço, prevaleceu a formação de cavacos segmentados do tipo 6.2 (vide figura 
16.4) conforme ISO 3685 [20] (anexo 3). No material com $5 \%$ houve formação, em quantidades também significativas, de cavacos do tipo 4.2, mostrando que para estes materiais nas condições pré-estabelecidas de avanço e profundidade de corte o quebra cavacos sinterizado na própria ferramenta demonstrou ser eficiente, embora a presença de aresta postiça de corte conforme visto no item 4.2.3 também pode ter sua parcela de contribuição.

Verificou-se ainda que para o tipo de cavaco em evidência nos materiais com $5 \%$, $10 \%$ e $15 \%$ (no caso tipo 6.2), o tamanho do mesmo diminuiu à medida em que ocorria o aumento da quantidade de reforço no material. Isso mostra a influência que as partículas de reforço exercem sobre o mecanismo de formação de cavaco em materiais deste tipo, tornando-os mais quebradiços.

$\mathrm{Na}$ usinagem do material sem reforço, o que prevaleceu foi a formação de cavaco do tipo 4.1 (vide figura 17.4) com algumas formações do tipo 1.3 e 2.3. Como neste caso o material é bastante dúctil, a ação do quebra cavacos não foi tão eficiente, limitando-se a no máximo mudar a direção de formação do mesmo, o que inclusive veio a causar alguns transtornos durante os experimentos, já que o cavaco se projetou enroscando-se nas fiações que faziam as conexões do sistema de medição de força, culminando com o seu rompimento.

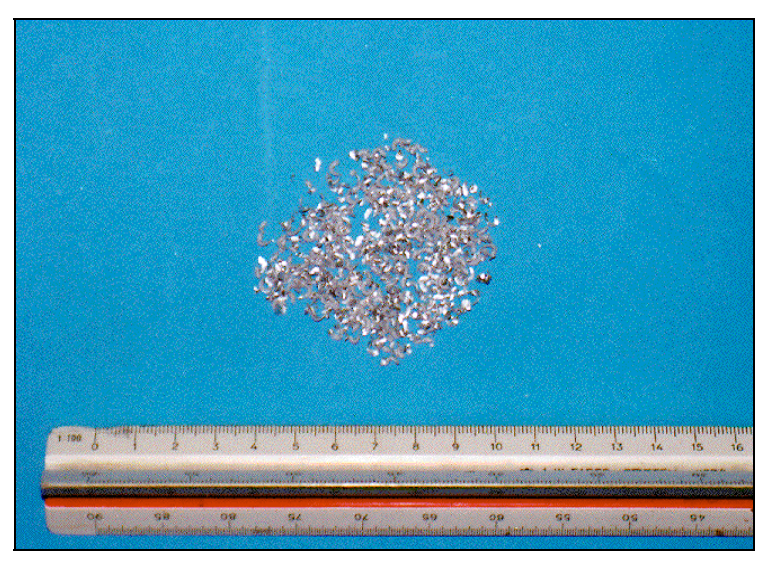

Figura 16.4 -Macrografia mostrando o tipo de cavaco predominante na usinagem dos materiais com $5 \%$, $10 \%$ e $15 \%$ de reforço com ferramenta de carboneto.

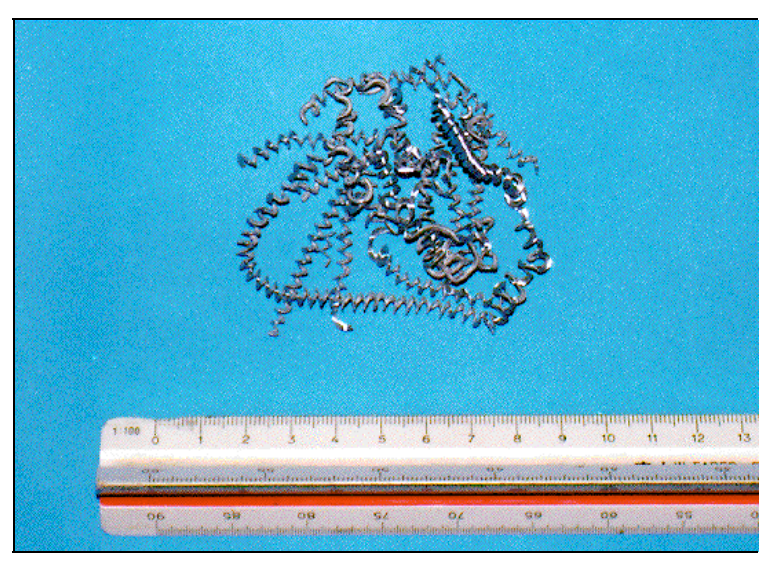

Figura 17.4 -Macrografia mostrando o tipo de cavaco predominante na usinagem do material sem reforço com ferramenta de carboneto. 
Na usinagem com ferramenta de cerâmica foram dois os tipos de cavacos que puderam ser observados 4.1 e 1.1 (vide figuras 18.4 (a-b)), sendo que a mudança de um para o outro no caso do tipo 4.1 para o tipo 1.1, ocorreu na medida em que houve o aumento da quantidade de material de reforço no material.

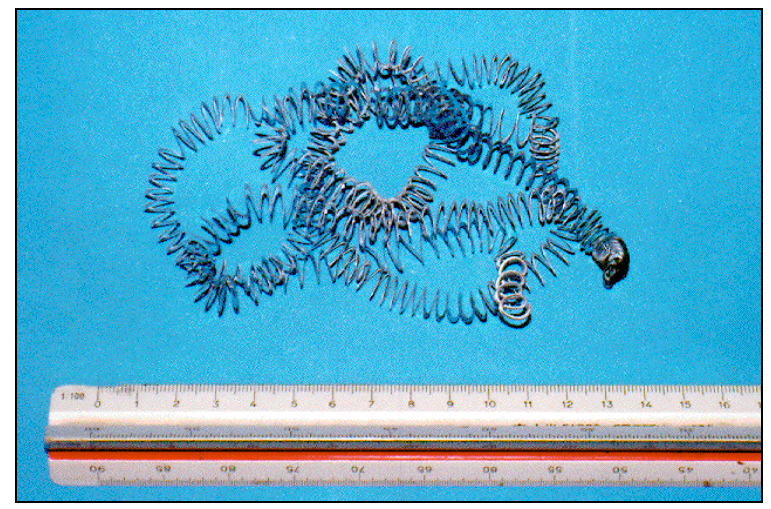

(a)

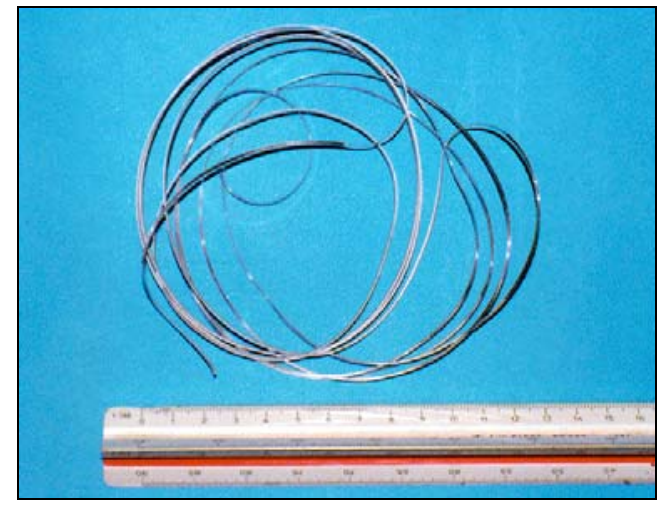

(b)

Figura 18.4 - Macrografia mostrando o tipo de cavaco predominante na usinagem dos materiais com 5 \%, $10 \%$ e $15 \%$ de reforço com ferramenta de cerâmica. (a) Al/SiC 5 \%; (b) Al/SiC 15 \%.

Com ferramenta de diamante também pode ser observada a formação de dois tipos de cavaco 1.3 e 4.1 (vide figuras 19.4 (a-b)), sendo que, a exemplo do que ocorreu com ferramenta de cerâmica a mudança de um para o outro no caso do tipo 1.3 para 4.1 também ocorreu à medida em que a quantidade de material de reforço presente no compósito aumentou.

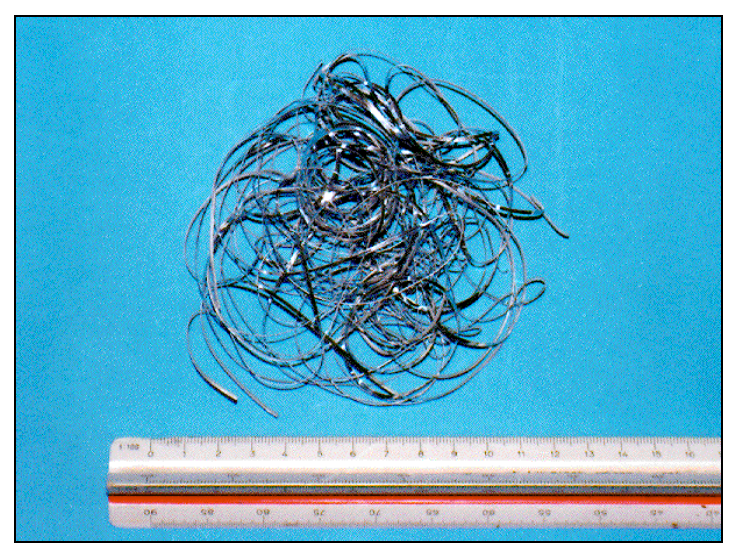

(a)

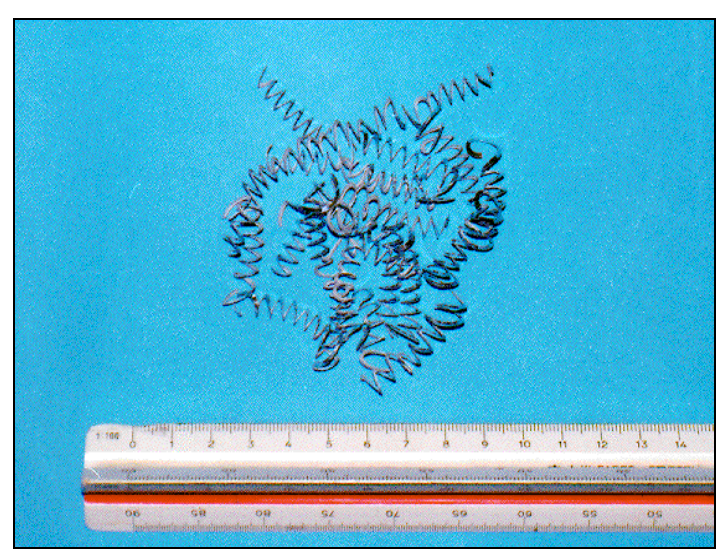

(b)

Figura 19.4 - Macrografia mostrando o tipo de cavaco predominante na usinagem dos materiais com 5 \%, $10 \%$ e $15 \%$ de reforço com ferramenta de diamante. (a) Al/SiC $5 \%$; (b) Al/SiC $15 \%$. 
Com relação à mudança do tipo de cavaco com o aumento da fração volumétrica de SiC para as ferramentas de cerâmica e diamante; curiosamente houve praticamente uma inversão nos tipos de cavacos formados, sendo que não há evidências do que possa ter levado à ocorrência do fenômeno.

A tendência pela formação de cavacos mais alongados com ferramentas de cerâmica e diamante nos materiais com $5 \%, 10$ e $15 \%$ de reforço, já que não foi feita usinagem do material sem reforço com estes materiais de ferramenta, pode ser atribuída à falta de quebra-cavacos nos dois casos.

Curiosamente nesses materiais, a formação de cavacos longos não representa o mesmo perigo que no caso do material sem reforço, porque são mais frágeis segmentando-se com facilidade ao menor sinal de resistência ou impacto. Isso mostra mais uma vez a influência da microestrutura do material sobre o mecanismo de formação do cavaco, com as partículas de reforço agindo como elementos de fragilização do mesmo.

Tomac e Tonnessen [34] quando da usinagem de AISi7Mg com $14 \%$ vol. SiC obtiveram resultados similares e concluem que as partículas de reforço em materiais deste tipo atuam como quebra cavacos. O Metals Handbook [35] no capítulo que trata da usinagem de CMM, destaca a tendência na formação de cavacos segmentados na usinagem de compósitos Al/SiC. Da mesma forma Lin, Bhattacharyya e Lane [36], obtiveram resultados similares atribuindo o fenômeno a duas razões principais: primeiro, à redução em ductilidade do material da matriz pela adição do material de reforço, induzindo à fratura na região de cisalhamento; segundo, à formação de aresta postiça de corte, que opera como quebra cavacos.

Com relação a todos os materiais de ferramenta, não foi verificada alteração significativa no tipo de cavaco com a mudança do valor de velocidade de corte.

Embora tenha sido possível registrar o tipo de cavaco gerado durante os ensaios, é importante salientar que os registros estão baseados naqueles tipos que se apresentaram em maiores quantidades. O que se observou na realidade em todos os 
materiais ensaiados inclusive o material sem reforço, é a tendência na mudança do tipo de cavaco repentinamente durante o processo de usinagem. Este comportamento pode estar associado ao tipo de processo empregado na obtenção dos materiais.

Como foi verificado anteriormente pelos resultados encontrados nos ensaios de densidade hidrostática, o processo de obtenção utilizado permite a formação de vazios. Mais especificamente para os materiais com $5 \%, 10 \%$ e $15 \%$ de reforço, a presença desses vazios e também a distribuição randômica das partículas de reforço, podem resultar na modificação momentânea da cinética de formação do cavaco, tornando ainda mais complexa a análise desse mecanismo na usinagem de materiais deste tipo. Quigley, Monaghan e O'Reilly [37], em ensaios do tipo "quick-stop" em CMM, também concluem que o mecanismo de corte nestes materiais é muito mais complexo do que em outros materiais quebradiços que produzem cavacos curtos.

\subsection{5 - Usinabilidade}

Os ensaios realizados com ferramenta de carboneto, muito embora pela quantidade de material removido ainda não representassem a melhor condição, enquadrando o ensaio no grupo daqueles ditos de curta duração, permitem algumas observações que podem levar ao estabelecimento do chamado índice de usinabilidade de cada material.

Aplicando-se o conceito sugerido por Ferraresi [10], que associa para uma dada velocidade de corte o comprimento usinado em metros pela ferramenta em cada material, até atingir um valor de desgaste de flanco (VB) pré estabelecido (no caso do presente trabalho $0,6 \mathrm{~mm}(600 \mu \mathrm{m}))$, caracterizando o chamado "Método do Comprimento Usinado", verificou-se que, para os materiais ensaiados a relação é mantida bastante próxima ou pelo menos dentro de uma certa faixa, quando o conceito é aplicado em cada uma das quatro velocidades de corte utilizadas no ensaio (vide figuras 20.4 (a-d); tabela 3.4). 


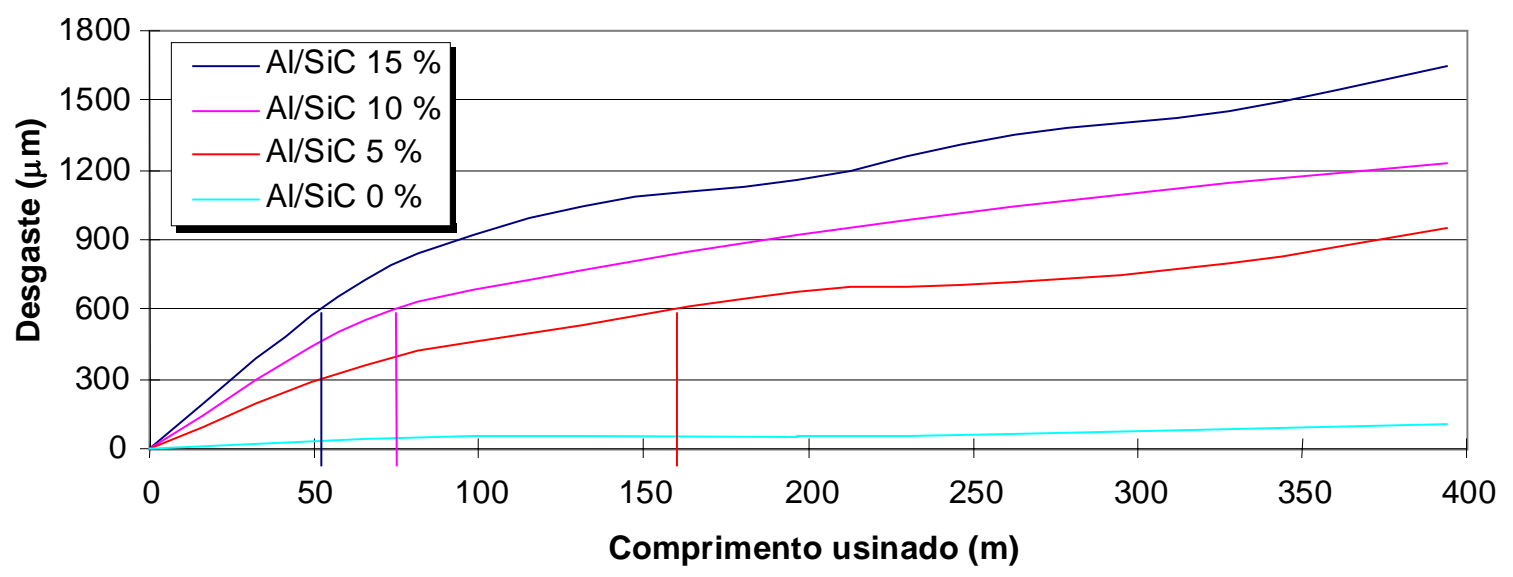

Figura 20.4 (a) - Evolução do desgaste da ferramenta ao longo do comprimento usinado para os materiais com $5 \%, 10 \%$ e $15 \%$ de reforço e para o material sem reforço, utilizando velocidade de corte de $273 \mathrm{~m} / \mathrm{min}$.

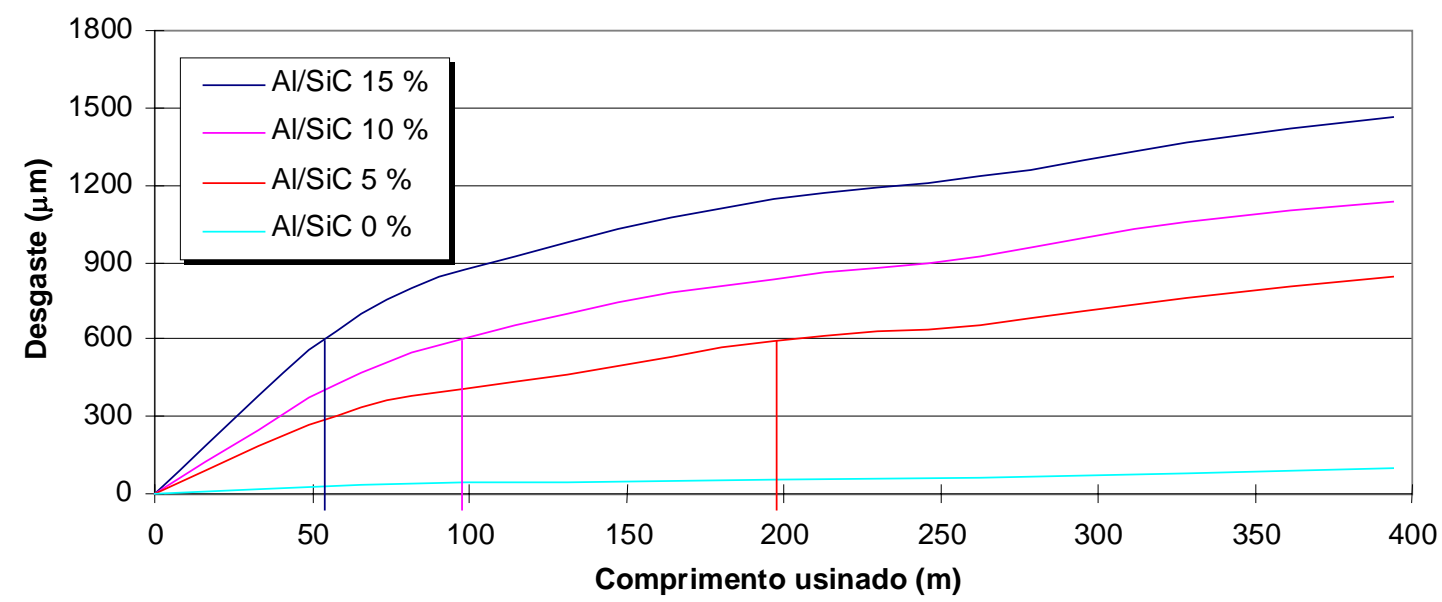

Figura 20.4 (b) - Evolução do desgaste da ferramenta ao longo do comprimento usinado para os materiais com $5 \%, 10 \%$ e $15 \%$ de reforço e para o material sem reforço, utilizando velocidade de corte de $229 \mathrm{~m} / \mathrm{min}$.

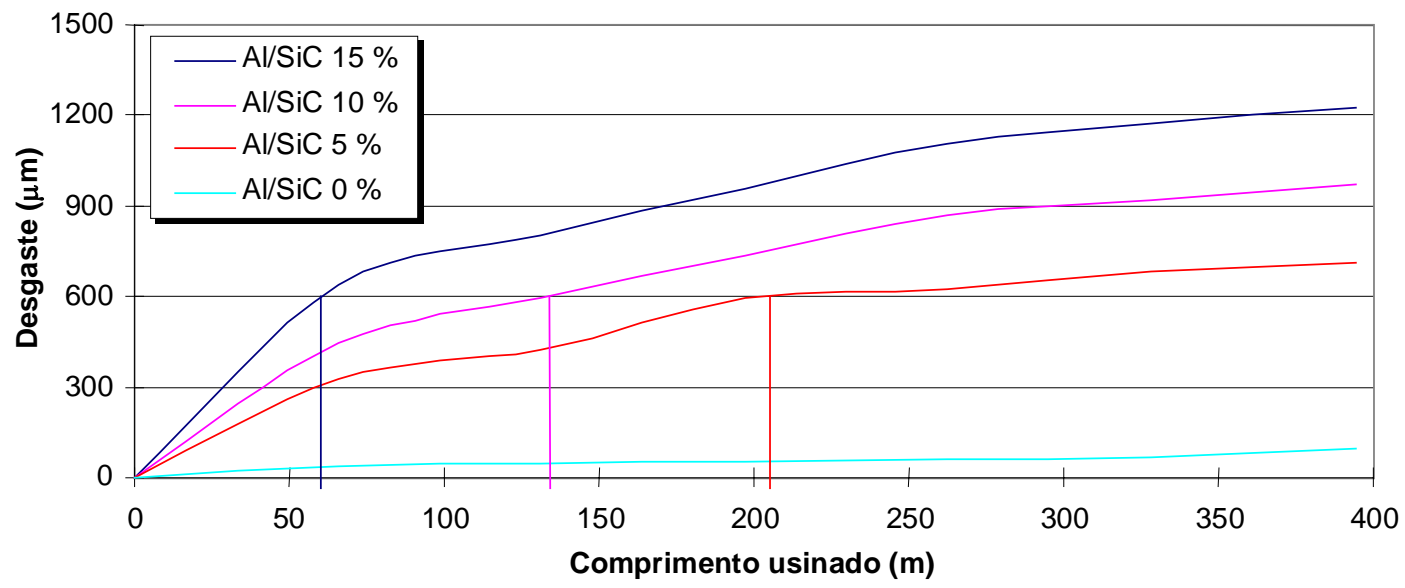

Figura 20.4 (c) - Evolução do desgaste da ferramenta ao longo do comprimento usinado para os materiais com $5 \%, 10 \%$ e $15 \%$ de reforço e para o material sem reforço, utilizando velocidade de corte de $185 \mathrm{~m} / \mathrm{min}$. 


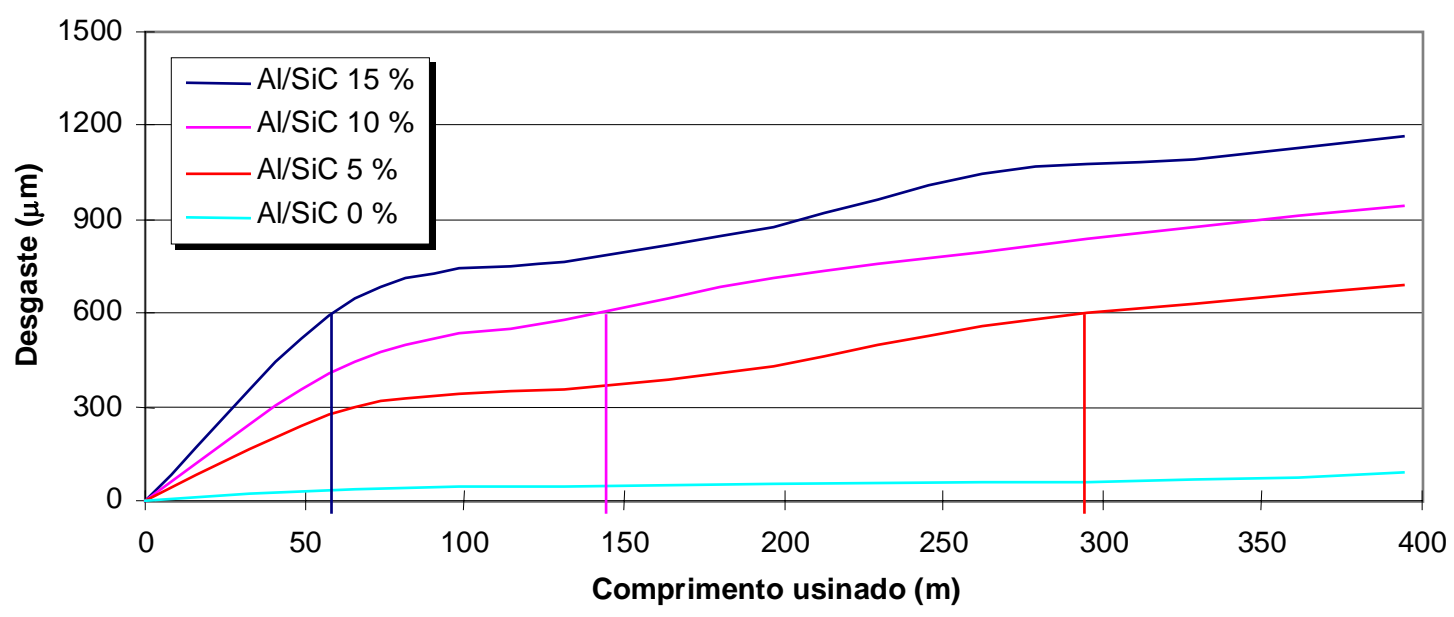

Figura 20.4 (d) - Evolução do desgaste da ferramenta ao longo do comprimento usinado para os materiais com $5 \%, 10 \%$ e $15 \%$ de reforço e para o material sem reforço, utilizando velocidade de corte de $141 \mathrm{~m} / \mathrm{min}$.

Tabela 3.4 - Valores de comprimento usinado para um desgaste de flanco (VB) igual a 0,6 $\mathrm{mm}$ (figuras 20.4 (a-d)) e respectivas relações de usinabilidade entre os materiais.

\begin{tabular}{|c|c|c|c|c|c|c|c|c|}
\hline Material & \multicolumn{2}{|c|}{$\begin{array}{l}\text { Comp. usin. (m) } \\
\text { vc } 273 \mathrm{~m} / \mathrm{min}\end{array}$} & \multicolumn{2}{|c|}{$\begin{array}{l}\text { Comp. usin. (m) } \\
\text { VC } 229 \text { m/min }\end{array}$} & \multicolumn{2}{|c|}{$\begin{array}{l}\text { Comp. usin. (m) } \\
\text { vC } 185 \mathrm{~m} / \mathrm{min}\end{array}$} & \multicolumn{2}{|c|}{$\begin{array}{l}\text { Comp. usin. (m) } \\
\text { VC } 141 \mathrm{~m} / \mathrm{min}\end{array}$} \\
\hline $\mathrm{Al} / \mathrm{SiC} 5 \%$ & 160 & $100 \%$ & 199 & $100 \%$ & 224 & $100 \%$ & 298 & $100 \%$ \\
\hline $\mathrm{Al} / \mathrm{SiC} 10 \%$ & 77 & $48 \%$ & 98 & $49 \%$ & 134 & $60 \%$ & 143 & $48 \%$ \\
\hline $\mathrm{Al} / \mathrm{SiC} 15 \%$ & 52 & $33 \%$ & 54 & $27 \%$ & 60 & $27 \%$ & 58 & $20 \%$ \\
\hline Al/SiC $0 \%$ & * & * & * & * & * & * & * & * \\
\hline
\end{tabular}

* No caso, a adoção do alumínio puro como padrão de referência para determinação da usinabilidade é impraticável, já que os valores de desgaste gerados na ferramenta foram muito reduzidos quando da usinagem deste material, e, a extrapolação desses resultados para um critério de vida da ferramenta igual a 0,6 $\mathrm{mm}$ seria um tanto quanto duvidosa.

$\mathrm{Na}$ impossibilidade de adotar o material sem reforço como referência, se for adotado o material com $5 \%$ de reforço, portanto como sendo de usinabilidade $100 \%$; observa-se que a usinabilidade do material com $10 \%$ de reforço em relação ao de $5 \%$ esta na faixa dos $48 \%$ que seria a média dos valores para as velocidades de corte 273 , 229, e $141 \mathrm{~m} / \mathrm{min}$ (tabela 3.4), ou seja é cerca de $52 \%$ mais difícil de usinar que o de 5 \%. Já o material com $15 \%$ de reforço fica na faixa dos $29 \%$, equivalente à média dos valores para as velocidades de corte 273, 229 e $185 \mathrm{~m} / \mathrm{min}$, portanto cerca de $71 \%$ mais difícil usinar do que o material com $5 \%$ de reforço. 
Os valores para o material de $10 \%$ (VC $185 \mathrm{~m} / \mathrm{min}$ ) e também para o material de 15 \% (VC $141 \mathrm{~m} / \mathrm{min}$ ) podem ser desconsiderados em virtude da dispersão em relação aos demais resultados, visto que podem ser resultado em algum momento, de erros na medição da evolução do desgaste ou outra influência qualquer do sistema durante o procedimento experimental.

\subsection{6 - Equação de Taylor}

Colocando-se os valores obtidos nos ensaios com ferramenta de carboneto em um gráfico logarítmico da velocidade de corte versus vida da ferramenta (para um critério de vida de $\mathrm{VB}=0,6 \mathrm{~mm}$ ) vide fig. 21.4 e, utilizando-se o método "by eye" na avaliação desses resultados, conforme anexo F item F.2 da ISO 3685 [20] obtem-se as constantes C e $\mathbf{n}$ da equação de Taylor (equação 1.4). Através desta equação, é possível extrair valores ideais de velocidade de corte, de acordo com a vida da ferramenta que se deseja obter ou vice-versa para as condições de avanço e profundidade de corte utilizadas nos ensaios.

LOG T x LOG Vc

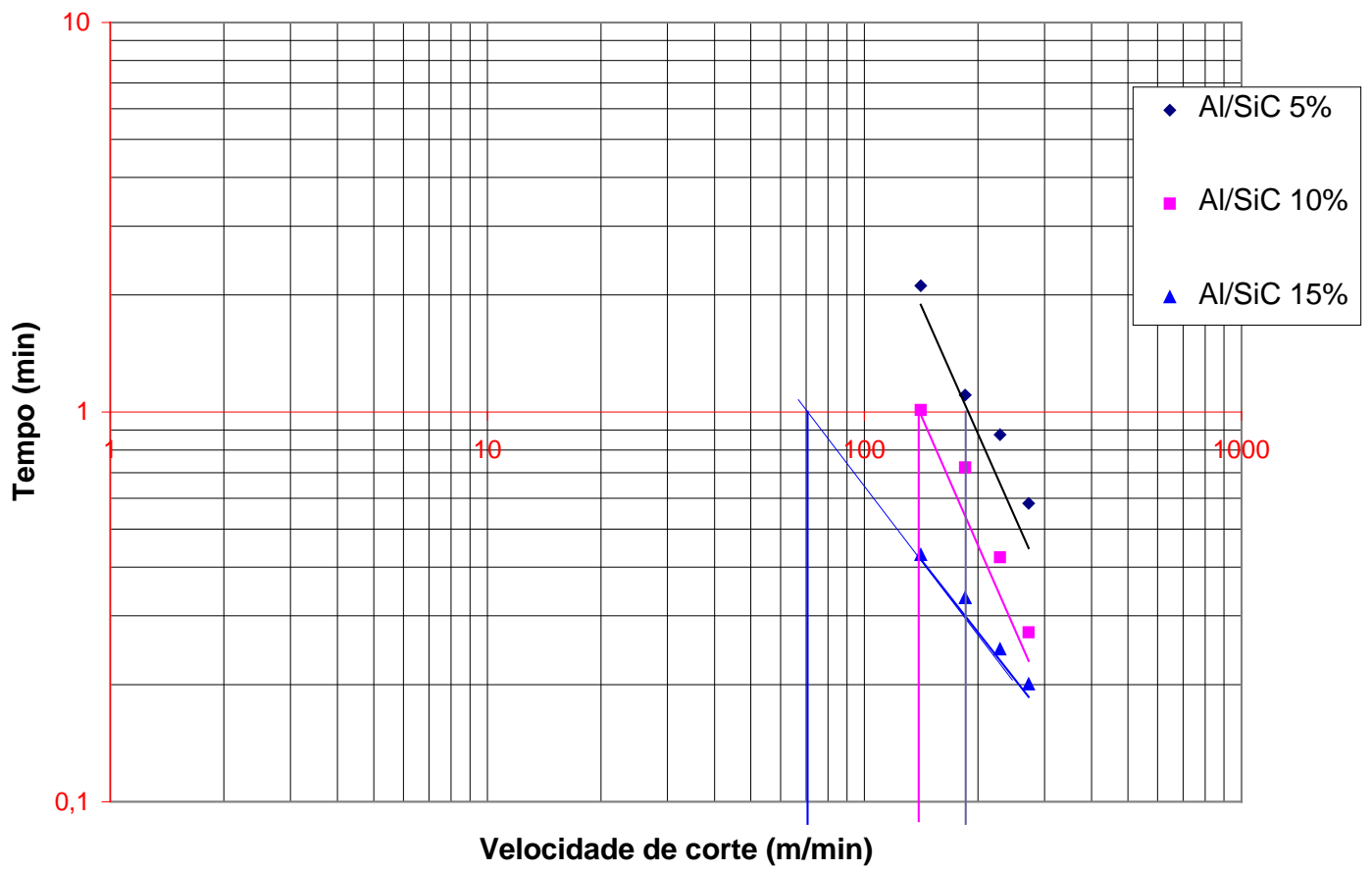

Figura 21.4 - Gráfico logarítmico da velocidade de corte versus vida da ferramenta (VB=0,6 mm), para os materiais compósitos com $5 \%, 10 \%$, e $15 \%$ de SiC. 


\section{$\mathbf{V c}=\mathbf{C} / \mathbf{t}^{\mathbf{n}} \quad$ (Equação 1.4)}

onde: $V c=$ Velocidade de corte $(\mathrm{m} / \mathrm{min})$

$\mathrm{C}$ e $\mathrm{n}=$ constantes

$\mathrm{t}=$ tempo $(\min )$

Pelo gráfico (vide figura 21.4) n é a inclinação da reta em cada caso e C é igual a velocidade de corte para uma vida de ferramenta igual a 1 minuto, então tem-se para cada caso uma configuração específica para a equação de Taylor (vide tabela 4.4):

Tabela 4.4 - Forma geral da equação de Taylor para os materiais compósitos com diversas frações volumétricas de SiC.

\begin{tabular}{|c|c|c|}
\hline \multicolumn{3}{|c|}{ Material } \\
\hline Al/SiC $5 \%$ & Al/SiC $10 \%$ & Al/SiC $15 \%$ \\
\hline$V c=190 / t^{0,5}$ & $\mathrm{Vc}=142 / \mathrm{t}^{0,51}$ & $V c=75 / t^{0,81}$ \\
\hline
\end{tabular}

Calculando-se em cada caso o valor de velocidade de corte para uma vida da

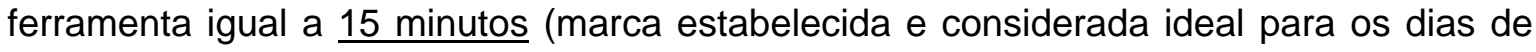
hoje, sendo inclusive adotada por alguns fabricantes de ferramentas como referência para o desenvolvimento de novos produtos); tem-se a tabela 5.4:

Tab. 5.4 - Valores de velocidade de corte extraídos da equação de Taylor de cada material, para uma vida de ferramenta igual a 15 minutos.

\begin{tabular}{|c|c|c|}
\hline \multicolumn{3}{|c|}{ Material } \\
\hline $\mathrm{Al} / \mathrm{SiC} 5 \%$ & $\mathrm{Al} / \mathrm{SiC} 10 \%$ & $\mathrm{Al} / \mathrm{SiC} 15 \%$ \\
\hline $\mathrm{Vc}=49 \mathrm{~m} / \mathrm{min}$ & $\mathrm{Vc}=36 \mathrm{~m} / \mathrm{min}$ & $\mathrm{Vc}=8 \mathrm{~m} / \mathrm{min}$ \\
\hline
\end{tabular}

Estes resultados, do ponto de vista industrial, são considerados extremamente baixos e torna, em alguns casos inviável a utilização de ferramenta de carboneto na usinagem desses materiais, principalmente quando se trata da produção de grandes lotes de peças. Tomac e Tonnessen [34], também encontram valores bastante baixos que podem variar de 20 a $50 \mathrm{~m} / \mathrm{min}$, e salientam que a utilização de ferramentas de carboneto só é aplicável no caso de produção de pequenos lotes. 
É possível notar que o valor de $\mathbf{n}$ é bastante alto para os três materiais, indicando que a variação no valor da velocidade de corte tem pouca influência sobre a vida da ferramenta. A esse respeito Weinert, Biermann e Meister [26], também chegam a conclusões semelhantes quando da usinagem de alumínio reforçado com $\mathrm{SiC}$ e $\mathrm{B}_{4} \mathrm{C}$. Ora, se a velocidade de corte (que normalmente em materiais convencionais é o fator que maior influência exerce sobre a vida da ferramenta) neste caso tem efeito reduzido, então, há de ser outro fator o responsável pela diminuição drástica da vida da ferramenta na usinagem deste tipo de material. Neste caso, este fator pode ser a presença de partículas extremamente duras e abrasivas na estrutura destes materiais.

Tomac e Tonnessen [34] encontram $n=0,61$ quando da usinagem de AlSi7Mg com $14 \%$ vol. SiC, e também concluem que este é um valor muito alto se comparado por exemplo, com os valores encontrados quando da usinagem de aço com metal duro onde o valor de $\mathbf{n}$ fica na faixa de 0,2 a 0,3.

\section{3 - Ensaios de desgaste}

Pelos resultados encontrados nos ensaios de desgaste, é possível verificar que a adição de partículas de reforço no material da matriz confere melhoria na resistência ao desgaste dos materiais compósitos se comparados ao material sem reforço. As primeiras evidências podem ser notadas quando se faz uma avaliação da perda de massa ao longo do ensaio para cada material (tabela 6.4; figura 22.4).

Tabela 6.4 - Valores médios de perda de massa para os dois corpos de prova durante os ensaios com materiais compósitos contendo $5 \%$, $10 \%$ e $15 \%$ de partículas de reforço de SiC, e para o material sem reforço.

\begin{tabular}{|l|c|}
\hline \multicolumn{1}{|c|}{ Material } & $\begin{array}{l}\text { Valor médio de perda de massa total para os dois } \\
\text { corpos de prova }(\mathrm{g})\end{array}$ \\
\hline Al/SiC 0 \% & 0,1221 \\
\hline Al/SiC 5 \% & 0,0948 \\
\hline Al/SiC $10 \%$ & 0,0814 \\
\hline Al/SiC $15 \%$ & 0,0767 \\
\hline
\end{tabular}




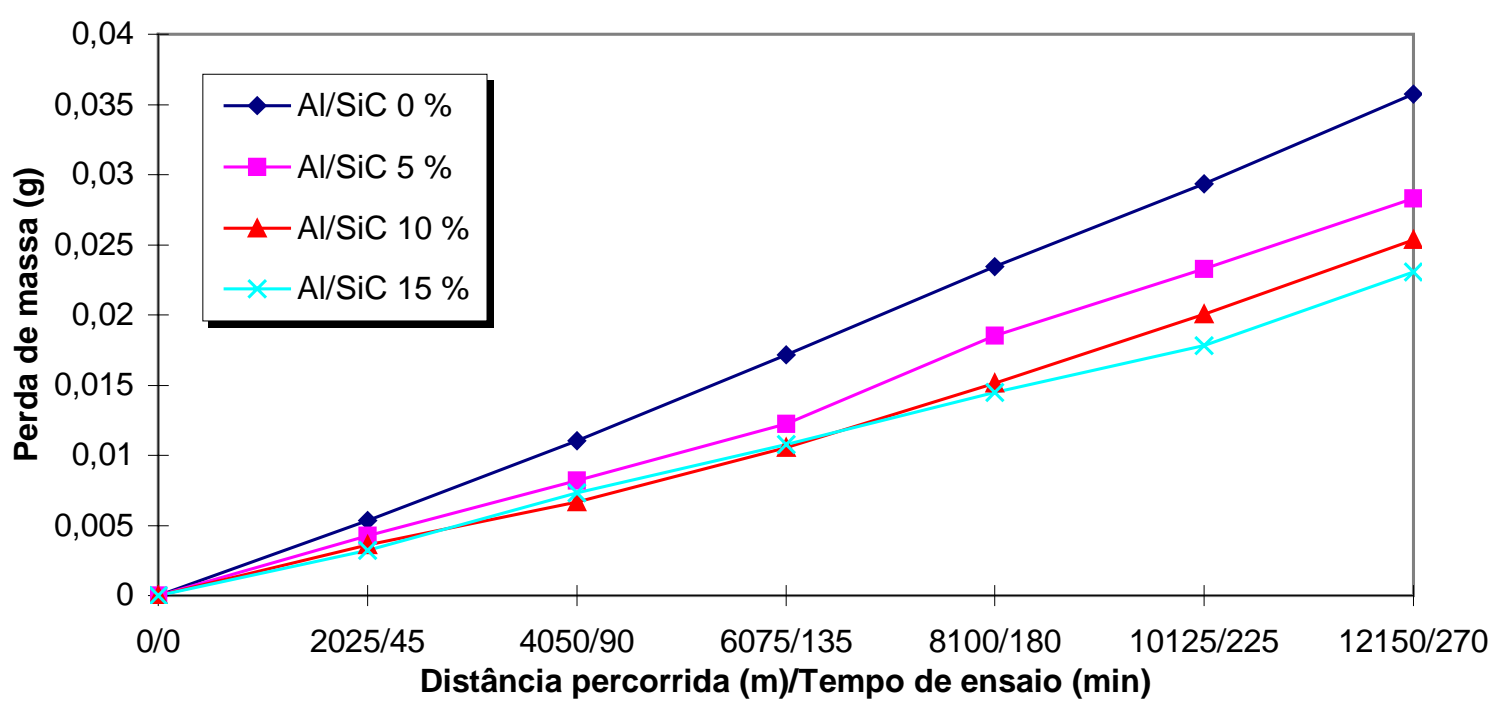

Figura 22.4 - Evolução da perda de massa dos materiais compósitos com $5 \%$, $10 \%$ e $15 \%$ de $\mathrm{SiC}$, e do material sem reforço ao longo do ensaio(valores médios para os dois corpos de prova).

Os resultados mostrados na tabela 6.4 e na figura 22.4 , indicam uma diminuição no valor de perda de massa à medida em que a quantidade de reforço cerâmico presente no material da matriz é aumentada.

Aplicando-se os valores obtidos nos experimentos na equação para determinação do coeficiente de desgaste (equação 2.4), conforme DIN 50321 [16], e citada por Gahr [11], é possível obter o valor de coeficiente de desgaste para cada material avaliado ao longo do ensaio (figura 23.4 ).

\section{$\mathbf{W}=\Delta \mathbf{M} / \rho \Delta \mathbf{O} \mathbf{L}($ Equação 2.4)}

Onde:

$\mathrm{W}=$ Coeficiente de desgaste

$\Delta \mathrm{M}=$ Perda de massa $(\mathrm{g})$

$\rho=$ Densidade do material $\left(\mathrm{g} / \mathrm{m}^{3}\right)$

$\Delta \mathrm{o}=$ Área da secção transversal do corpo de prova $\left(\mathrm{m}^{2}\right)$

$\mathrm{L}=$ Distância percorrida $(\mathrm{m})$ 


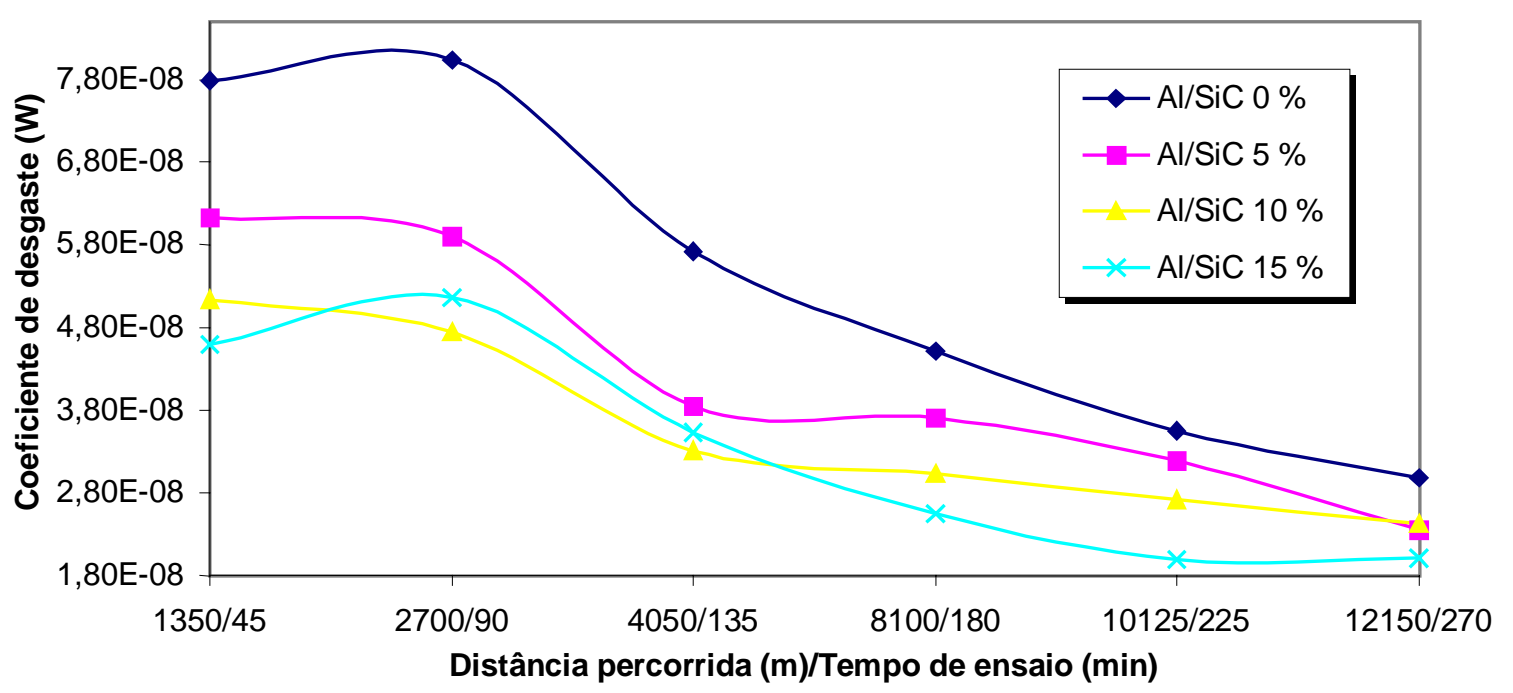

Figura 23.4 - Valores médios de coeficiente de desgaste para os dois corpos de prova ao longo do ensaio para os materiais compósitos com diferentes frações volumétricas de SiC, e para o material sem reforço.

Pela figura 23.4, é possivel verificar para todos os materiais nas condições de ensaio que existe um período inicial para que ocorra estabilização do coeficiente de desgaste. Alpas e Embury [38] também verificaram a existência do período de estabilização de desgaste em experimentos feitos com Al 2014/SiC 20\% utilizando aço tratado como contracorpo. Al-Rubaie et all [24], verificaram em testes de desgaste com compósitos Al/SiC, a ausência de período de estabilização de desgaste, a explicação pode estar no tipo de contracorpo utilizado. Al-Rubaie et all [24], utilizaram lixas enquanto que também no presente trabalho a exemplo do trabalho desenvolvido por Alpas e Embury [38] foram utilizados discos de aço SAE 1045 tratados térmicamente e retificados.

Considerando que o valor real do coeficiente de desgaste deve ser tomado a partir do momento em que ocorre a estabilização do mesmo, e embora pelo tempo de ensaio não tenha sido possível alcançar com exatidão o patamar de estabilização, é possível obter valores muito próximos aos reais utilizando a média dos dois ultimos valores em cada caso admitindo que estes já se encontram em regime de estabilização (vide figura 23.4). Neste caso teremos os seguintes valores de coeficiente de desgaste para cada material avaliado (tabela 7.4; figura 24.4). 
Tabela 7.4 - Valores de coeficiente de desgaste tomados a partir do ponto de estabilização, para os materiais com $5 \%, 10 \%$ e $15 \%$ de reforço e para o material sem reforço.

\begin{tabular}{|c|c|}
\hline Material & Coeficiente de desgaste [W] \\
\hline Al/SiC 0 \% & $3,26675 \cdot 10^{-8}$ \\
\hline Al/SiC 5 \% & $2,76992 \cdot 10^{-8}$ \\
\hline Al/SiC 10 \% & $2,57023 \cdot 10^{-8}$ \\
\hline Al/SiC 15\% & $2,00527 \cdot 10^{-8}$ \\
\hline
\end{tabular}

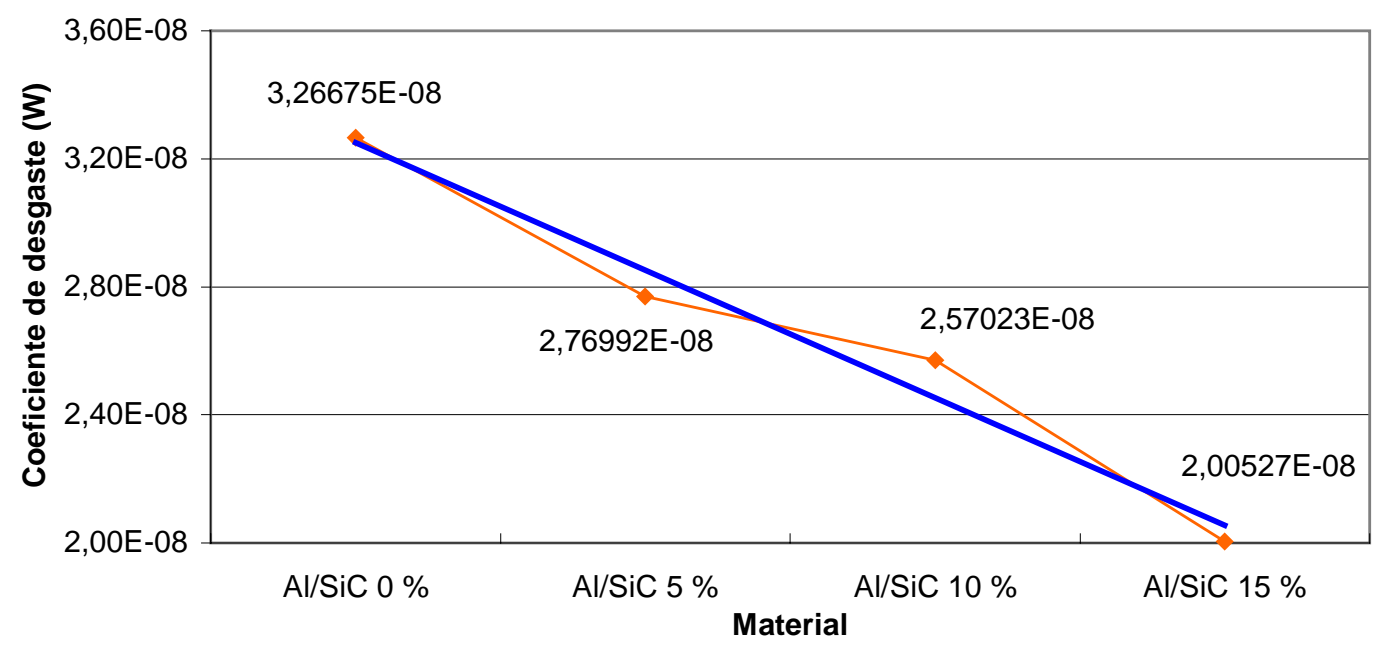

Figura 24.4 - Evolução do coeficiente de desgaste dentro do patamar de estabilização, para os materiais com $5 \%, 10 \%$ e $15 \%$ de reforço e para o material sem reforço.

Considerando uma dispersão de valores, dispersão esta que não pode ser determinada, já que foram ensaiadas apenas duas amostras de cada material. Se aproximarmos a curva da figura 24.4 a uma reta (linha azul), é possível dizer que o coeficiente de desgaste decresce linearmente com o aumento da fração volumétrica de SiC. É possível verificar ainda que, a melhoria em termos de resistência ao desgaste proporcionada pela adição de partículas de reforço no material da matriz chega a ser 1,63 vezes superior, (cerca de $40 \%$ ) no caso do Al/SiC $15 \%$ em relação ao material sem reforço (vide tabela 7.4).

Zongyi, Jing, Yuxiong, Hongwey e Yinxuan [39] concluem em testes de desgaste com AA6061 reforçado com whiskers de SiC, que a resistência ao desgaste destes materiais é reduzida pela presença de aglomerados de SiC . Então, é de se esperar que 
a resistência ao desgaste no presente trabalho para os materiais com $5 \%$, $10 \%$ e 15\% de reforço possa ser melhorada, já que a presença de aglomerados de partículas de SiC é evidente, conforme visto anteriormente (item 4.1.3.2 - pag. 43).

De acordo com Rana e Stefanescu [40] que realizaram testes de desgaste em compósitos Al/SiC com diversas frações de particulas de reforço, para as mesmas condições de ensaio, o valor do coeficiente de atrito tende a cair à medida em que ocorre o aumento da quantidade de partículas de reforço na matriz. Os resultados encontrados durante os experimentos neste trabalho mostram um comportamento à princípio similar aos encontrados por Rana e Stefanescu [40], com o material sem reforço sendo superior aos demais materiais. Entretanto os valores para os materiais com $5 \%, 10 \%$ e $15 \%$ se apresentaram muito próximos e bastante confusos, função talvez da falta de controle de temperatura e humidade relativa durante os ensaios já que o equipamento estava em um ambiente que não comportava aparelhos para controle destes parâmetros (vide figura 25.4).

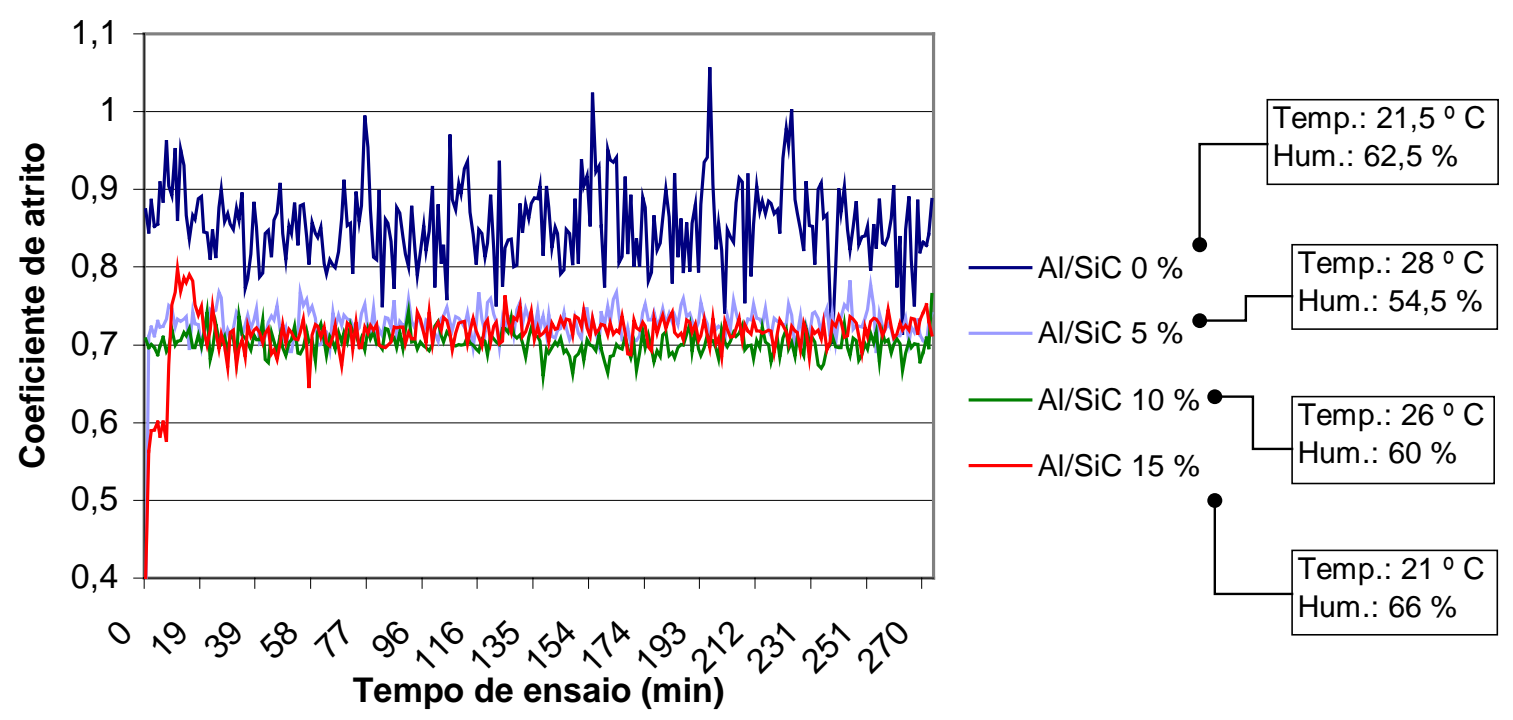

Figura 25.4 - Valores médios de coeficiente de atrito, temperatura e humidade relativa do ar ao longo dos ensaios para os materiais compósitos com diferentes frações volumétricas de SiC e para o material sem reforço.

Pelas micrografias das regiões desgastadas (figuras 26.4 (a-b); 27.4 (a-d) e 28.4 (a-b)), é possível verificar que ocorre uma distinção na aparência e nos mecanismos de desgaste de acordo com a variação da quantidade de reforço na matriz. 
No material sem reforço observa-se uma aparência de material fadigado o que supõe atuante o mecanismo de delaminação, embora possa se supor também atuante o mecanismo de adesão, já que o material é bastante dúctil e foram encontrados no contracorpo indícios de material do pino impregnados na região da pista de desgaste (figuras $26.4(a-b))$.

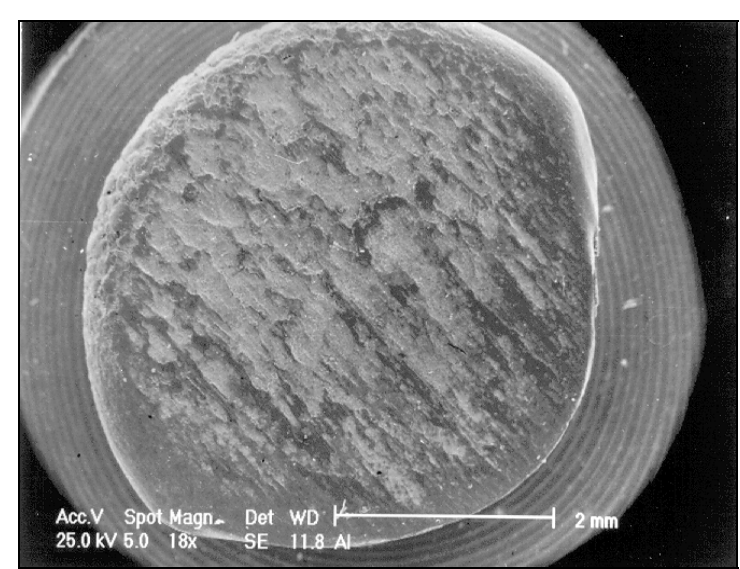

(a)

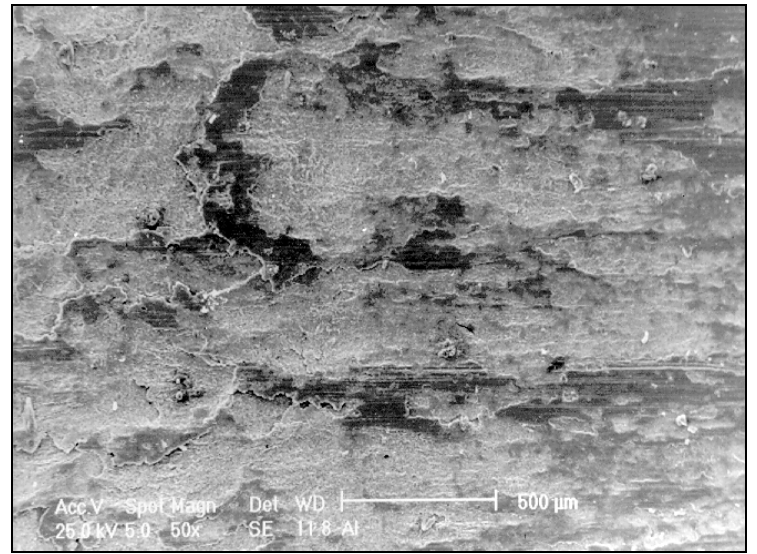

(b)

Figura 26.4 - Micrografia eletrônica de varredura mostrando o aspecto da superfície desgastada do corpo de prova ensaiado, construído a partir do material sem reforço (AI/SiC $0 \%$ ). (a) vista geral da superfície desgastada; (b) vista ampliada da superfície desgastada.

Para os materiais com $5 \%$ e $10 \%$ de reforço verifica-se a aparência de material riscado o que sugere uma intensa atuação do mecanismo de abrasão. Supõe-se neste caso, que o mecanismo tem origem nas próprias partículas abrasivas de reforço que ao se desprender da matriz agem como um terceiro corpo abrindo sulcos que tem início preferencialmente na região onde há somente material da matriz (figuras 27.4 (a-d)).

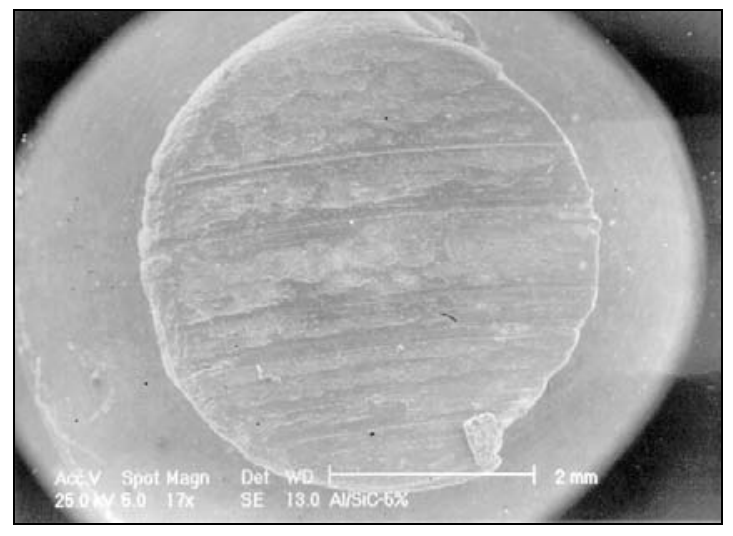

(a)

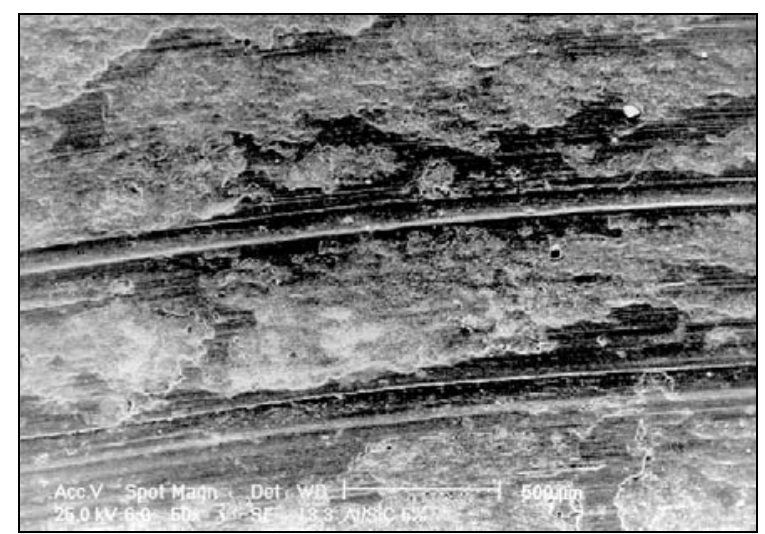

(b) 


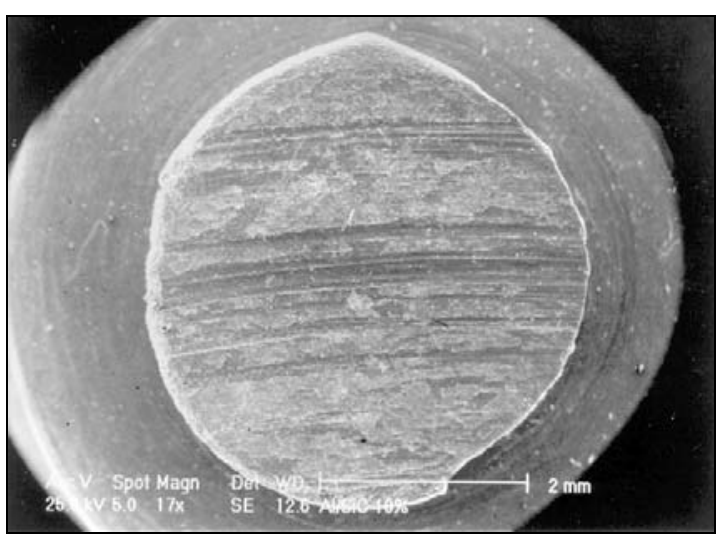

(c)

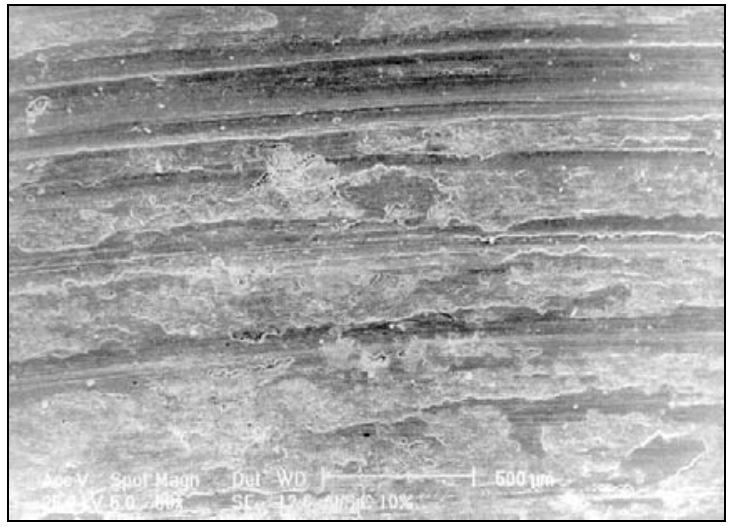

(d)

Figura 27.4 - Micrografia eletrônica de varredura mostrando o aspecto da superfície desgastada dos corpos de prova ensaiados, construídos a partir do material com 5\% de reforço (Al/SiC $5 \%$ ) e do material com 10 \% de reforço (Al/SiC $10 \%$ ). (a) vista geral da superfície desgastada (Al/SiC 5 $\%) ;$ (b) vista ampliada da superfície desgastada (Al/SiC $5 \%$ ); (c) vista geral da superfície desgastada (Al/SiC $10 \%$ ); (d) vista ampliada da superfície desgastada (Al/SiC $10 \%)$.

No material com 15\% de reforço a aparência da região desgastada é muito parecida com a do material sem reforço. O mecanismo atuante neste caso, supõe-se, seja apenas o de delaminação, já que neste caso o material já não é tão dúctil para que ocorra adesão e, o aumento da resistência do material aliada à uma diminuíção do espaçamento existente entre uma partícula e outra de reforço, impedem a ação abrasiva das poucas partículas de reforço que se desprendem do material e agem como um terceiro corpo entre o corpo (pino ) e o contracorpo (disco) vide figuras 28.4 (a-b).

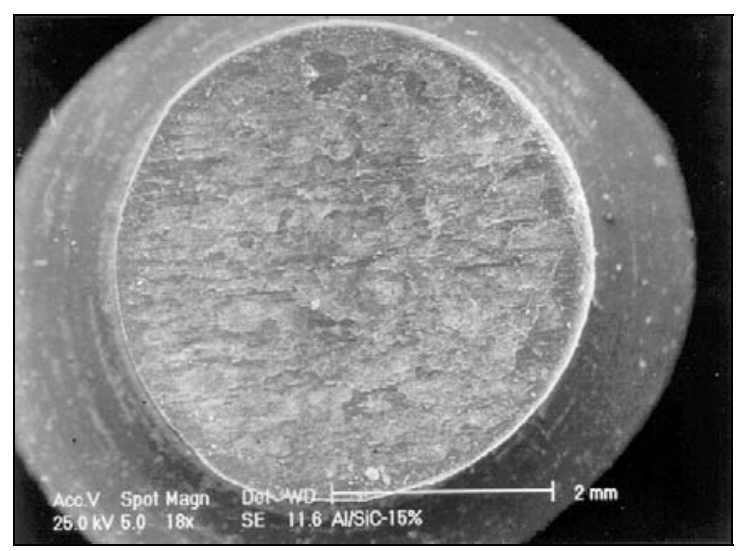

(a)

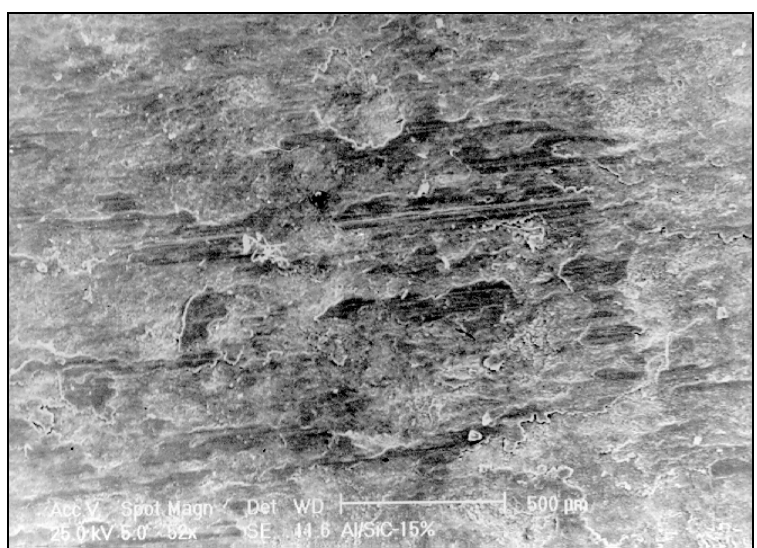

(b)

Figura 28.4 - Micrografia eletrônica de varredura mostrando o aspecto da superfície desgastada do corpo de prova ensaiado, construído a partir do material com $15 \%$ de reforço (Al/SiC $15 \%$ ). (a) vista geral da superfície desgastada; (b) vista ampliada da superfície desgastada. 
Quando é estabelecida uma relação entre as propriedades de desgaste de cada material com as suas respectivas características mecânicas e de usinagem, é possível verificar um comportamento lógico que associa a variação da taxa de desgaste em cada material com a variação das demais propriedades. Sendo assim a diminuição da taxa de desgaste está associada ao aumento de dureza, do limite de resistência (LR) e da dificuldade de usinagem do material (verificado pela diminuição da usinabilidade) ou vice-versa. Todos estes fatores estão intimamente relacionados com a quantidade de material de reforço presente dentro da matriz (figura 29.4).

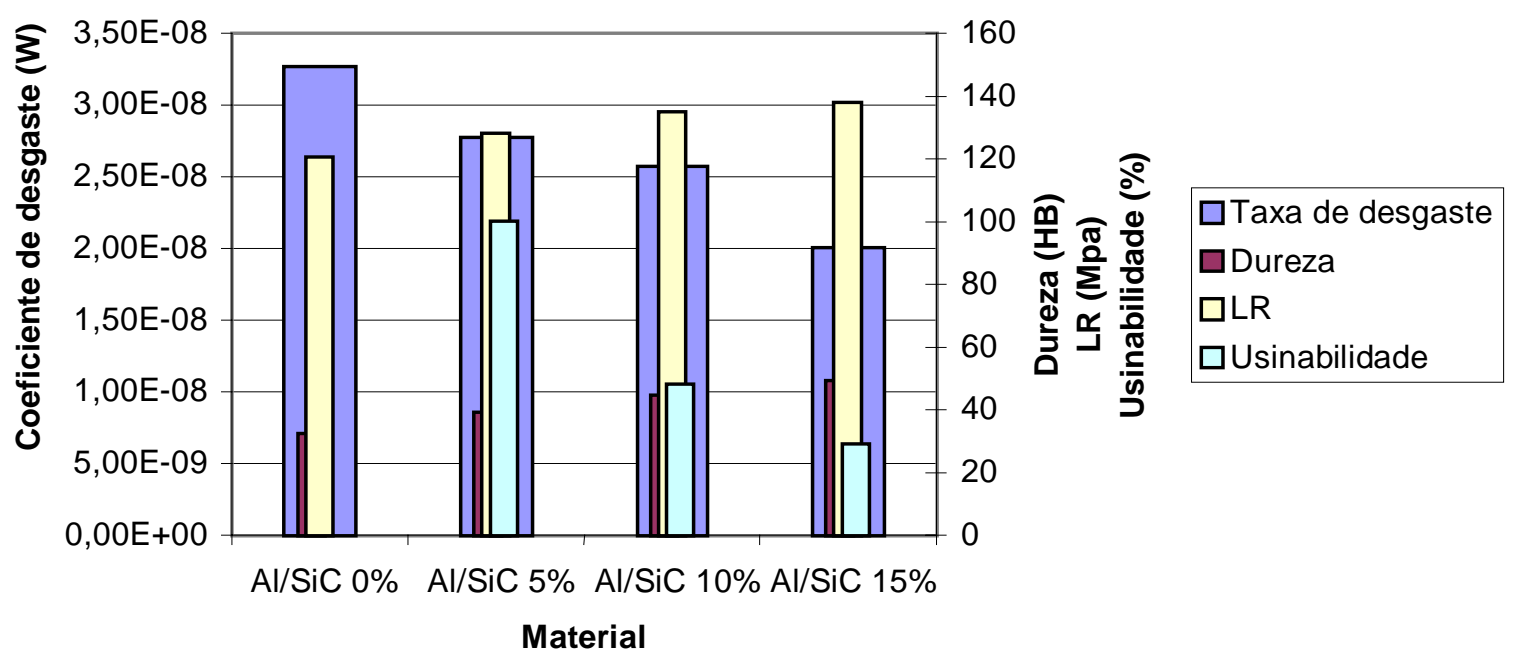

Figura 29.4 - Relação entre resistência ao desgaste e demais propriedades para os materiais compósitos com $5 \%, 10 \%$, e $15 \%$ de reforço e para o material sem reforço. 


\section{5 - CONCLUSÕES}

- Os resultados mostraram que o comportamento à usinagem por métodos convencionais de compósitos de matriz metálica é inaceitável do ponto de vista industrial e produtivo. Com ferramentas de carboneto e cerâmica, somente a baixas velocidades de corte é possível alcançar valores aceitáveis de vida da ferramenta. Ferramentas de diamante apresentam rendimento superior, podendo trabalhar a velocidades de corte mais elevadas.

- O material de ferramenta que apresenta melhor desempenho na usinagem de materiais deste tipo é o PCD; este chega a ter rendimento 20 vezes superior se comparado a ferramentas de carboneto nas mesmas condições de usinagem.

- Em compósitos de matriz metálica, a microestrutura exerce forte influência no mecanismo de formação do cavaco atuando como elemento fragilizador do mesmo que se rompe facilmente ao menor sinal de resistência ou impacto.

- As partículas de reforço influem sobremaneira nas características de usinagem destes materiais, agindo no sentido de reduzir drasticamente a vida da ferramenta quando se tenta utilizar parâmetros de usinagem normalmente utilizados na usinagem de materiais convencionais. A aplicação dos valores obtidos na usinagem com ferramentas de carboneto na equação de Taylor, mostrou que a variação da velocidade de corte exerce pouca influência na vida da ferramenta. A redução drástica da vida da ferramenta neste caso pode então ser atribuída à presença de partículas extremamente duras e abrasivas na estrutura destes materiais. 
- A adição de partículas de reforço no material da matriz implica na melhoria da resistência ao desgaste desses materiais. A melhoria é verificada na medida em que a quantidade de reforço no material da matriz é aumentada, tendo portanto sido muito mais evidente no material com $15 \%$ de reforço.

- Os índices de usinabilidade para os materiais com $10 \%$ e $15 \%$ de reforço, tomando o material de $5 \%$ como padrão de referência (portanto de usinabilidade $100 \%$ ), está na faixa de $48 \%$ e $29 \%$ respectivamente. Estes são valores muito baixos e indicam a extrema dificuldade de usinagem deste tipo de material se comparado à usinagem de materiais convencionais. 


\section{SUGESTÕES PARA TRABALHOS FUTUROS.}

- Verificar a validade da equação de Taylor para materiais compósitos, baseado nos resultados encontrados no presente trabalho, e também com a variação dos parâmetros de usinagem.

- Avaliar os danos causados pela usinagem em materiais compositos por meio de cortes transversais em corpos de prova ensaiados, de modo que se possa examinar mais criteriosamente a espessura da camada afetada e a intensidade das tensões residuais inferidas pelo processo de usinagem nesta região.

- Verificar se ocorre variação no índice de usinabilidade, com a variação dos parâmetros de usinagem (avanço e profundidade de corte) e também com a mudança do material da ferramenta.

- Realizar ensaios onde possam ser avaliados também temperatura na região de corte e rugosidade da superfície usinada, traçando paralelos com os resultados obtidos no presente trabalho.

- Buscar processos alternativos de usinagem para materiais compósitos, se possível utilizando métodos não convencionais como por exemplo o ultrasom, já que o método convencional demonstrou não ser muito eficiente.

- Efetuar testes de desgaste mais prolongados com os mesmos parâmetros utilizados no presente trabalho, de modo a atingir com maior precisão o patamar de estabilização do desgaste e consequentemente o valor de taxa de desgaste de cada material. 


\section{BIBLIOGRAFIA}

[1] CHAWLA, K. K. - Composite Materials Science and Engineering. New York, Springer Verlag - 1987. p 3-5.

[2] SCHWARTZ, M. M. - Composite Materials Handbook - Mc Graw Hill - 1983. p 1.1-1.3.

[3] MATHEWS, F. L.; RAWLINGS, R. D. - Composite Materials: Engineering and Science - Chapman \& Hall - 15t edition - 1994. p 3-8.

[4] MOURISCO, A. J. - Preparação e caracterização de compósito de matriz de alumínio 1100 com partículas de SiC por metalurgia do pó - Dissertação de mestrado IPEN-USP - 1995. p 5-9/34-35.

[5] TAYA, M.; ARSENAULT, R. J. - Metal Matrix Composites Thermomechanical Behavior - Pergamon Press - 1989. p 5-8/209-221.

[6] CLYNE, T. W.; WITHERS, P. J. - An Introduction to Metal Matrix Composites Cambridge University Press - 1993. p 1-3.

[7] SRIVATSAN, T. S.; IBRAHIM, I. A.; MOHAMED, F. A.; LAVERNIA, E. J. - Processing techniques for particulate-reinforced metal aluminium matrix composites $-\mathrm{J}$. of Materials Science - 26 (1991). p 5965-78.

[8] AMBROZIO FILHO, F.; ROSSI, J. L.; GONÇALVES, M.; GOLDENSTEIN, H.; SOUZA, R. M.; YOSHIMURA, H. N. - Desenvolvimento de compósitos de matriz metálicaMetalurgia e Materiais - Abril/96. p 248-252

[9] MARCONDES, F. C. - A História do Metal Duro - Sandvik - $1^{\text {a }}$ edição - Unida Artes Gráficas e Editora Ltda - 1990. p 27-28.

[10] FERRARESI, D. - Fundamentos da Usinagem dos Metais - Vol. 1 - Ed. Edgard Blücher - 1970. p XXV-XLIV/566-568.

[11] GAHR, K. H. Z. - Microstructure and Wear of Materials - (Tribology series 10) Elsevier - 1987. p 1-7.

[12] HUCHINGS, I. M. - Tribology, Friction and Wear of Engineering Materials - Metallurgy and Materials Science Series - 1992. p 1-3.

[13] JOST, H. P. - Tribology-origin and future - Wear 136 (1990) 1-17.

[14] DIN 50320 - Análise sistemática dos processos de desgaste. Classificação dos fenômenos de desgaste - Traduzido do original para o português - Metalurgia e Materiais - Outubro/1997. p 619-22.

[15] BAYER, R. G. - Mechanical Wear Prediction and Prevention - Marcel Dekker First edition - 1994. p 1-4. 
[16] DIN 50321 - Wear measuring quantities - December 1979.

[17] YOSHIMURA, H. N. - Produção e caracterizacão de compósitos de matriz de alumínio, reforçado com partículas de SiC obtidos por extrusão de pós Dissertação de Mestrado - EPUSP - 1994. p 10-15.

[18] DIN 50125 - Ensaios de materiais metálicos - corpos de prova de tração - diretrizes para a execução - Versão traduzida para o português - 1976.

[19] BLACK, S. C.; CHILES, V.; LISSAMAN, A. J.; MARTIN, S. J. - Principles of Engineering Manufacture - Third edition - Arnold - 1996. p 279-300.

[20] ISO/DIS 3685 - Tool-life testing with single point turning tools. International Organization for Standardization - Second Edition - 1993.

[21] ZIMMERMAN, C.; BOPPANA S. P. and KATBI, K. - Machinability test methods Metals Handbook - Ninth Edition - Volume 16 - Machining - ASM International 1989. p 639-647.

[22] ASTM G99 - Standard testing method for wear testing with a pin-on-disk apparatus The American Society for Testing and Materials - 1995.

[23] ASTM G118 - Standard guide for recommended data format of sliding wear test data suitable for databases - The American Society for Testing and Materials - 1995.

[24] AL-RUBAiE, K. S. F.; GOldenStein, H.; MELLO, J. D. B. - Comportamento de compósitos Al-SiC em abrasão à dois corpos - IV Seminário de Desgaste - São Paulo - SP - 20 à 22 julho - 1998. p 125-41.

[25] COELHO R. T.; ASPINWALL D. K. - Usinagem de compósitos de Al com ferramentas de PCD na produção de autopeças - Máquinas e Metais - Abril 1996. p 58-64.

[26] WEIRNERT, K.; BIERMANN, D.; MEISTER, D. - Machining of metal matrix composites - tool wear and surface integrity. Proc. of ICCM-10, Whistler, B. C., Canada, August, Vol. III, 1995. p III-589-96.

[27] ZIMMERMAN, C.; BOPPANA, S. P.; KATBI, K. Machinability test methods. In: Vol. 16 Machining, Metals Handbook - Ninth Edition, Metals Park, ASM, 1989. p 63947.

[28] CHADWICK, G. A.; HEATH, P. J. Machining metal matrix composites. Metals and Materials, Vol. 6, No. 2, Feb., 1990. p 73-6.

[29] CHAMBERS, A. R. - The machinability of light alloy MMC's composites: Part A - Vol. 27A - Number 2 - Elsevier - 1996. p 143-147.

[30] CRONJÄGER, L.; BIERMANN, D. Turning of metal matrix composites. In: CLYNE, T. W.; WITHERS, P. J. eds. Proc. of the 2nd European Conf. on Advanced Materials 
and Processes, EUROMAT 91, Cambridge 22-24 July, vol. 2, 1991. p 73-80.

[31] BERGMAN, F.; JACOBSON, S. - Tool wear mechanisms in intermittent cutting of metal matrix composites - Wear 179 - 1994. p 89- 93.

[32] COELHO, R. T. - The machinability of aluminium-based SiC reinforced metal matrix composite (MMC) alloy with emphasis on hole production - PhD Thesis - School of Manufacturing and Mechanical Engineering - The University of Birmingham Edgbaston - December/1994.

[33] BOEHS, L.; GIRONDI, A. E. C.; MACHADO, A. R. - Materiais para ferramentas: as novas gerações e suas aplicações - IX Congresso Brasileiro de Engenharia Mecânica - Florianópolis, SC - Dezembro 1987. p 1039-42.

[34] TOMAC, N.; TØNESSEN, K. Machinability of particulate aluminium matrix composites. Annals of the CIRP, Vol. 41/1/1992. p 55-8

[35] CHANDLER, H. E. - Machining of metal-matrix composites and honeycomb structures - Metals Handbook - Ninth Edition - Volume 16 - Machining - ASM International - 1989. p 893-901.

[36] LIN, J. T.; BHATTACHARYYA, D.; LANE, C. - Machinability of a silicon carbide reinforced aluminiun metal matrix composite - Wear 181-183 - 1995 - $p$ 883-888.

[37] QUIGLEY, O.; MONAGHAN, J. AND O'REILLY, P. - Factors affecting the machinability of na Al/SiC metal-matrix composites - J. of Materials Processing Technology - 43 (1994) 21-36.

[38] ALPAS, A. T.; EMBURY, J. D. - Sliding and abrasive wear behaviour of na aluminum (2014)-SiC particle reinforced composite - Scripta Metallurgica et Materialia, vol. 24, 1990. p 931-935.

[39] ZONGYI, M.; JING, B.; YUXIONG, L.; HONGWEY, S. and YINXUAN, G. - Abrasive wear of discontinuous SiC reinforced aluminum alloy composites - Wear 148 1991. p 287-293.

[40] RANA, F.; STEFANESCU, D. M. - Friction properties of Al-1.5 pct Mg/SiC particulate metal-matrix composites - Metallurgical Transactions A, Volume 20 ${ }^{\mathrm{A}}$, august 1989. p 1564-1566. 


\section{BIBLIOGRAFIA RECOMENDADA}

[1] BRAZIL, D.; MONAGHAN, J. An investigation of the cutting mechanism associated with the machining of an Alum/SiC metal matrix composite. Proc. of the 12th conf. of the Irish Manufacturing Committee - IMC12 - Competitive Manufacturing, 6-8 September, 1995. p 177-84.

[2] BRUN, M. K.; LEE, M. - Wear characteristics of various hard materials for machining SiC-reinforced aluminum alloy - Wear, 104 (1995) 21-29.

[3] CHIAVERINI, V. - Metalurgia do Pó - Técnicas e produtos - ABM - 1982

[4] COELHO, R. T.; ASPINWALL, D. K. - Usinagem de compósitos de Al com ferramentas de PCD na produção de autopeças - Máquinas e Metais, $n^{\circ} 363$, abril 1996. p 58-64.

[5] COOK, N. H. - What is machinability ? - Influence of metallurgy on machinability, Proceedings of the International Symposium Sponsored by the Machinability Activity of the Mechanical Working and Forming Division, ASM, October 1975. p 110.

[6] CRONJÄGEN, L.; MEISTER, D. - Drilling of fibre reinforced aluminium metal matrix composites: Property optimisation and applications - City Conference Centre London - 8-9 November 1989. p 14.1-14.3.

[7] DEANRLEY, P. A. - Rake and flank wear mechanisms of coated and uncoated cemented carbides - Transactions of the ASME - Journal of engineering materials and technology - January 1985. p 69-82.

[8] DegARMO, E. P.; BLACK, J. T.; KOHSER, R. A. - Material and Processes in Manufacturing - Eighth edition - Prentice Hall - 1997

[9] DEUIS, R. L.; SUBRAMANIAN, C.; YELLUP, J. M. - Abrasive wear of aluminium composites - a review - Wear, 201(1996) 132-144.

[10] ELIASSON, J.; SANDSTRÖN, R. - Analysis of the coherence of published data on aluminum matrix composites - J. of Testing and Evaluation, JTEVA, Vol. 23, №. 4, July 1995. p. 288-94.

[11] FEEST, E. A.; TWEED, J. H. - Powder metallurgy composites in Powder Metallurgy: An Overview - Edited by Jenkins, I. and Wood, J. V. - The Institute of Metals 1991. p 267-286.

[12] FERREIRA, J.R. - Características da usinagem de um compósito de resina fenólica, reforçada com fibras de vidro e carbono - Dissertação de Mestrado - UNICAMP 1992.

[13] FRIDLYANDER, J. N. - Metal Matrix Composites - Chapman \& Hall - First edition 1995. 
[14] LIANG, Y. N.; MA, Z. Y.; LI, S. Z.; LI, S.; BI, J. - Impact abrasive behavior of $\mathrm{SiCp} / 2024 \mathrm{Al}$ composites in single pendulum scratch testing - Wear 178 - 1994. p 9-15.

[15] MACHADO, A. R.; GIANINI, W. L.; GONÇALVES, R. A. - Verificação experimental do comportamento das forças de corte e de avanço no torneamento dos aços ABNT 1020/1045 e do alumínio comercial - IX Congresso Brasileiro de Engenharia Mecânica - Florianópolis - SC - Dezembro 1987. p 1029-1033.

[16] MEHROTRA, P. K. - Wear mechanisms in ceramic tools for machining superalloys. Ceramic Transactions - Advanced Composite Materials - Vol. 19. p 1071-1077.

[17] MENG, H. C.; LUDEMA, K. C. - Wear models and predictive equations: their form and content - Wear 181-183 (1995) 443-457.

[18] MORIN, E; MASOUNAVE, J.; LAUFER, E. E. - Effect of drill wear on cutting forces in the drilling of metal matrix composites - Wear 184 - 1995. p 11-16.

[19] NETO, H. L.; PINHÃO, C. M. A. M. - Compósito: panorama e perspectiva no Brasil. Anais do $9^{\circ}$ CBECIMAT, Águas de São Pedro - SP - Dezembro 1990. p 485-488.

[20] OBERG, E.; JONES, F. D.; HORTON, H. L. - Manual Universal da Técnica Mecânica - Tomo II - tradução da 20ª edição americana. Editora Hemus, São Paulo, 1979.

[21] SHAW, M. C. - Metal Cutting Principles - Oxford Science Publications - 1984.

[22] TIPNIS, V. A; JOSEPH, R. A. - Testing for machinability - Influence of metallurgy on machinability, Proceedings of the International Symposium Sponsored by the Machinability Activity of the Mechanical Working and Forming Division, ASM, October 1975. p 11-30.

[23] TRENT, E. M. - Metal cutting and the tribology of seizure: II Movement of work material over the tool in metal cutting - Wear 128 (1988) 47-64.

[24] TRENT, E. M. - Metal cutting and the tribology of seizure: III Temperatures in metal cutting - Wear 128 (1988) 65-81.

[25] TRENT, E. M.; Metal cutting and the tribology of seizure: I seizure in metal cuting Wear 128 (1988) 29-45.

[26] VENKATESH, V. C. AND SATCHITHANANDAM - A discussion on tool life criteria and total failure causes - Annals of the CIRP - Vol 29/1/1980. p 19-22.

[27] WEINGAERTNER, W. L.; SCHOETER, R. B. - Tecnologia de Usinagem de Alumínio e Suas Ligas - ALCAN - $2^{\mathrm{a}}$ edição - 1991

[28] WELLER, E. J.; HAAVISTO, M. - Nontraditional Machining Processes - Society of Manufacturing Engineers - 2nd edition - 1984 
(ANEXO 1)

PROGRAMA PARA UTILIZAÇẪO COM FERRAMENTA DE CARBONETO (CONFORME ISO)

\begin{tabular}{|c|c|c|c|c|c|}
\hline N05 & M29 & & & & \\
\hline N10 & M39 & & & & \\
\hline N15 & T0101 & & & & Ferr. de desbaste \\
\hline $\mathrm{N} 20$ & G50 & S4000 & & & \\
\hline $\mathrm{N} 25$ & G96 & S150 & & & \\
\hline N30 & G00 & X33 & Z162 & M14 & \\
\hline N35 & G90 & X31 & Z-2 & $F 0,1$ & Ciclo de desbaste \\
\hline $\mathrm{N} 40$ & & $\times 30$ & & & \\
\hline N45 & & $\times 29$ & & & \\
\hline N50 & & $\mathrm{X} 28$ & & & \\
\hline N55 & & $\times 27$ & & & \\
\hline $\mathrm{N} 60$ & G00 & $\mathrm{X} 100$ & Z162 & & \\
\hline N65 & M00 & & & & \\
\hline N70 & T0202 & & & & Ferr. de teste (Carb - K05) \\
\hline N75 & G96 & S273*/ S229** & & & $*(\mathrm{CP} 1) / * \star(\mathrm{CP} 2)$ \\
\hline $\mathrm{N} 80$ & G00 & $\times 25,25$ & Z162 & M4 & \\
\hline N85 & G01 & & Z80 & $F 0,1$ & \\
\hline N90 & G00 & $\mathrm{X} 100$ & Z162 & & \\
\hline N95 & M00 & & & & Medir desgaste \\
\hline N100 & G00 & $\times 25,5$ & $Z 80,5$ & M4 & \\
\hline N105 & G01 & $\times 25,25$ & & $\mathrm{~F} 0,1$ & \\
\hline N110 & G01 & & Z-2 & & \\
\hline N115 & G00 & X100 & Z162 & & \\
\hline N120 & MO0 & & & & Medir desgaste \\
\hline N125 & G00 & $\times 23,5$ & & M4 & \\
\hline N130 & G01 & & $Z 74,255$ & $\mathrm{~F} 0,1$ & \\
\hline N135 & G00 & X100 & Z162 & & \\
\hline N140 & M00 & & & & Medir desgaste \\
\hline N145 & G00 & $\times 24$ & $Z 74,7$ & M4 & \\
\hline N150 & G01 & $\times 23,5$ & & & \\
\hline N155 & G01 & & Z-2 & & \\
\hline N160 & G00 & $\times 24$ & Z162 & & \\
\hline N165 & G00 & $\times 21,75$ & & & \\
\hline N170 & G01 & & Z147,622 & & \\
\hline N175 & G00 & X100 & Z162 & & \\
\hline N180 & MOO & & & & Medir desgaste \\
\hline N185 & G00 & $\times 22,3$ & Z148 & M4 & \\
\hline N190 & G01 & $\times 21,75$ & & & \\
\hline N195 & G01 & & Z55,245 & & \\
\hline N200 & G00 & X100 & Z162 & & \\
\hline N205 & M00 & & & & Medir desgaste \\
\hline N210 & G00 & $\times 22,2$ & Z55,7 & & \\
\hline N215 & G01 & $\times 21,75$ & & $F 0,1$ & \\
\hline N220 & G01 & & Z-2 & & \\
\hline N225 & G00 & $\times 22,2$ & Z162 & & \\
\hline N230 & G00 & $\times 20$ & & & \\
\hline
\end{tabular}




\begin{tabular}{|c|c|c|c|c|c|}
\hline N235 & G01 & & Z119,726 & & \\
\hline N240 & G00 & $\mathrm{X} 100$ & Z162 & & \\
\hline N245 & $\mathrm{M} 00$ & & & & Med. Desg./ Trocar aresta \\
\hline N250 & G96 & S185*/ S141** & & & $*(\mathrm{CP} 1) / * \star(\mathrm{CP} 2)$ \\
\hline N255 & G00 & $\times 20,5$ & $\mathrm{Z} 120,2$ & M4 & \\
\hline $\mathrm{N} 260$ & G01 & $\mathrm{X} 20$ & & $F 0,1$ & \\
\hline N265 & G01 & & $Z 19,605$ & & \\
\hline $\mathrm{N} 270$ & G00 & $\mathrm{X} 100$ & Z162 & & \\
\hline N275 & $\mathrm{M00}$ & & & & Medir desgaste \\
\hline $\mathrm{N} 280$ & G00 & $\times 20,5$ & $Z 20$ & M4 & \\
\hline N285 & G01 & $\mathrm{X} 20$ & & $F 0,1$ & \\
\hline N290 & G01 & & Z-2 & & \\
\hline N295 & G00 & $\times 20,5$ & Z162 & & \\
\hline N300 & G00 & $\times 18,75$ & & & \\
\hline N305 & G01 & & Z73,255 & & \\
\hline N310 & G00 & $\mathrm{X} 100$ & Z162 & & \\
\hline N315 & $\mathrm{M} 00$ & & & & Medir desgaste \\
\hline N320 & G00 & $\mathrm{X} 19,2$ & $Z 73,7$ & M4 & \\
\hline N325 & G01 & $\mathrm{X} 18,75$ & & $\mathrm{~F} 0,1$ & \\
\hline N330 & G01 & & Z-2 & & \\
\hline N335 & G00 & $\times 19,2$ & Z162 & & \\
\hline N340 & G00 & $\mathrm{X} 16,5$ & & & \\
\hline N345 & G01 & & Z121,947 & $F 0,1$ & \\
\hline N350 & G00 & $\mathrm{X} 100$ & Z162 & & \\
\hline N355 & $\mathrm{M} 00$ & & & & Medir desgaste \\
\hline N360 & G00 & $\mathrm{X} 17$ & Z122,5 & M4 & \\
\hline N365 & G01 & $\mathrm{X} 16,5$ & & & \\
\hline N370 & G01 & & Z3,364 & $\mathrm{F} 0,1$ & \\
\hline N375 & G00 & X100 & Z162 & & \\
\hline N380 & $\mathrm{M} 00$ & & & & Medir desgaste \\
\hline N385 & G00 & $\mathrm{X} 17$ & $Z 3,8$ & M4 & \\
\hline N390 & G01 & $\mathrm{X} 16,5$ & & $\mathrm{~F} 0,1$ & \\
\hline N395 & G01 & & Z-2 & & \\
\hline N400 & G00 & $\mathrm{X} 17$ & Z162 & & \\
\hline N405 & G00 & X14,75 & & & \\
\hline N410 & G01 & & $Z 30,034$ & & \\
\hline N415 & G00 & X100 & Z162 & & \\
\hline N420 & $\mathrm{M} 00$ & & & & Medir desgaste \\
\hline N425 & G00 & $\mathrm{X} 15,2$ & Z30,5 & M4 & \\
\hline N430 & G01 & X14,75 & & $\mathrm{F} 0,1$ & \\
\hline N435 & G01 & & $\mathrm{Z}-2$ & & \\
\hline N440 & $\mathrm{G} 00$ & $\mathrm{X} 15,2$ & Z162 & & \\
\hline N445 & G00 & X13 & & & \\
\hline N450 & G01 & & Z43,183 & & \\
\hline N455 & G00 & $\mathrm{X} 100$ & Z162 & & \\
\hline N460 & $\mathrm{M} 30$ & & & & Med. Desg. / Mudar CP \\
\hline
\end{tabular}


(ANEXO 2)

PROGRAMA PARA UTILIZAÇÃO COM FERRAMENTAS DE CERÂMICA E DIAMANTE (CONFORME ISO)

\begin{tabular}{|c|c|c|c|c|c|}
\hline N05 & M29 & & & & \\
\hline N10 & M39 & & & & \\
\hline N15 & T0101 & & & & Ferr. de desbaste \\
\hline $\mathrm{N} 20$ & G50 & S4000 & & & \\
\hline $\mathrm{N} 25$ & G96 & S150 & & & \\
\hline N30 & G00 & X33 & Z162 & M14 & \\
\hline N35 & G90 & X31 & Z-2 & $F 0,1$ & Ciclo de desbaste \\
\hline $\mathrm{N} 40$ & & $\times 30$ & & & \\
\hline N45 & & $\times 29$ & & & \\
\hline N50 & & $\times 28$ & & & \\
\hline N55 & & $\times 27$ & & & \\
\hline $\mathrm{N} 60$ & G00 & $\mathrm{X} 100$ & Z162 & & \\
\hline N65 & M00 & & & & \\
\hline N70 & T0202 & & & & Ferr. teste (Cer., Diam) \\
\hline N75 & G96 & S273 & & & \\
\hline $\mathrm{N} 80$ & G00 & $\times 25,25$ & Z162 & M4 & \\
\hline N85 & G01 & & Z80 & $\mathrm{F} 0,1$ & \\
\hline N90 & G00 & $\mathrm{X} 100$ & Z162 & & \\
\hline N95 & $\mathrm{MO0}$ & & & & Medir desgaste \\
\hline N100 & G00 & $\times 25,5$ & $Z 80,5$ & M4 & \\
\hline N105 & G01 & $\times 25,25$ & & $\mathrm{~F} 0,1$ & \\
\hline N110 & G01 & & Z-2 & & \\
\hline N115 & G00 & X100 & Z162 & & \\
\hline N120 & M00 & & & & Medir desgaste \\
\hline N125 & G00 & $\times 23,5$ & & M4 & \\
\hline N130 & G01 & & $Z 74,255$ & $\mathrm{~F} 0,1$ & \\
\hline N135 & G00 & X100 & Z162 & & \\
\hline N140 & M00 & & & & Medir desgaste \\
\hline N145 & G00 & $\times 24$ & $\mathrm{Z74,7}$ & M4 & \\
\hline N150 & G01 & $\times 23,5$ & & & \\
\hline N155 & G01 & & Z-2 & & \\
\hline N160 & G00 & $\times 24$ & Z162 & & \\
\hline N165 & G00 & $\times 21,75$ & & & \\
\hline N170 & G01 & & Z147,622 & & \\
\hline N175 & G00 & X100 & Z162 & & \\
\hline N180 & $\mathrm{MOO}$ & & & & Medir desgaste \\
\hline N185 & G00 & $\times 22,3$ & Z148 & M4 & \\
\hline N190 & G01 & $\times 21,75$ & & & \\
\hline N195 & G01 & & Z55,245 & & \\
\hline N200 & G00 & X100 & Z162 & & \\
\hline N205 & MOO & & & & Medir desgaste \\
\hline N210 & G00 & $\times 22,2$ & $Z 55,7$ & & \\
\hline N215 & G01 & $\times 21,75$ & & $F 0,1$ & \\
\hline N220 & G01 & & $\mathrm{Z}-2$ & & \\
\hline N225 & G00 & $\times 22,2$ & Z162 & & \\
\hline N230 & G00 & $\times 20$ & & & \\
\hline
\end{tabular}




\begin{tabular}{|c|c|c|c|c|c|}
\hline N235 & G01 & & Z119,726 & & \\
\hline N240 & G00 & $\mathrm{X} 100$ & Z162 & & \\
\hline N245 & $\mathrm{M} 00$ & & & & Med. Desg./ Trocar aresta \\
\hline N250 & G96 & S229 & & & \\
\hline N255 & G00 & $\times 20,5$ & $\mathrm{Z} 120,2$ & M4 & \\
\hline $\mathrm{N} 260$ & G01 & $\mathrm{X} 20$ & & $F 0,1$ & \\
\hline N265 & G01 & & $Z 19,605$ & & \\
\hline $\mathrm{N} 270$ & G00 & $\mathrm{X} 100$ & Z162 & & \\
\hline N275 & $\mathrm{M00}$ & & & & Medir desgaste \\
\hline $\mathrm{N} 280$ & G00 & $\times 20,5$ & $Z 20$ & M4 & \\
\hline N285 & G01 & $\mathrm{X} 20$ & & $F 0,1$ & \\
\hline N290 & G01 & & Z-2 & & \\
\hline N295 & G00 & $\times 20,5$ & Z162 & & \\
\hline N300 & G00 & $\times 18,75$ & & & \\
\hline N305 & G01 & & Z73,255 & & \\
\hline N310 & G00 & $\mathrm{X} 100$ & Z162 & & \\
\hline N315 & $\mathrm{M} 00$ & & & & Medir desgaste \\
\hline N320 & G00 & $\mathrm{X} 19,2$ & $Z 73,7$ & M4 & \\
\hline N325 & G01 & $\mathrm{X} 18,75$ & & $\mathrm{~F} 0,1$ & \\
\hline N330 & G01 & & Z-2 & & \\
\hline N335 & G00 & $\times 19,2$ & Z162 & & \\
\hline N340 & G00 & $\times 16,5$ & & & \\
\hline N345 & G01 & & Z121,947 & $F 0,1$ & \\
\hline N350 & G00 & X100 & Z162 & & \\
\hline N355 & $\mathrm{M} 00$ & & & & Medir desgaste \\
\hline N360 & G00 & $\mathrm{X} 17$ & Z122,5 & M4 & \\
\hline N365 & G01 & $\mathrm{X} 16,5$ & & & \\
\hline N370 & G01 & & Z3,364 & $\mathrm{F} 0,1$ & \\
\hline N375 & G00 & X100 & Z162 & & \\
\hline N380 & $\mathrm{M} 00$ & & & & Medir desgaste \\
\hline N385 & G00 & $\mathrm{X} 17$ & $Z 3,8$ & M4 & \\
\hline N390 & G01 & $\mathrm{X} 16,5$ & & $\mathrm{~F} 0,1$ & \\
\hline N395 & G01 & & Z-2 & & \\
\hline N400 & G00 & $\mathrm{X} 17$ & Z162 & & \\
\hline N405 & G00 & X14,75 & & & \\
\hline N410 & G01 & & $Z 30,034$ & & \\
\hline N415 & G00 & $\mathrm{X} 100$ & Z162 & & \\
\hline N420 & $\mathrm{M} 00$ & & & & Medir desgaste \\
\hline N425 & G00 & $\mathrm{X} 15,2$ & Z30,5 & M4 & \\
\hline N430 & G01 & X14,75 & & $\mathrm{F} 0,1$ & \\
\hline N435 & G01 & & $\mathrm{Z}-2$ & & \\
\hline N440 & $\mathrm{G} 00$ & $\mathrm{X} 15,2$ & Z162 & & \\
\hline N445 & G00 & X13 & & & \\
\hline N450 & G01 & & Z43,183 & & \\
\hline N455 & G00 & $\mathrm{X} 100$ & Z162 & & \\
\hline N460 & $\mathrm{M} 30$ & & & & Med. Desgaste \\
\hline
\end{tabular}


(ANEXO 3)

Classificação dos diferentes tipos de cavaco de acordo com a ISO 3685 [20]. Retirado da norma [20].

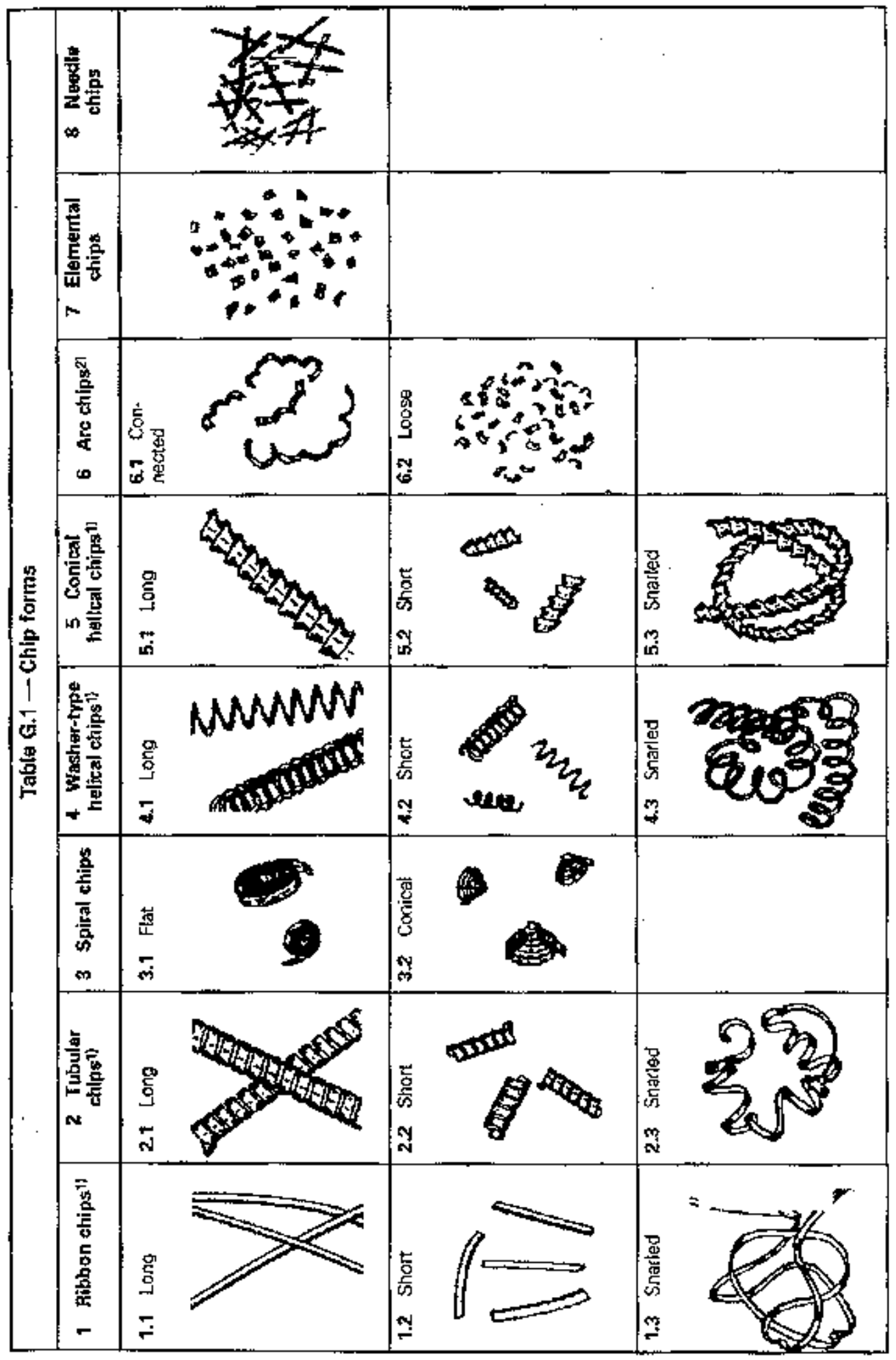

